Journal of Educational

and Psychological Sciences

Volume (6), Issue (9): 28 Feb 2022

P: 23 - 59

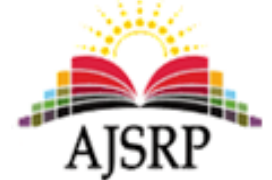

ISSN: 2522- 3399

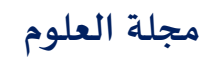

التربوية والنفسية

المجلد (6))، العدد (9): 28 فبراير 2022 م

ص: 23 - 59

\title{
Study of Female undergraduate students enrolled in e- learning courses at Taibah University (college of education) and their attitudes towards learning platforms and mobile learning: Edmodo and Blackboard
}

\author{
Hanan Nassar Aljermawi \\ Taibah University $\|$ Madina $\|$ KSA
}

\begin{abstract}
The aim of the current study is to determine the extent to which the female students at the College of Education registered for e- learning courses at Taibah University using educational platforms and their attitudes towards platforms and mobile learning (Edmodo Blackboard as a model). The sample consists of (14) students and two different questionnaires were designed and applied.The first questionnaire consisted of (12) items and related to the students' use of the EdmodoEd platform, and the Bb- Blackboard platform, whereas the second questionnaire consisted of (45) distributed items. The research concluded that the students use the (Ed) platform with a medium degree, and with a mean of (1.96 out of 3), while they use the $(\mathrm{Bb})$ platform with a degree of High, with an arithmetic mean (2.64 out of 3$)$. The results also revealed that the general average of the female students' attitudes towards the (Ed) platform was (2.52), with a high degree of appreciation, and the arithmetic averages of the female students' attitudes on the axes of the questionnaire ranged between (2.88- 2.21), with a large to medium degree, while the results revealed that the average the year of the students' attitudes towards the (Bb) platform was (2.53), with a high degree of appreciation, and the arithmetic averages of the students' attitudes on the questionnaire axes ranged between (2.92-2.25), and to a large to medium degree. The researcher recommended a number of recommendations, including the integration of more than one platform in education and training students on the optimal use of the skills of using educational platforms.
\end{abstract}

Keywords: Educational platforms, Edmodo, Blackboard, attitudes, Taibah University.

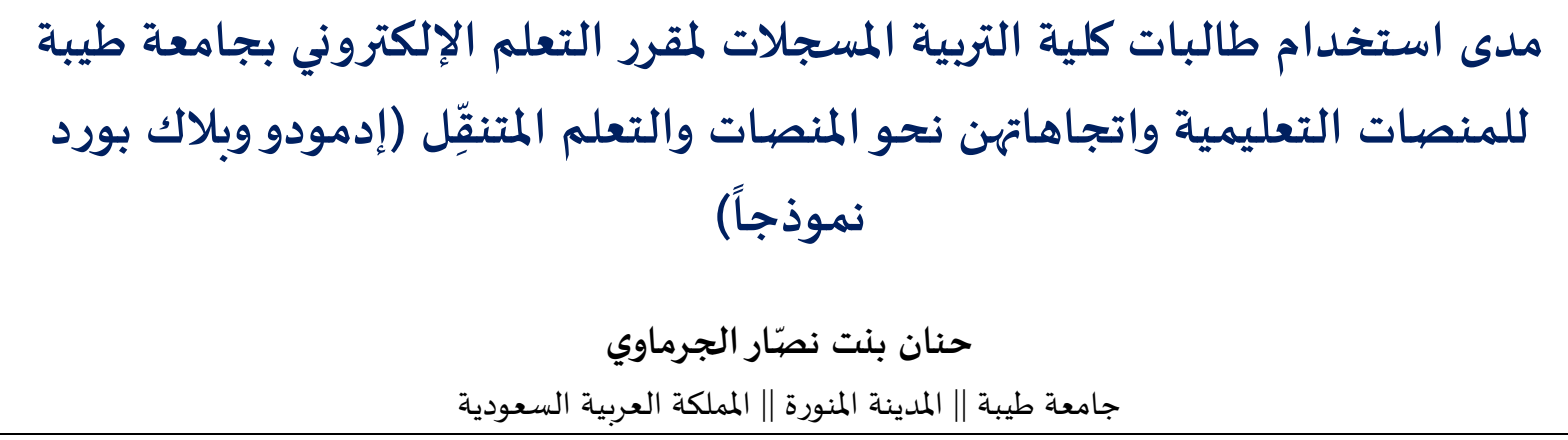

المستخلص: هدفت الدراسة الحالية إلى الوقوف على مدى استخدام طالبات كلية التربية المسجلات لمقرر التعلم الإلكتروني بجامعة

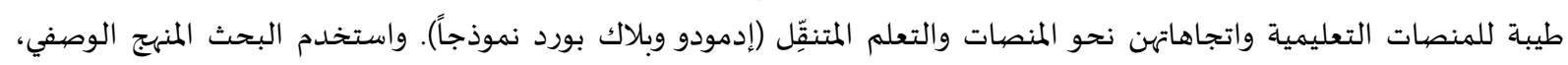

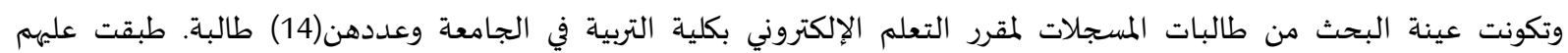

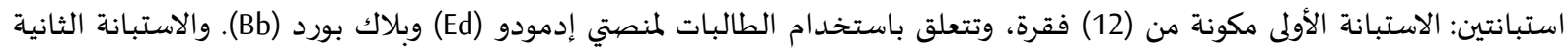

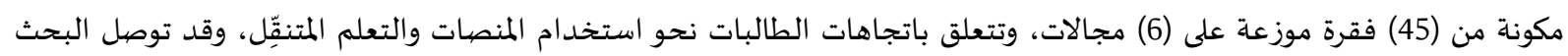
إلى عدد من النتائج من أهمها: أن الطالبات يستخدمن منصة ملية Ed بدرجة متوسطة، وبمتوسط حسابي (1.96 من3)، بينما يستخدمن 
منصة Bb بدرجة مرتفعة وبمتوسط حسابي (2.64من 3). كما كشفت النتائج أن المتوسط العام لاتجاهات الطالبات نحو منصات (Ed)

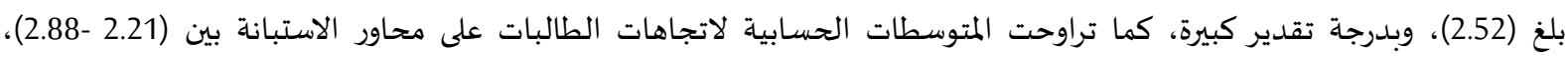

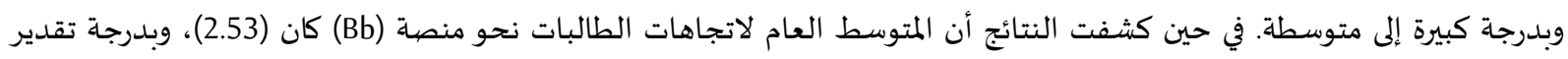

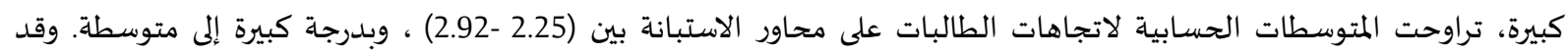

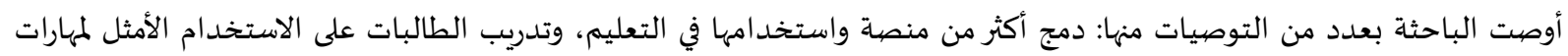

استخدام المنصات التعليمية.

الكلمات المفتاحية: المنصيات التعليمية، بلاك بورد، إدمودو، اتجاهات، جامعة طيبة.

المقدمة.

يعيش العالم اليوم شكلاً للانفجار التكنولوجي والمعرفي لم يشهد له مثيلاً في العقود السابقة، الأمر والذي

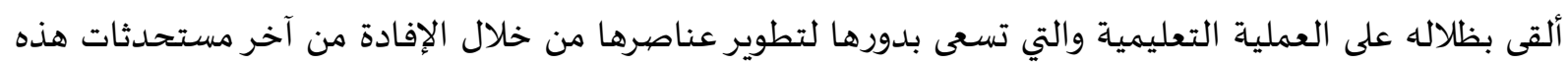

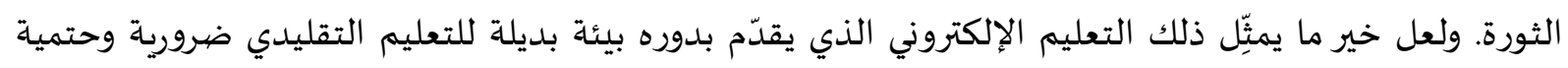

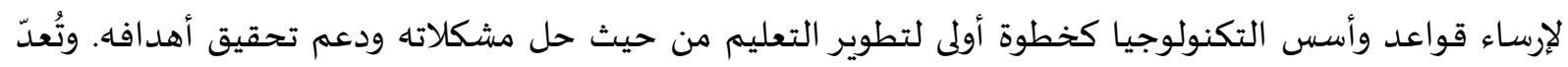
الشبكات الاجتماعية ممثلة في ويب 2 (web2) الوجه الأبرز لبيئات التعلم البديلة أو الإلكترونية. فالشبكات ولئكات

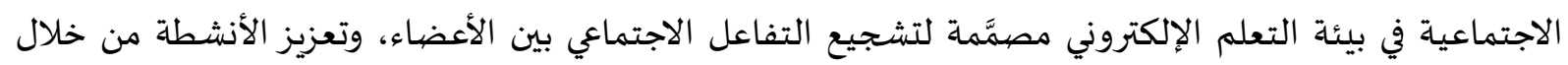

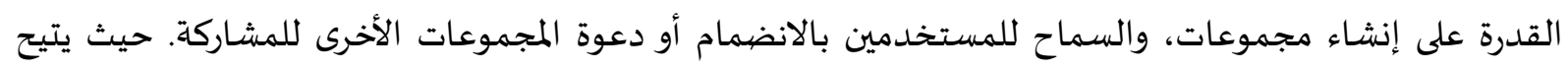

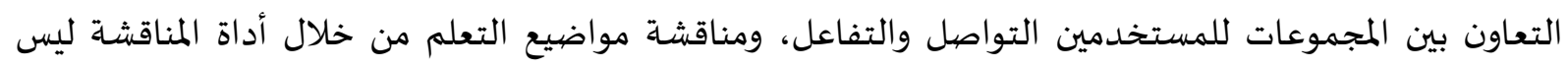

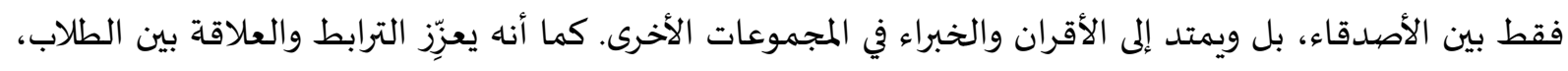

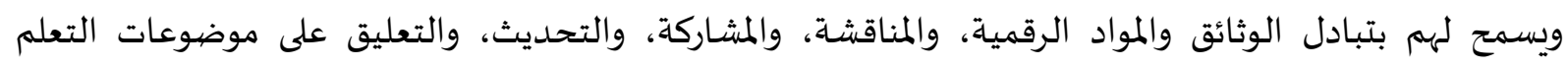

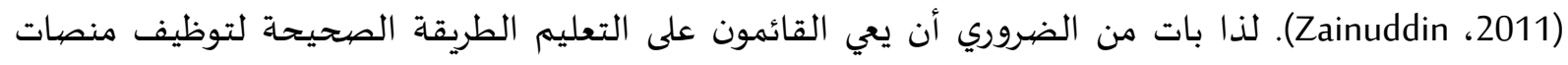

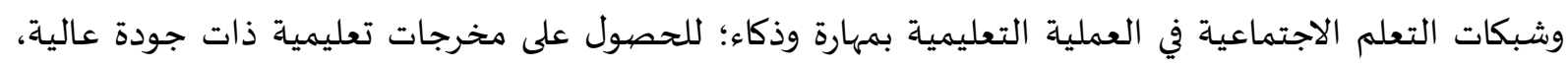

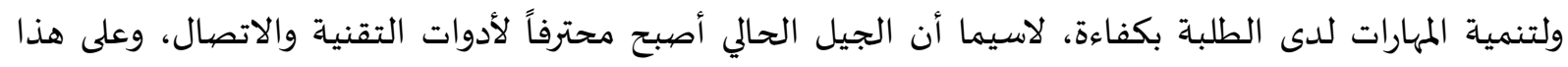

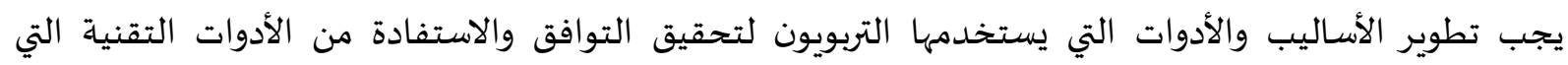

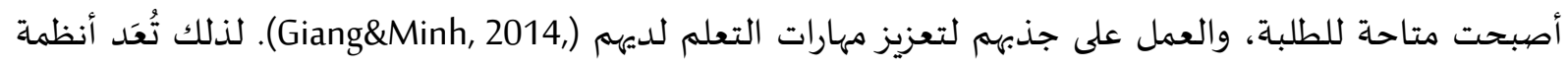

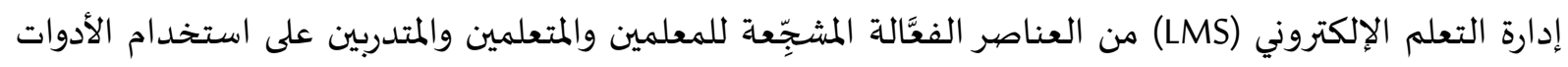

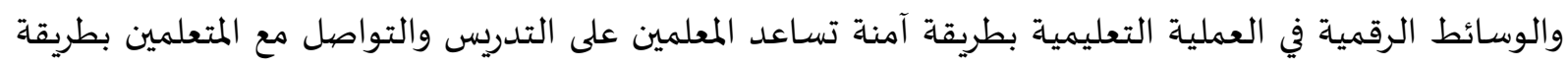

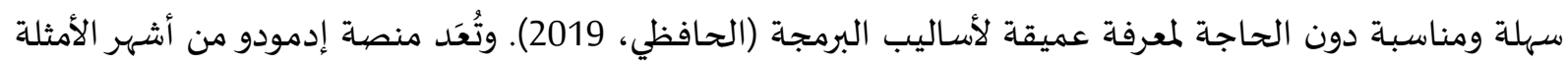

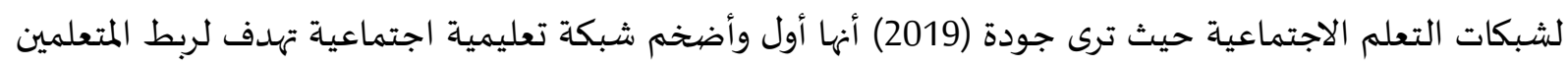

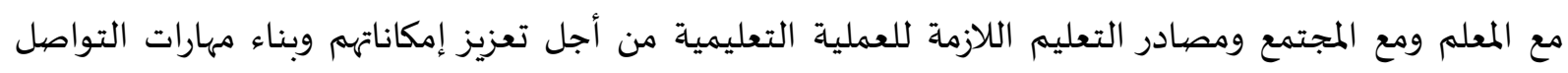

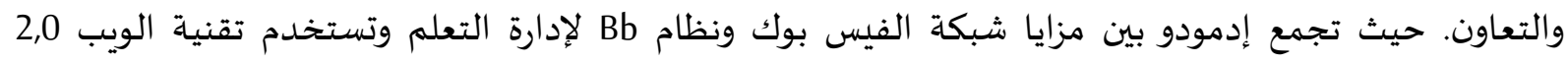

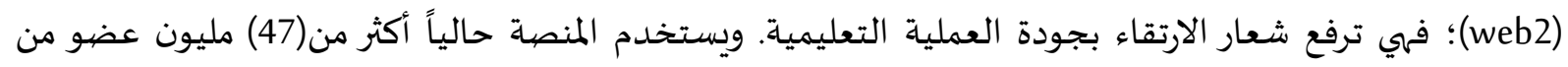

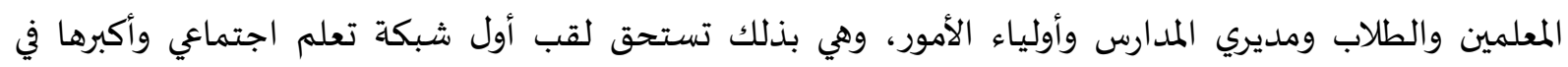

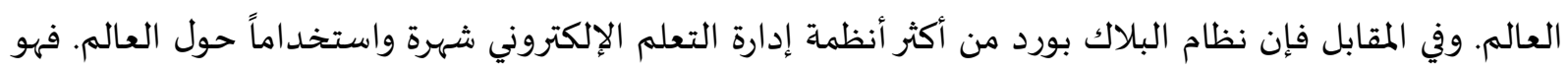

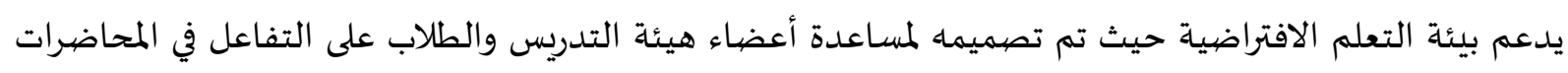

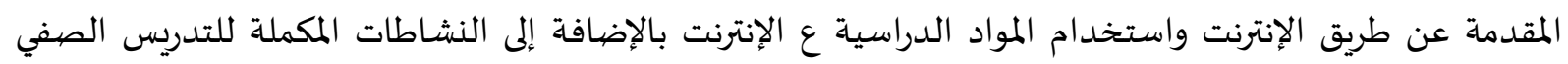


العادي، وكلك يمكن النظام المدرسين من توفير مواد المقررات الدراسية، منتديات الحوار، الدردشـة، الامتحانات

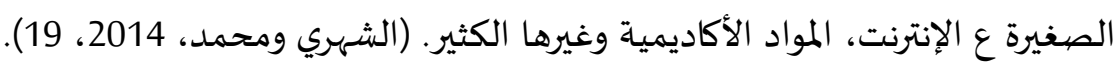

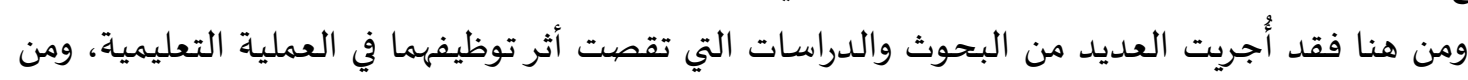

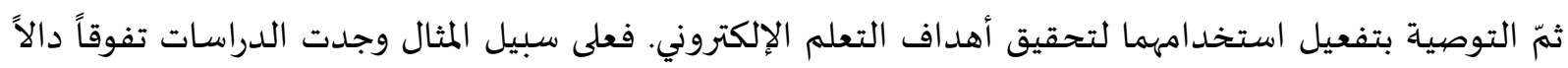

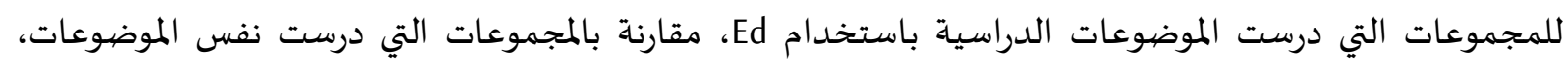

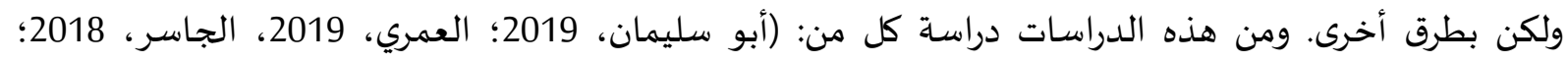

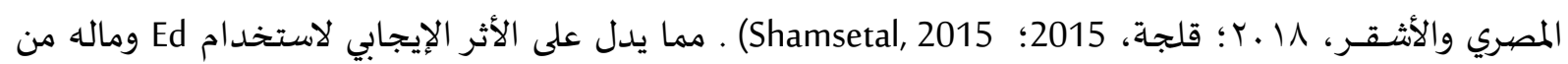

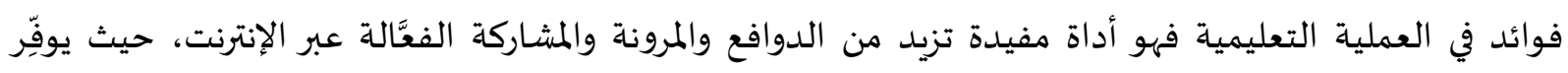

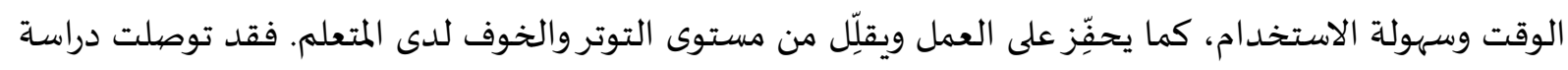

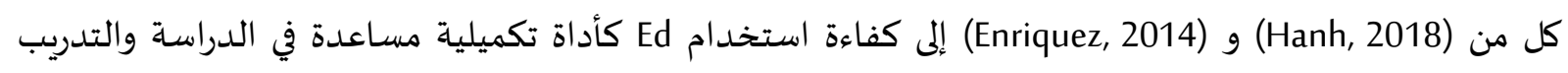
وأشارت أن غالبيتهم يعتبرون Ed منصبة جيدة مفيدة في تعلمهم، حيث ساعدنهم على تحسين معرفتهم بالمقررات

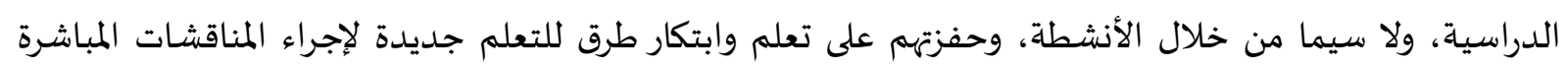

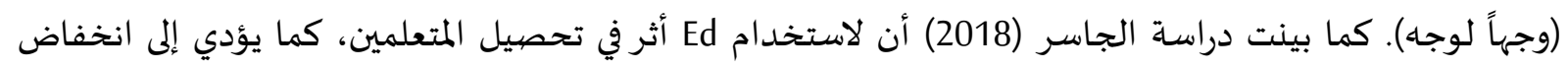

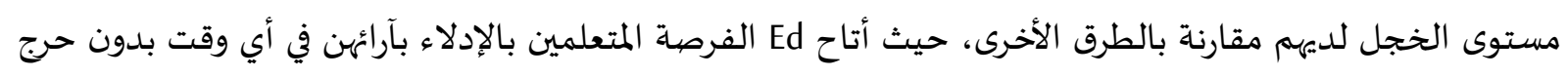

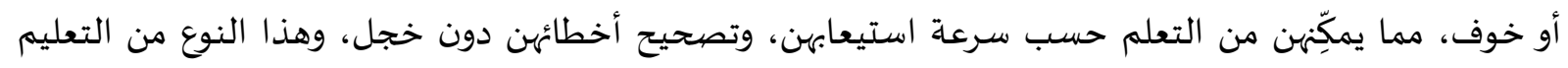

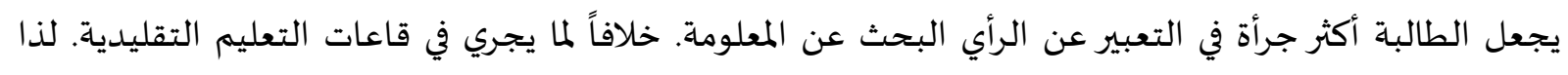

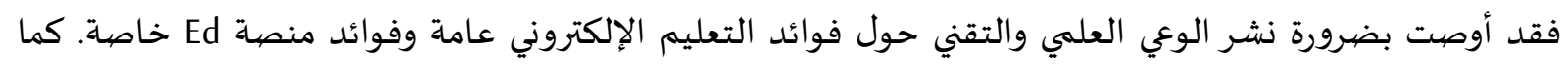

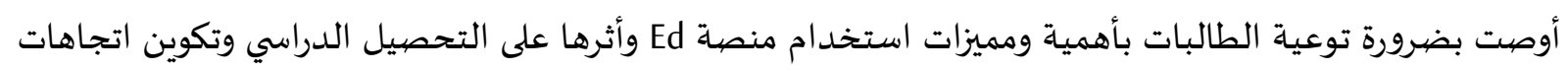
إيجابية ليهن نحو استخدامه. وعلى نفس النحو أوصت العديد من الدراسات باستخدام Ed في التعليم، وضرورة

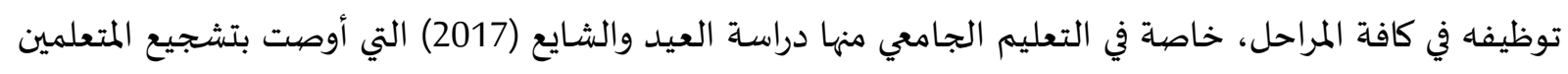

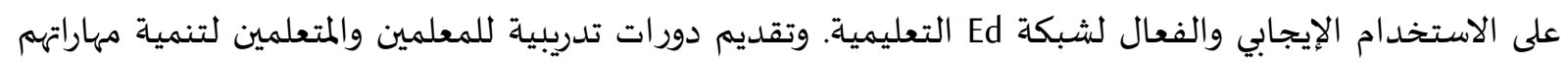

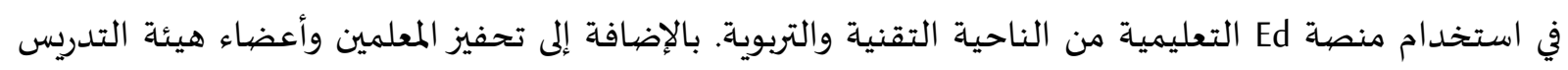

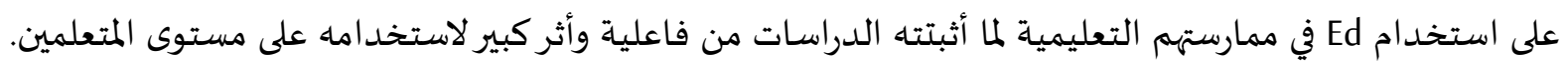

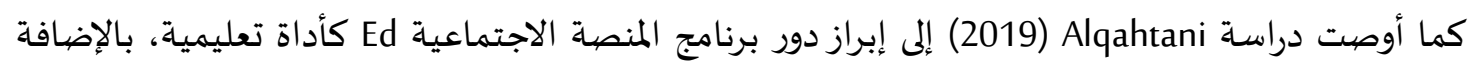

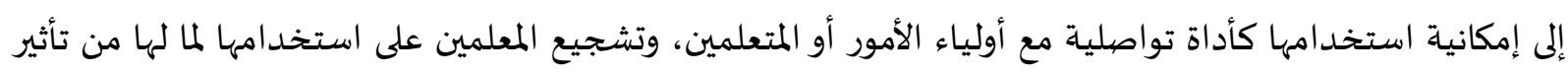

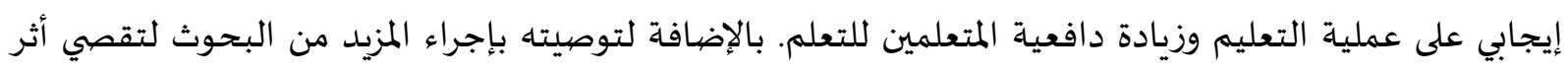

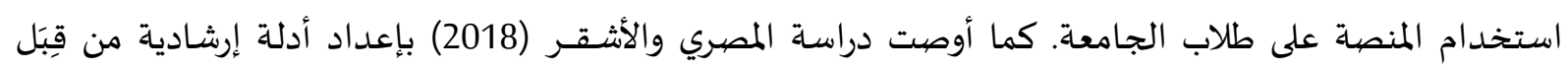

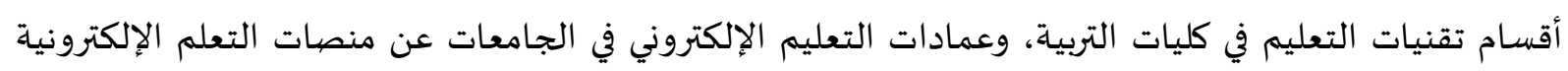
ومن ضمنها منصة Ed كي يستفيد منها الطلاب والطالبات وأعضياء هيئة التدريس.

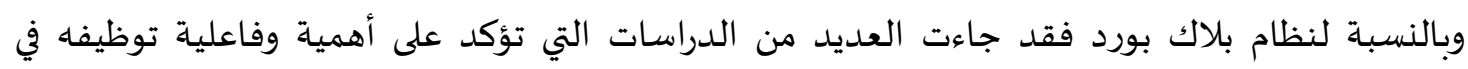

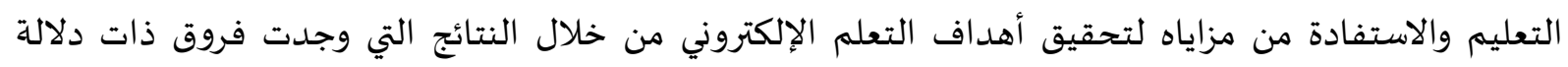

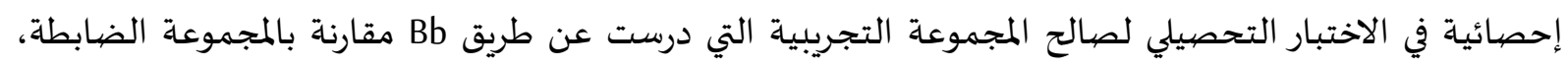

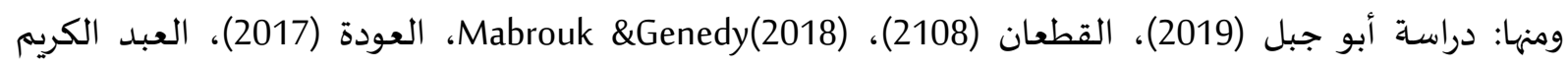
والرويس (2015). وعلى نحوٍ خاص توصلت دراسة عثمان والزبيدي (2018) إلى فاعلية توظيف نظام إدارة التعلم

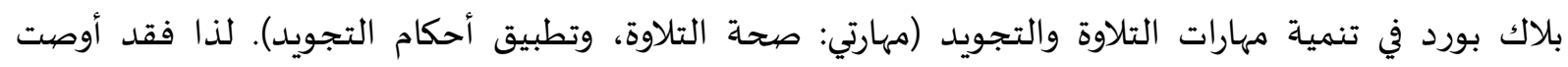


الدراسة بضرورة الدمج بين طرق التعلم التقليدية وطرق التعلم بالبلاك بورد في تنمية مهارات التلاوة والتجويد. ومن

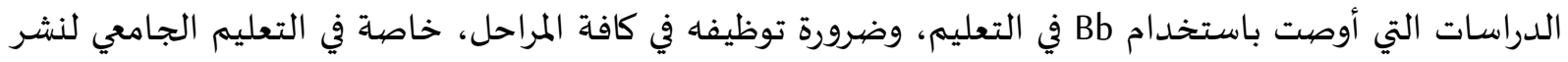

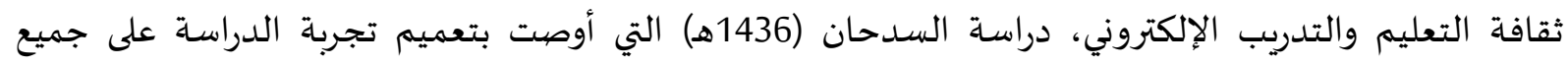

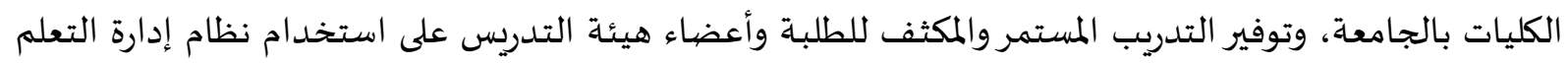

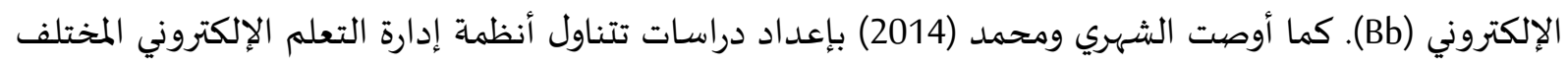
في الجامعات السعودية والعربية. كذلك فقد أوصى الشهري (2018) بإجراء دراسات مقارنة بين أنظمة إدارة التعلم الأخرى لمقارنة خصائصها ومكوناتها.

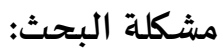
إن شيوع الأدوات التقليدية من بريد إلكتروني وتطبيقات المحادثة الكتابية وتحميل الملفات، بالإضافة للطرق التقليدية في التدريس من محاضرات وتلقين وحفظ واستظهار، يعمل على الحد من اكتساب المتعلم لمهارات

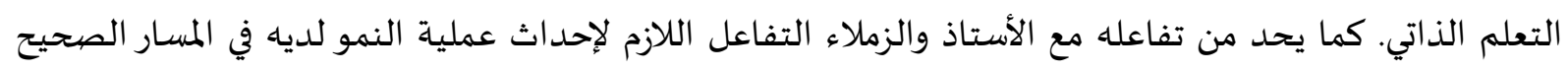

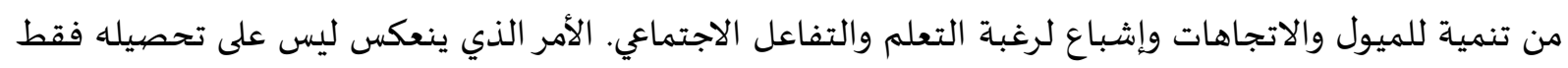

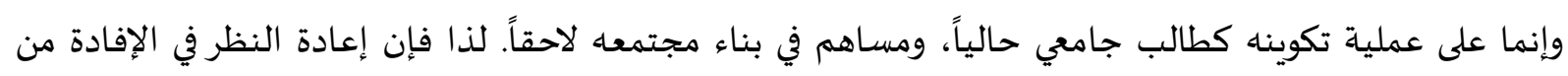

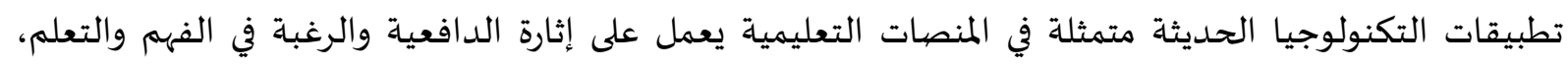

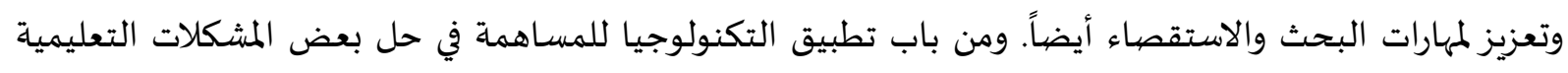

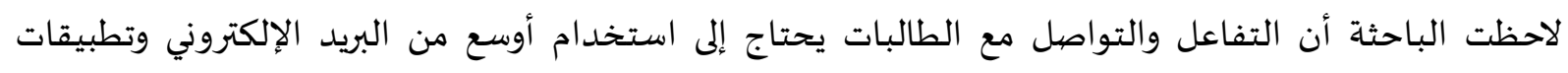

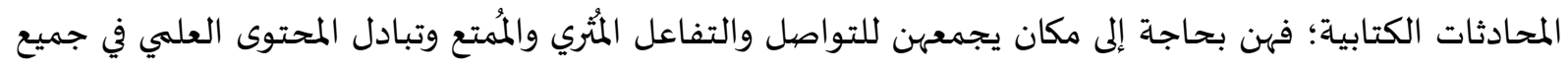

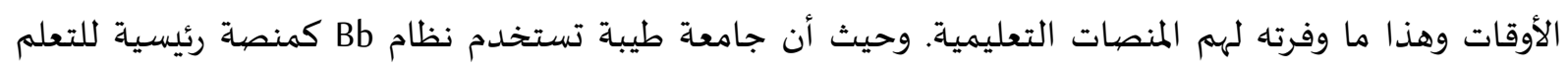

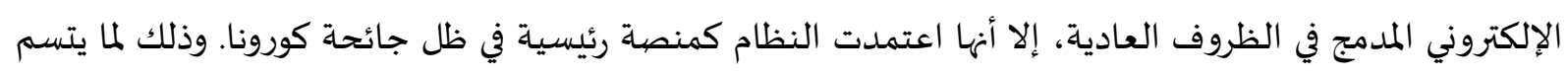

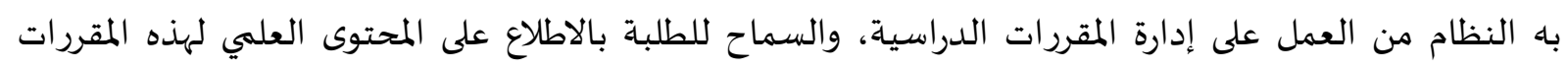

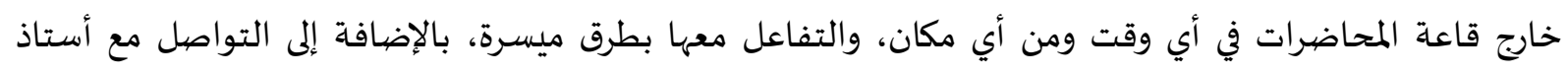

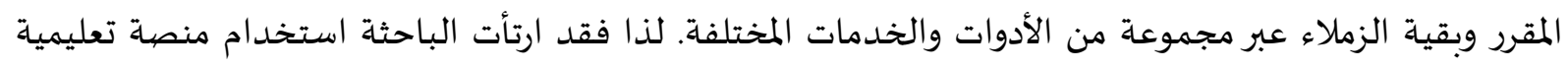

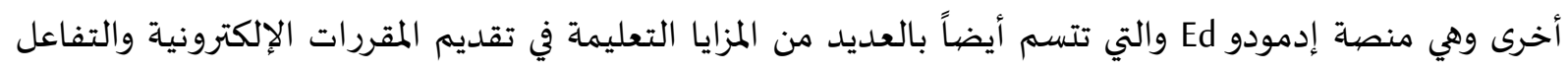
كإجراء الاختبارات وغيره، وذلك بهدف العمل على المقارنة بين المنصتين من حيث مدى المدود الاستخدام وكذلك اتجاه الطالبات نحو التعلم من خلالهماء.

أسئلة البحث:

1- ما مدى استخدام طالبات كلية التربية المسجلات لمقرر التعلم الإلكتروني بجامعة طيبة لمنصة إدمودو (Ed) في

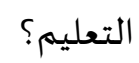

2- ما مدى استخدام طالبات كلية التربية المسجلات لمقرر التعلم الإلكتروني بجامعة طيبة لمنصية بلاك بورد (Bb) في التعليم؟ ما ملدى التحاهن

3- ما اتجاهات طالبات كلية التربية المسجلات لمقرر التعلم الإلكتروني بجامعة طيبة نحو منصية إدمودو (Ed)

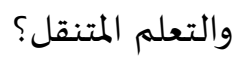

4- ما اتجاهات طالبات كلية التربية المسجلات لمقرر التعلم الإلكتروني بجامعة طيبة نحو منصة بلاك بورد (Bb) والتعلم المتنقل؟ 


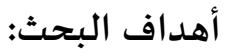

1- التعرف على مدى استخدام طالبات كلية التربية المسجلات لمقرر التعلم الإلكتروني بجامعة طيبة لمنصة إدمودو

(Ed) في التعليم. (Ed)

2- التعرف على مدى استخدام طالبات كلية التربية المسجلات لمقرر التعلم الإلكتروني بجامعة طيبة لمنصية بلاك

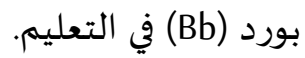

3- تحديد اتجاهات طالبات كلية التربية المسجلات لمقرر التعلم الإلكتروني بجامعة طيبة نحو منصة إدمودو (Ed)

والتعلم المتنقل.

4- تحديد اتجاهات طالبات كلية التربية المسجلات لمقرر التعلم الإلكتروني بجامعة طيبة نحو منصة إدمودو (Bb) والتعلم المتنقل.

أهمية البحث:

1- تقديم استمارة لقياس مدى استخدام الطالبات المنصات التعليمية.

2- تقديم استمارة لقياس اتجاه الطالبات نحو استخدام المنصات التعليمية.

3- قد يساهم البحث في لفت أنظار أعضاء هيئة التدريس بجامعات المملكة للمزايا التعليمية لمنصتي بلاك بورد

وإدمودو للإفادة منها في دعم عمليتي التعليم والتعلم.

4- من الممكن أن يساهم البحث الحالي في التقييم الفعلي لمنصتيّ بلاك بورد وإدمودو كنمط تعليمي حديث من خلال عرض رأي واتجاه الطالبات حول استخدامهما للعمل على تدعيم المميزات وتطوير البيئة التعليمية

الإلكترونية.

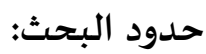

نقتصر الدراسة وتتحدد نتائج البحث بالحدود الآتية:

الحدود الموضوعية: مدى استخدام الطالبات للمنصات التعليمية واتجاهاتهن نحو المنصات والتعلم المتنقِّل (إدمودو وبلاك بورد نموذجاً).

الحدود البشرية: الطالبات المسجلات لمقرد التعلم الإلكتروني (EDTE101).

الحدود المكانية: كلية التربية في جامعة طيبة بالمدينة المنورة.

الحدود الزمانية: الفصل الدراسي الثاني من العام الجامعي 1440/ 1441هـ.

مصطلحات البحث:

- المنصات التعليمية: يعرفها عبد العال (2015) بأنها بيئة تعليمية تفاعلية توظف تقنية الويب 2.0 (web2)

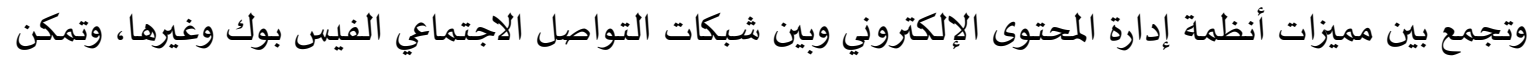
المعلمين من نشر الدروس، وحل الواجبات، وتطبيق الأنشطة التعليمية، والتواصل بالمعلمين من خلال تقنيات

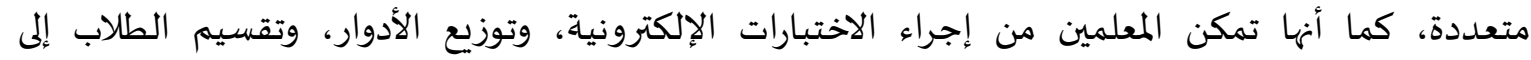
مجموعات عمل، وتساعد على تبادل الأفكار والآراء بين المعلمين الطلاب ومشاركة في فهم المحتوى العلمي، كما تتيح لأولياء الأمور التواصل مع المعلمين والاطلاع على نتائج أبنائهم مما يساعد على تحقيق مخرجات تعليمية 
O وتعرفّ الباحثة المنصات التعليمية إجرائياً بأنها بيئة تعليمية تفاعلية يدمج مزايا شبكة الإنترنت بالتطبيقات

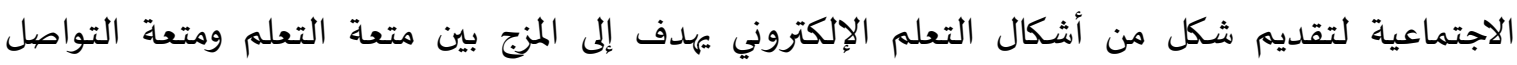
الاجتماعي الفعّال لتحقيق أهداف العملية التعليمياة، وتحسين مخرجاتها.

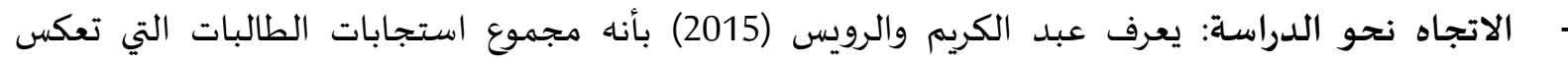

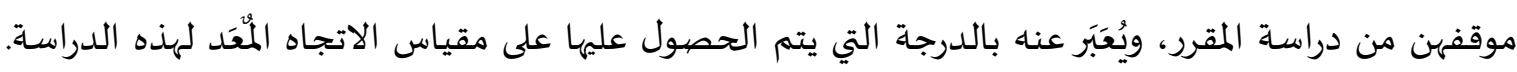

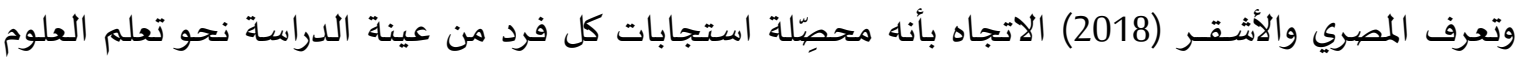
والتي تعد مؤشراً للقبول أو الرفض نحو المادة، ويعبر عنه بالدرجة التي يحصل عليها التلميذ لاستجابته لفقرات مقياس الاتجاه. وتعرفّ الباحثة الاتجاه للتعلم إجرائياً بأنه موقف الطالبة من الدراسة من خلال منصتي بلاك بورد وإدمودو التعليمية، وتحديد النقاط الإيجابية والسلبية الناتجة عن هذا الاستخدام من وجها لناهية نظرها.

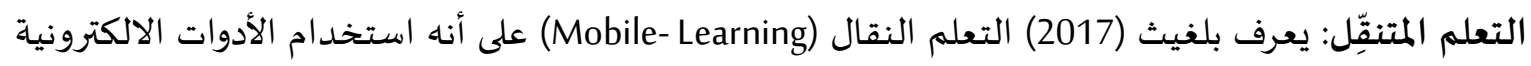
القابلة للنقل والحمل كالهواتف النقالة، وحواسيب القرص الشخصية (Tablet PC)، في عمليات التعليم والتعلم. وتعرفّ الباحثة التعلم المتنقِّل إجرائياً بأنه استخدام المستحدثات التكنولوجية وتطبيقاتها المتعددة من أجهزة

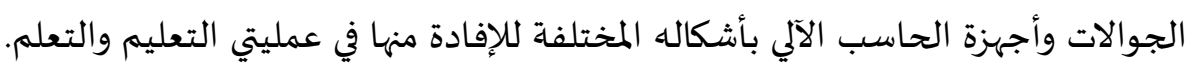

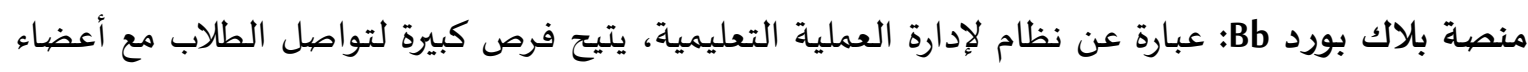

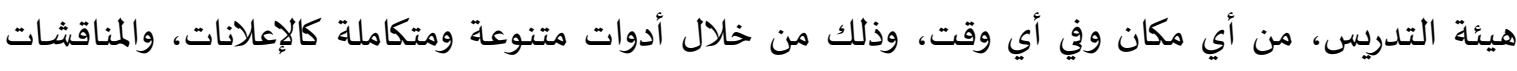

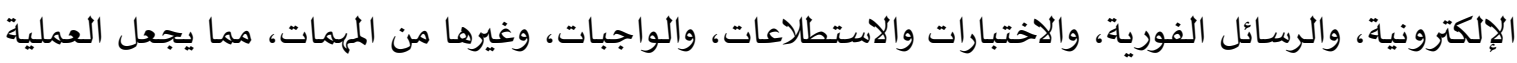

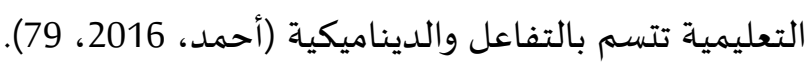
وتعرفّ الباحثة منصية بلاك بورد إجرائياً بأنه أحد أنظمة التعلم الإلكترونية التي تجمع بين النظامين (LMS) وَ

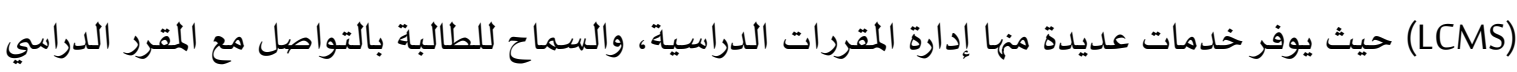

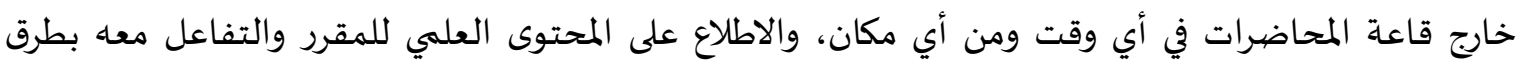

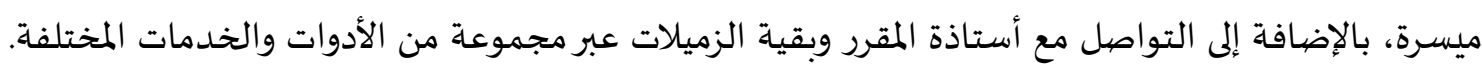

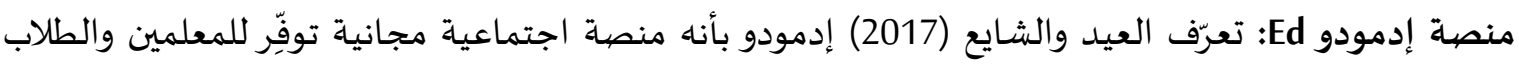

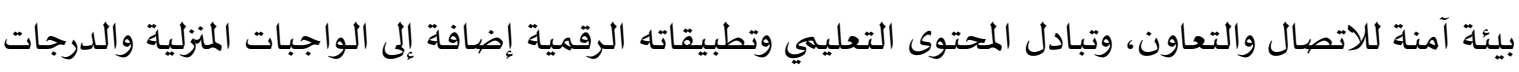

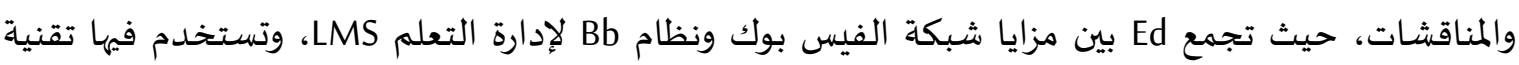

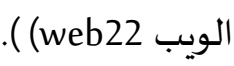
O متعرفّ الباحثة منصية إدمودو إجرائياً بأنها منصة تعليمية اجتماعية تعمل على المزج بين مزايا المواقع التعليمية

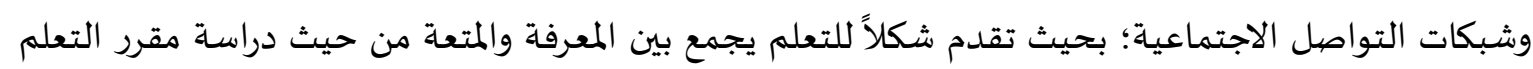

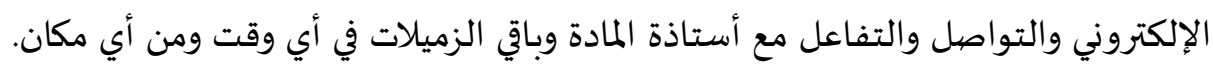


تشير الصفحة الرئيسية لموقع Ed على الإنترنت إلى تبنيه لشعار رسمي يؤكد على كونه- بالدرجة الأولى- شبكاة اجتماعية آمنة للمدارس,safe social networking for schools مصمَّمة خصيصًا بهدف مد يد العون لمساعدة المعلمين في تحقيق أكبر استفادة ممكنة من توظيف الإمكانات التقنية الهائلة للوسائط الاجتماعية Social Media في مئه

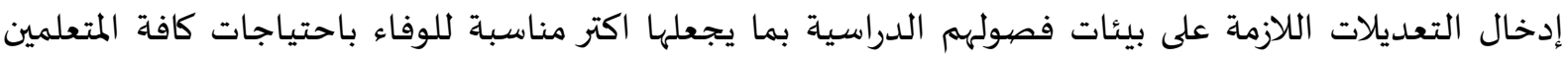

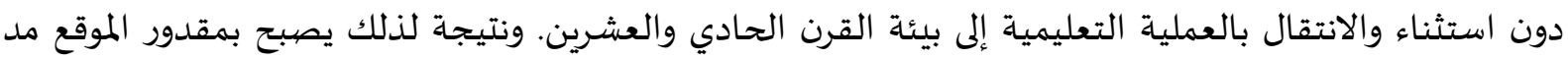

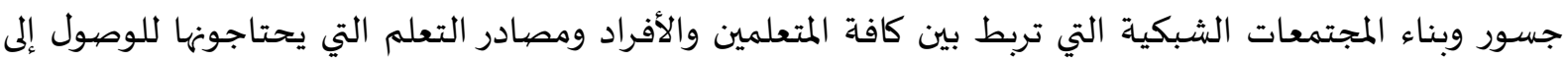

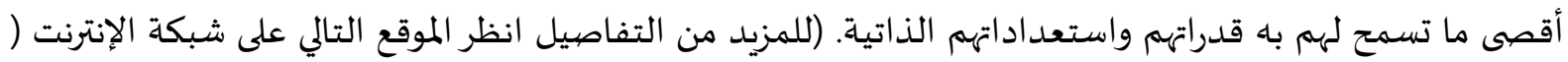
www.Edmodo.com Ed: الدليل العملي للاستفادة من خدمات شبكته للتعلم الاجتماعي داخل حجرات الفصيول الدراسية بقائمة أخرى

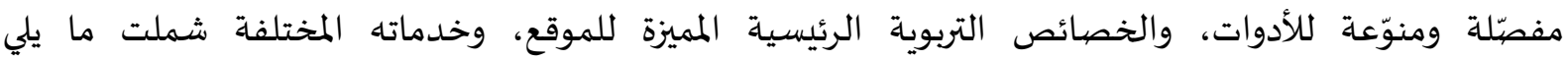

:(Edmod,2014)

سهولة متابعة أنشطة وتفاعلات الطلاب.

سرعة وسهولة ونشر المحتوى الدراسي والتطبيقات التعليمية.

السماح بحدوث عمليات اتصال مفتوحة وآمنة بالإمكان مراقبتها والتحكم بها بواسطة المعلم.

تمكين المعلمين وغيرهم من العاملين بالمدارس والمؤسسات التعليمية من تكوين مجموعات وفرق عمل مهنية. تمكين المعلمين من نشر التكليفات الدراسية والاختبارات التقييمية إلكترونياً فضلاً عن تصحيحها ورصيد درجاتها آلياً.

إتاحة الفرصة أمام المعلمين، والطلاب للتعاون، والمشاركة في المناقشات الصفية في إطار بيئة تعليمية مغلقة، وآمنة.

تزويد المستخدمين باستبيانات مسحية للتقييم الذاتي سهلة الاستخدام عملياً في فحص وتقويم مستويات الفهم والاستيعاب.

الالتزام الصارم بمعايير السرية والخصوصية والأمان فضلاً عن مراعاة حقوق النسخ والاقتباس والملكية الفكرية للمؤلفين. تمكين المعلمين والطلاب من حفظ وتخزين ونشر وتداول الوثائق والملفات المطلوبة بالاستعانة بمجموعة متنوعة من الصيغ والقوالب المختلفة في إطار بيئة آمنة. تقديم خدمات الموقع مجاناً وخلوها من الإعلانات التجارية التي عادًة ما تشتت التباه إنداه المستخدمين بعيداً عن عمليتي التدريس والتعلم. سرعة وسهولة الوصول والاطلاع على الواجبات الدراسية، والدرجات التحصيلية فضلاً عن المناقشات الصفية، والتنبيهات الرسمية للمناهج والمقررات الدراسية. تمكين المعلمين من الاطلاع باستمرار على كل ما هو جديد في "مكتبة الوسائط الرقمية "digital store" بالموقع، والمشاركة في نشرها والتعريف بها مع زملائهم من المعلمين الآخرين. 
تمكين أولياء الأمور من إنشاء "حسابات شخصية "Persnal Accounts" لهم على الموقع بهدف تيسير مهمة التواصل والتفاعل مع مجموعات وفرق عمل تعلم أبنائهم الطلاب. توافر واجهة تفاعل مستخدمين user interface تتميز بالبساطة الشديدة وعدم تعقيد لغات البرمجة المستخدمة وعدم الحاجة إلى تلقي تدريب فني متخصص على كئل كيفية استخدامها عملياً.

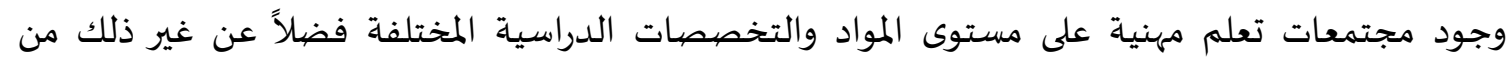

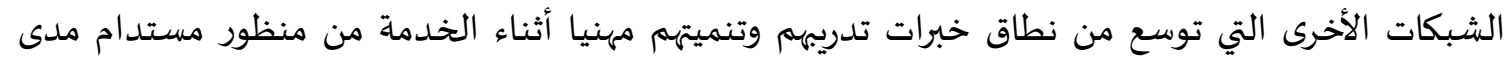

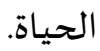
سرعة وسهولة وصول الطلاب بشكل فوري إلى الملفات المطلوبة طوال الوقت من خلال مطالعة محتويات مكتباتهم الشخصية" personal libraries" بالموقع على نحو يسمح بإمكانية التغلب على القيود التقليدية للزمان

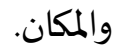
الاستفادة من خدمة "المشاركة في نشر الملفات التي تمكن المعلمين من نشر محتويات موديولات أو وحدات

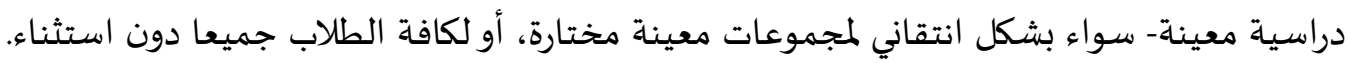

ثانياً: منصية بلاك بورد (BLACKBOARD): يُعَد منصية إدارة التعلم بلاك بورد من الأنظمة التعليمية المستخدمة في أكبر الجامعات العالمية؛ ولفاعلية

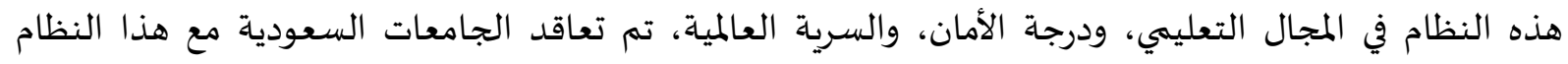

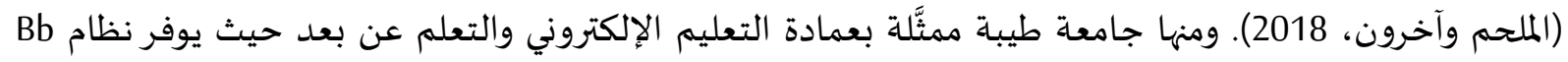

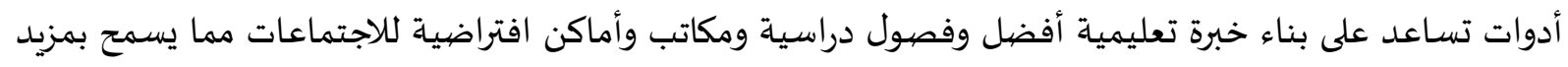

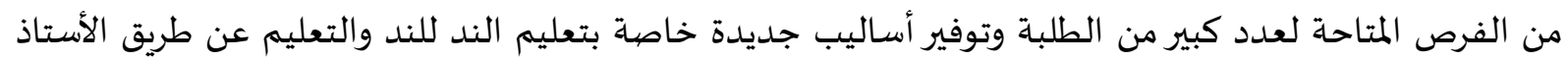

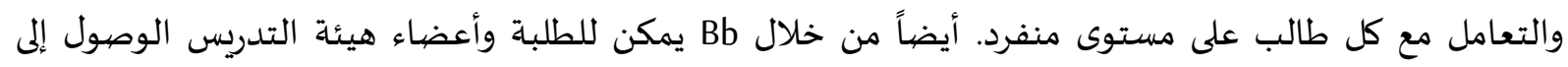

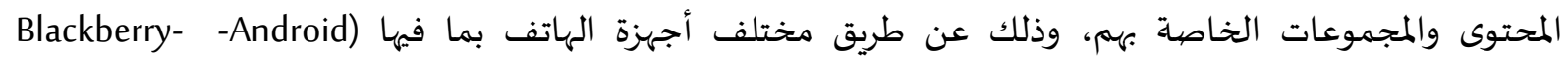
(IPhone). (الجامعة الإلكترونية السعودية، 2020). ومن المزايا التعليمية لمنصية بلاك بورد تذكر أحمد (2016) (2020): أ- يتيح للجامعة إدارة عملية التعلم ومتابعة كفاءتها.

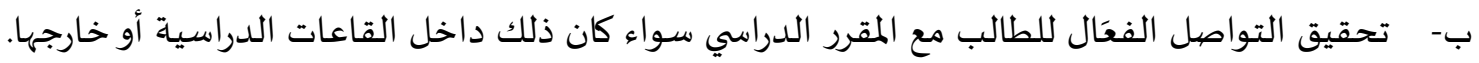

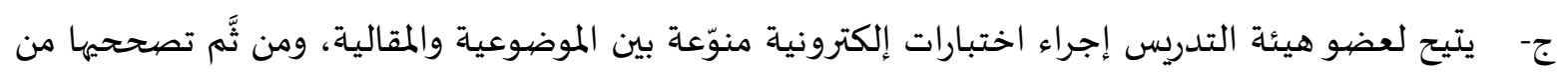
خلال النظام نفسه. د- يمكن للطالب تقديم الواجبات والمهام والأبحاث إلكترونياً عبر النظام، كما يمكن لعضو هيئة التدريس الاطلاع عليها وتقييمها إلكترونياً والتعقيب الفوري عليها.

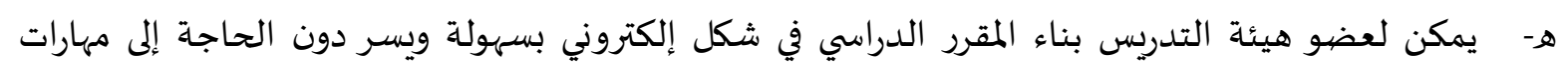
برمجية مثل خدمة إضافة وحدات تعلم نمطية للمحاضرات.

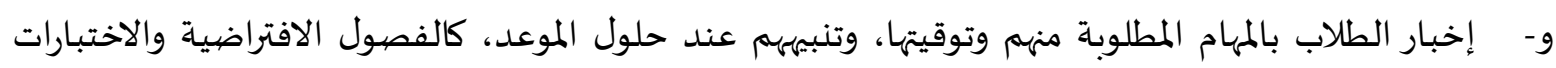
والواجبات، كما يمكن للأستاذ إرسال مهمة معينة لطالب معين. 
ز- يمكّن عضو هيئة التدريس من أداء بعض المحاضرات عن بعد من خلال استخدام خدمة الفصول الافتراضية التي يوفّرها النظام أو من خلال التسجيل الإلكتروني للمحاضرات من من خلال نظام لمنام الإيكو

ح- يتيح سهولة التواصل بين الطلاب وبعضهم أو بين الطلاب وأعضياء هيئة التدريس سواء بشكل متزامن أو غير ألمات

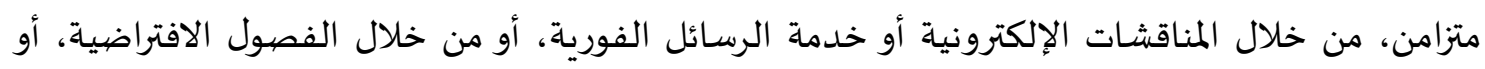
من خلال الإعلانات.

ثالثاً: التعلم المتنقِّل (LEARNING MOBILE): يرى بلغيث (2017) أن الهواتف النقالة صارت في السنوات الأخيرة من أكثر التقنيات الحديثة انتشاراً بين

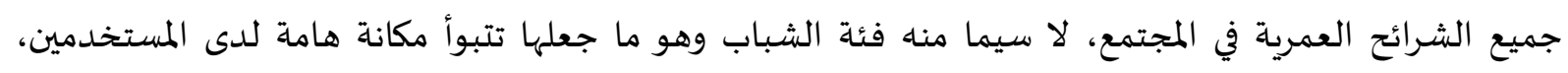

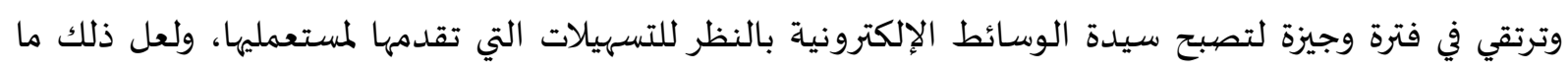

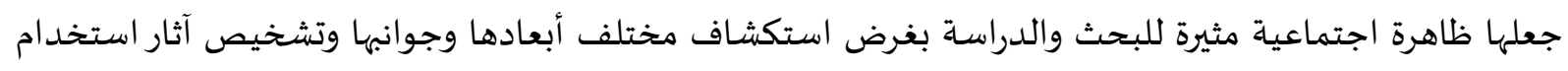

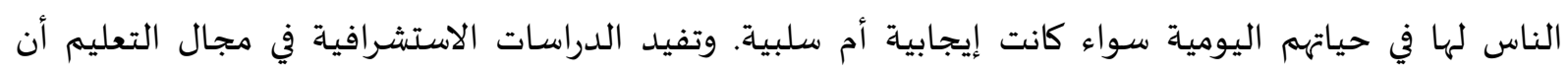

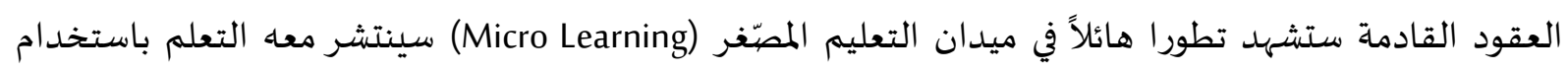

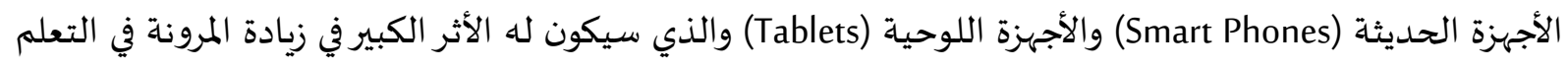

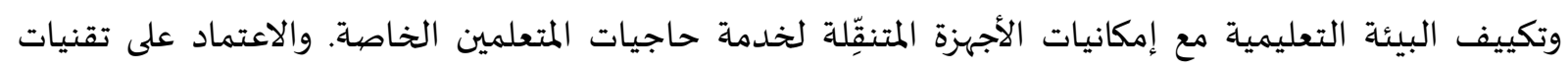

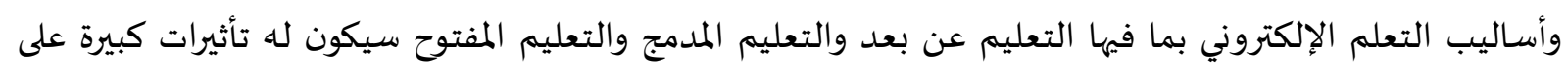

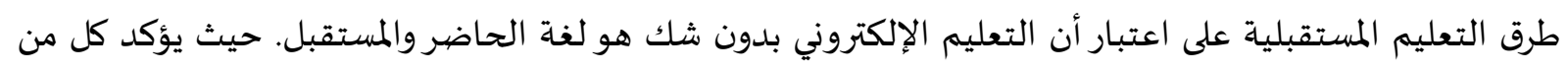

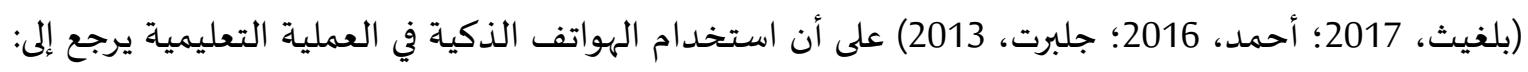

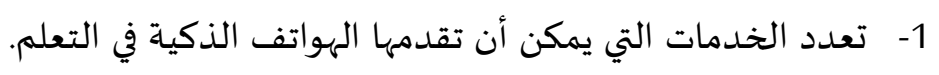

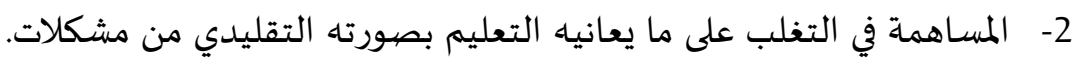

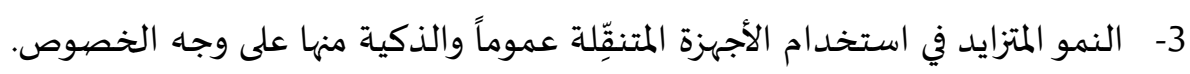

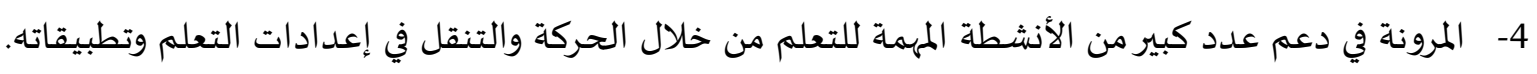

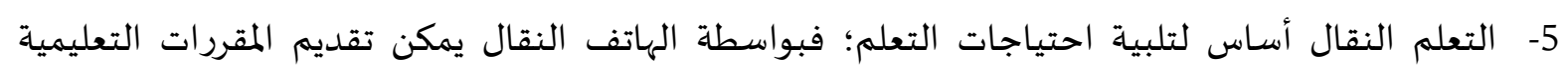
بالطريقة التي تلبي حاجات كل متعلم وظروفه. 6- المبادرة إلى اكتساب المعرفة؛ فوجود الهاتف في يد المتعلم بساعد في أن يكون له دوراً أسـاسياً في سرعة مبادرته للحصول على تلك المعارف. 7- الوصول إلى الأفراد في أي مكان وأي وقت؛ مما يفتح آفاق التعلم لشرائح كبيرة من المجتمع قد يكون من الضروري أن يصل النظام التعليهي إليها. 8- يساعد التعلم النقال على تكامل الحلقة التعليمية حيث يساعد طلاب المرحلة الجامعية خاصة لمن يسكنون

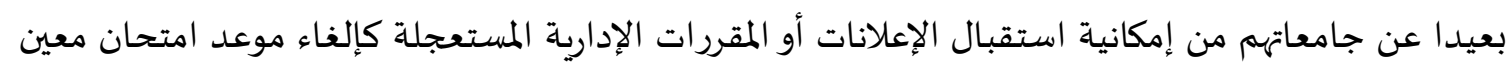

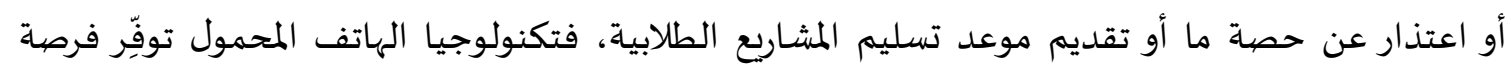

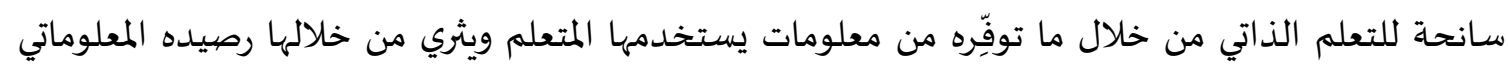

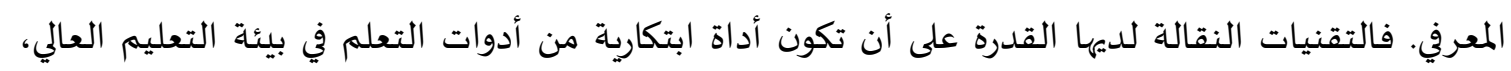
بحكم طبيعتها الشخصية والمحمولة، القادرة على تمكين التعلم من التكامل مع مقتضيات الحياة اليومية. 
وحيث يتميز التعلم النقال بسهولة استخدامه، وتعدد مزاياه التعليمية فقد أوصت الدراسات بضرورة استخدامه وتوظيفه في كافة المراحل التعليمية خاصة في التعليم الجامعي، ومن هذه الدراسات دراسة (أحمد 2016) التي أوصت بنشر ثقافة التعلم النقال المعتمد على الهاتف المحمول بين أعضاء هيئة التدريس والطابلاب.

رابعاً: التعلم الإلكتروني في جامعة طيبة:

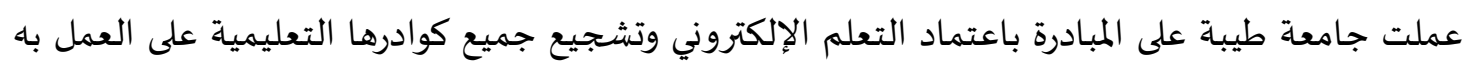

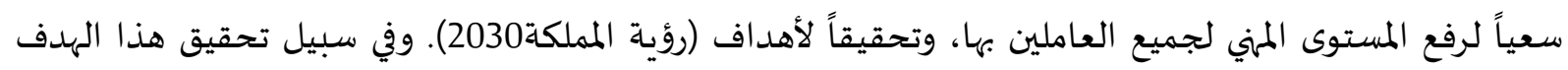

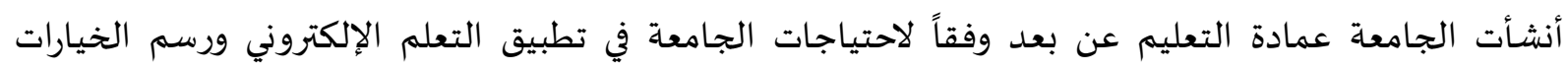

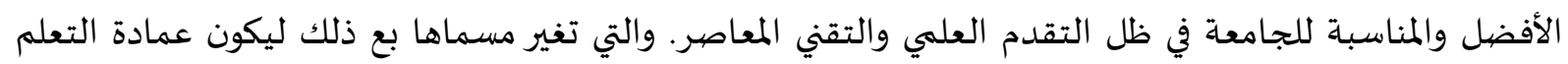
الإلكتروني، والتي من أهدافها ورؤيتها ما يلي:

1- التوظيف الفعال للتقنيات الحديثة في تحسين التعليم الإلكتروني حسب المبن المعايير المحلية والعالمية للجودة.

$$
\text { 2- توفير بيئة متميزة وجاذبة لنشر التعليم الإلكتروني وتطويره. }
$$

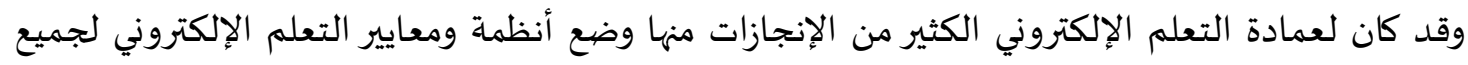

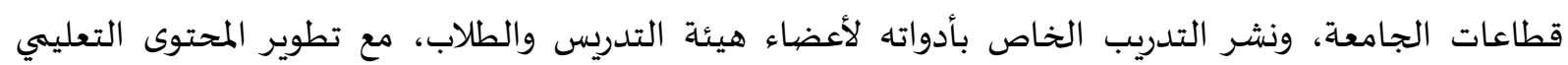

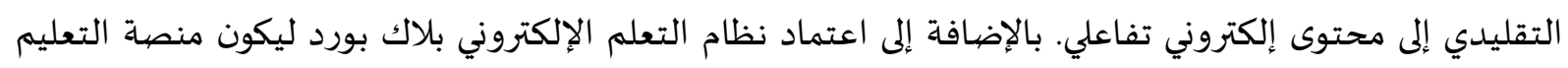

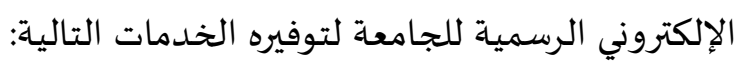

- - الحضور المباشر للمحاضرات إلكترونياً.

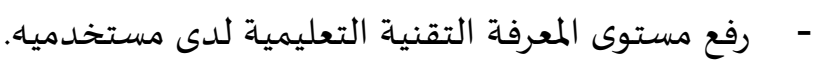

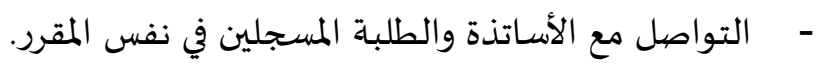

- الاطلاع على المحاضرات في أي وقت إلكترونياً، وإجراء المناقشات بشكل مباشر أثناء المحاضرة، أو غير مباشر في

المنتدى الخاص بالمقرر.

- توفر الكثير من الأدوات التي تساعد الطالب وأستاذ المقرر في العملية التدريسية؛ كإرسال الواجبات، وإجراء

الاختبارات بكافة أنواعها وأشكالها.

https://www.taibahu.edu.sa/Pages/AR/Service/ServiceDescription.aspx?ID=84.

ومن هنا تقرر أن تكون الدراسة عن طريق التعلم الإلكتروني بجامعة طيبة بنمطين:

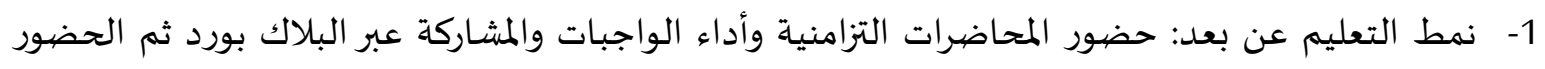

$$
\text { للحرم الجامعي لأداء الاختبار النهائي. }
$$

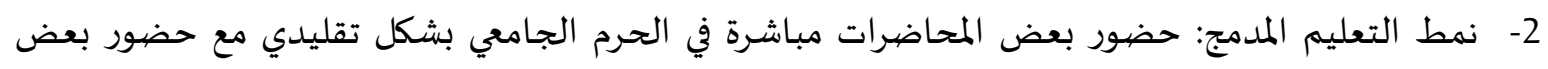

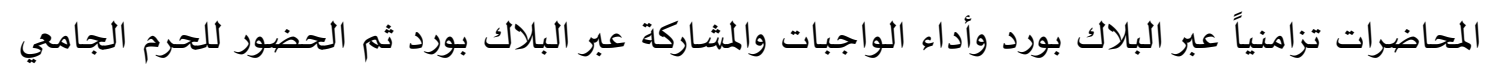

$$
\text { لأداء الاختبار النهائي. }
$$

وقد اثبت نظام البلاك بورد فاعليته في دعم التعلم بشكل قوي ونتائج ناجحة وذلك أثناء إيقاف الحضيور

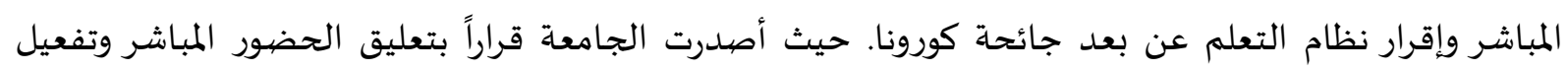

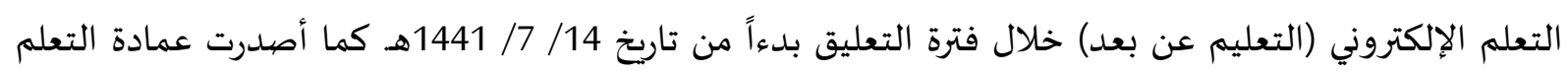

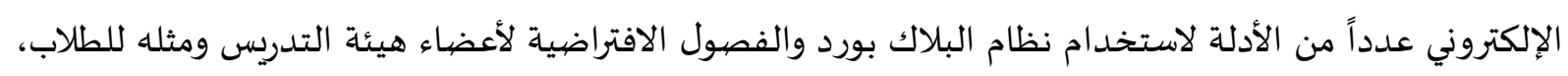

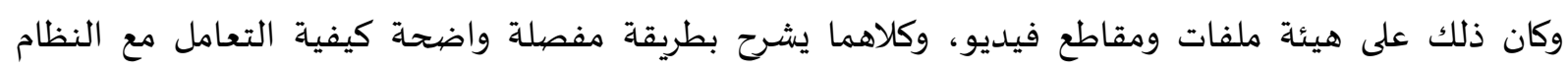




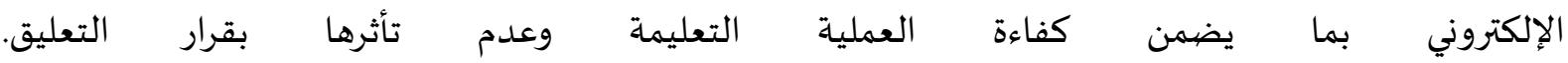
https://www.taibahu.edu.sa/Pages/AR/Sector/SectorPage.aspx?ID=41\&Pageld=320

ثانياً- الدراسـات السابقة:

تعرضت الباحثة في هذا الإطار إلى نوعين من الدراسات السابقة ذات الصلة بموضوع البحث وهما: أ- دراسات بحثت في واقع ومدى استخدام المنصتين إدمودو Ed وبلاك بورد Bb في التعليم، ومنها دراسات: - الرشيدي والبراهيم (2019) والتي هدفت إلى التعرف على واقع استخدام معلمات الحاسب الآلي للمنصات

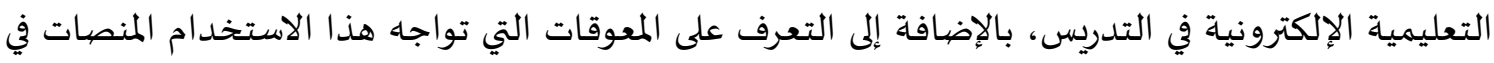
التدريس، ومدى وجود فروق في اتجاهات العينة نحو استخدام المنصات في التدريس تبعا لمتغيري الخبرة التبرة التدريسية والمستوى العلمي. ولتحقيق أهداف الدراسة استخدمت الباحثة الاستبانة أداة للدراسة. كما تكونت العينة من (70) معلمات الحاسب الآلي في منطقة الرياض. وتوصلت النتائج إلى موافقة العينة بدرجة كبيرة على للمنصات التعليمية الإلكترونية في التدريس. الشواربة (2019) وهدفت إلى التعرف على درجة استخدام طلبة الدراسات العليا في الجامعة الأردنية

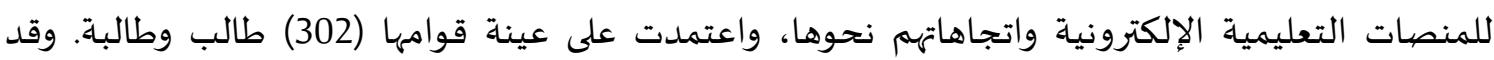

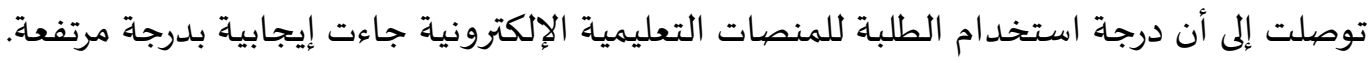

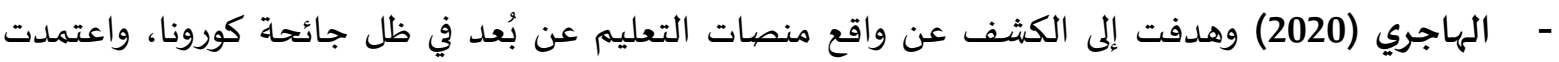

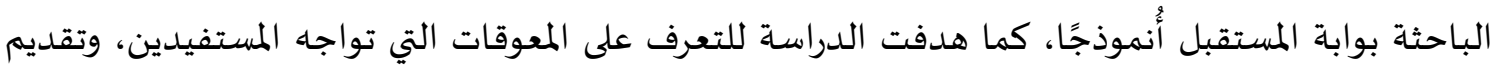
المقترحات التي تسهم في تحسين مستوى الأداء، وقد تم تطبيق الدراسة على عينة عشوائية بلغت (200) من

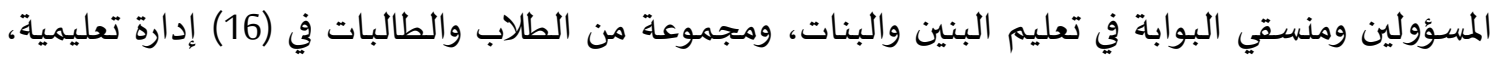
واستخدمت الاستبانة أداة للدراسة. وتوصلت الدراسة إلى مستوى أداء البوابة (الإداري، والفني، والتعليمي) من وجهة نظر الطلاب والطالبات جاء بدرجة جيدة جداً.

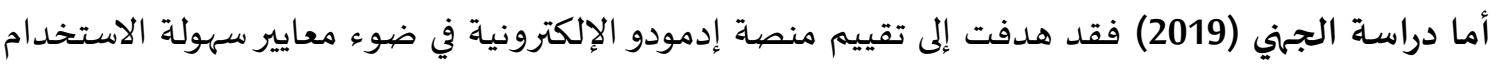

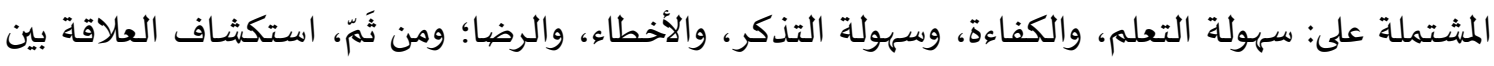

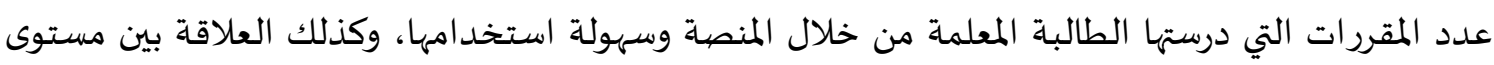

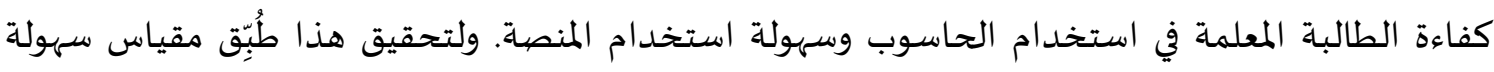

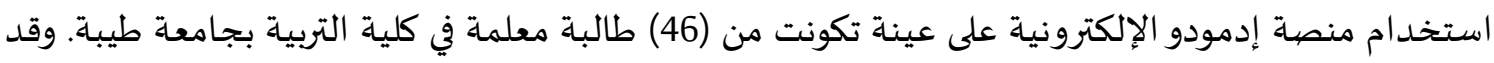

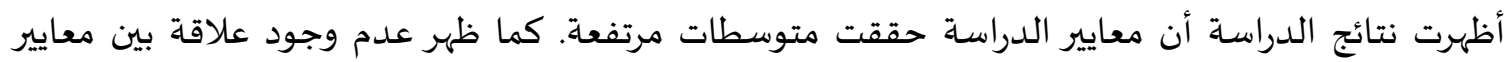

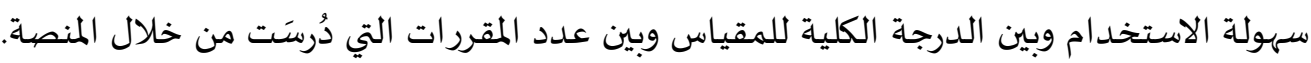
ب- دراسات تعلقت بمدى وواقع استخدام Bb في التعليم الجامعي ومنها دراسـات:

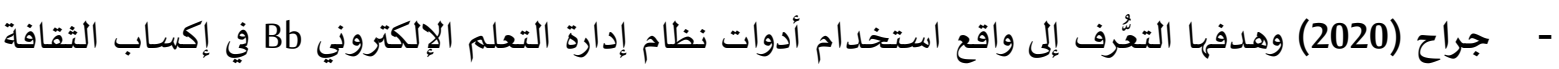

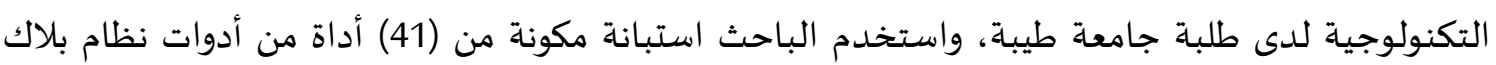

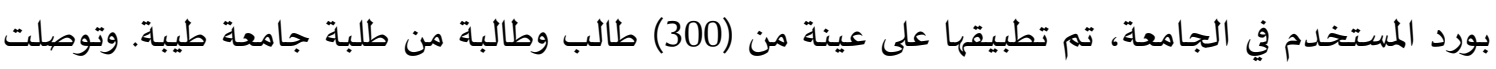

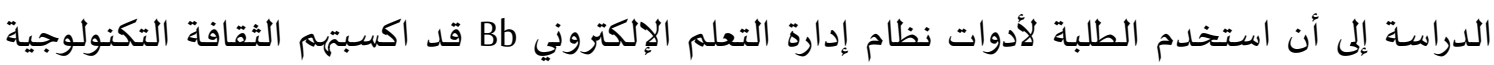
بمتوسط حسابي مرتفع، ونسبة مئوية (89\%). 
- الملحم وآخرون (2018) والتي هدفت إلى التعرف على واقع استخدام الطالبات لنظام إدارة التعلم البلاك بورد

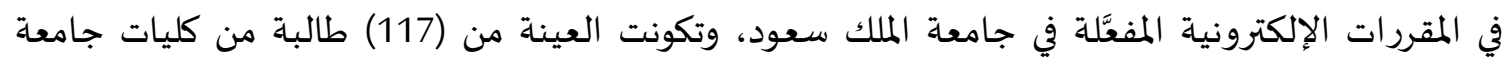

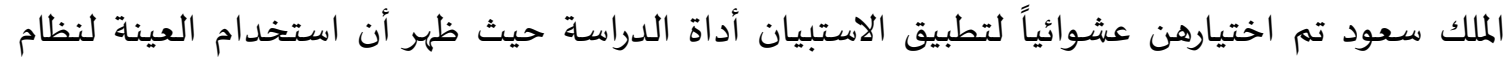
البلاك بورد كان بمتوسط حسابي مرتفع.

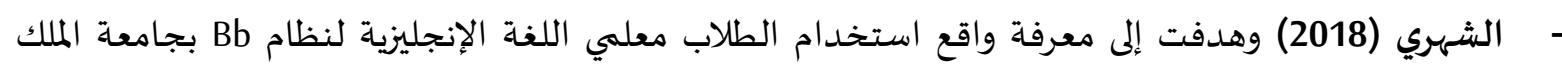

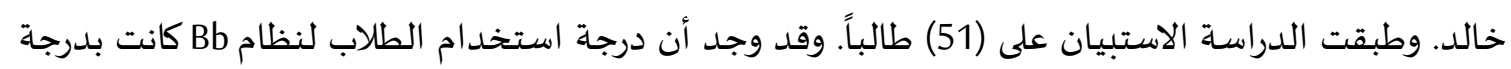
عالية. دراسة الرندي وأبا الخيل (2016) إلى التعرف على مدى استخدام طلبة البكالوريوس في كلية العلوم

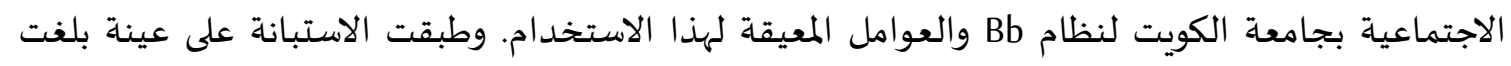

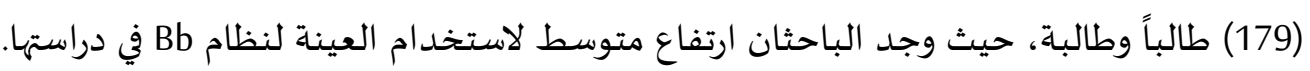
ت- دراسات تناولت دور المنصتين إدمودو Ed وبلاك بورد Bb في تنمية الاتجاه نحو التعلم ومنها دراسات:

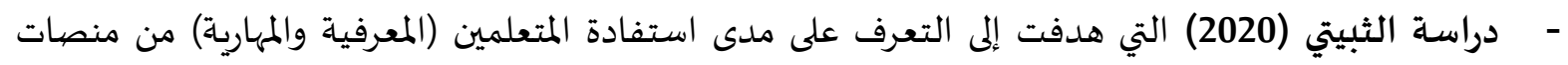

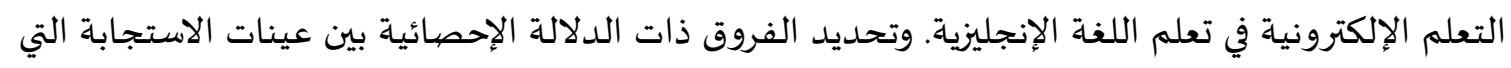

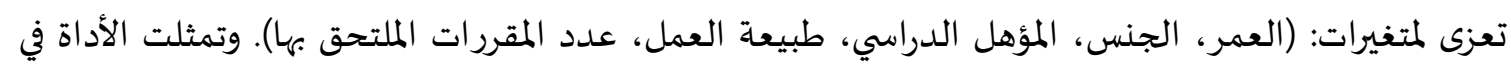

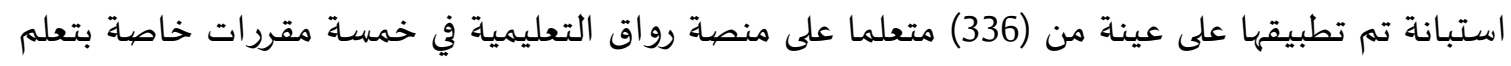

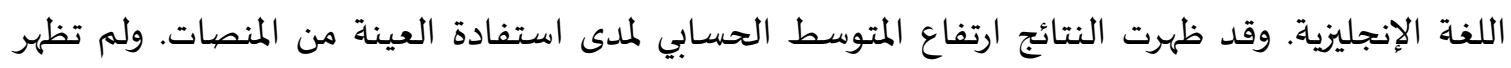
فروق ذات دلالة إحصائية بين استجابات العينة تبعاً للمتغيرات. - العييد (2019) والتي سعت لمعرفة تصورات طالبات جامعة الأميرة نورة بنت عبد الرحمن حول استخدام Ed عبر الأجهزة المتنقِّلة على التعلم والوصول لمصادر المعلومات. باستخدام استبانة على عينة قوامها (48)

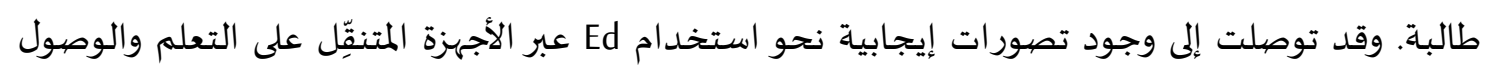
لمصيادر المعلومات.

Ed وهدفها التعرف على مستوى إدراك طلاب جامعة طيبة للتعلم المحمول من خلال AL- Said (2015)

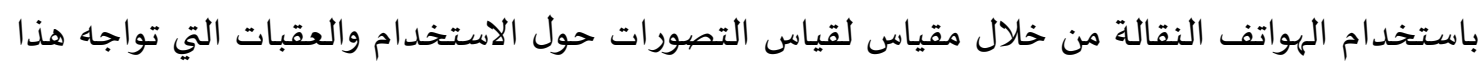

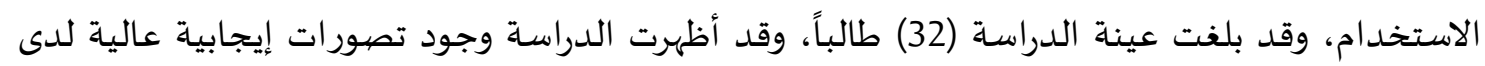
الطلاب تجاه Ed والتعلم النقال.

الشبو والعوضي (2020) التي سعت إلى الكشف عن مدى فاعلية استخدام تطبيقات التعلم الإلكتروني من

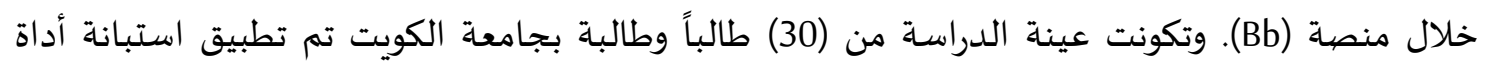

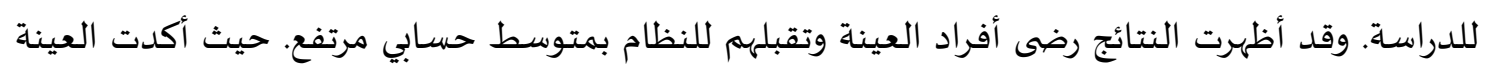

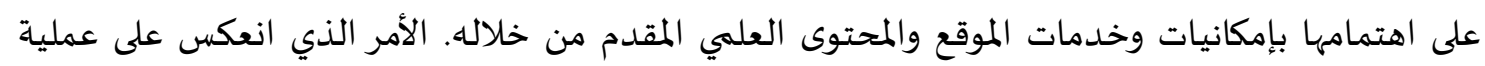
التعلم لديهم.

غزالة ونبيل (2019) والتي هدفت إلى الكشف عن واقع اتجاه طلاب جامعة الجوف نحو استخدام Bb في

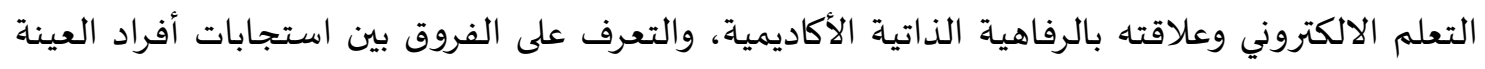

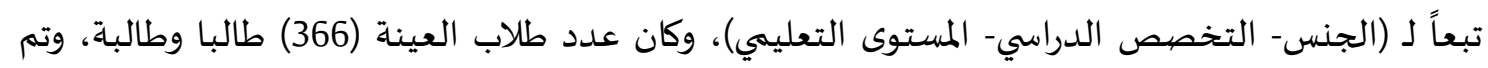

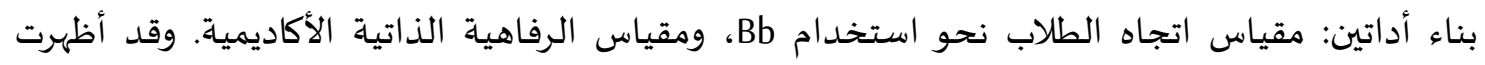
الدراسة أن مدى استجابة نحو الاتجاه لاستخدام Bb في التعلم الإلكتروني كانت إيجابية وكبيرة. 
- أبو الحاج (2019) وهدفها معرفة آراء طلاب جامعة القصيم حول استخدام نظام Bb في دراسة مقرر

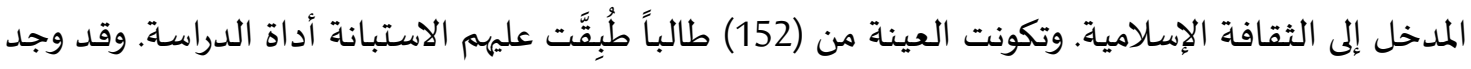
البحث أن اتجاهات الطلاب نحو استخدام نظام Bb في التعليم كانت بدرجة جيدة الإنداً

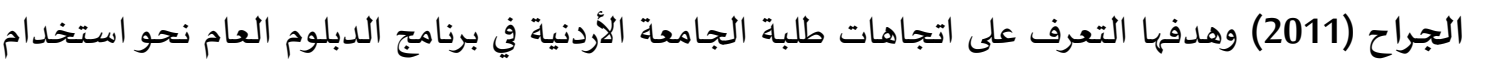

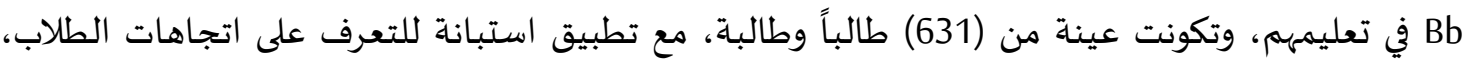

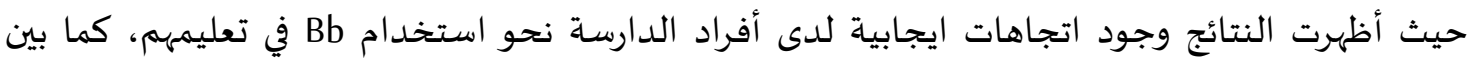
المشاركون أن النظام ساعدهم في تسهيل عملية التعلم وزيادة مشاركتهم الصفية وتحصيلهيه.

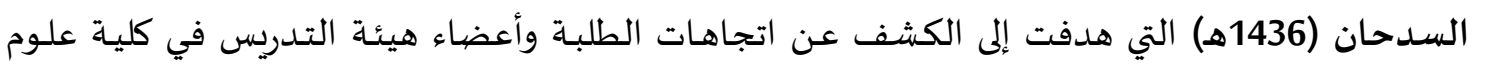

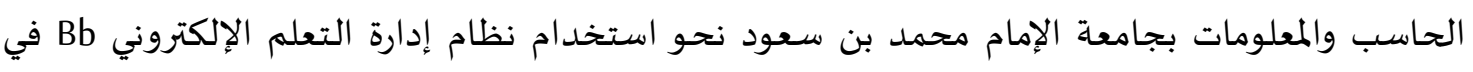
التعليم والتدريس الجامعي. ولتحقيق هذا الهدف طبق الباحث استبانة على عينة بلغت (533) طالباً

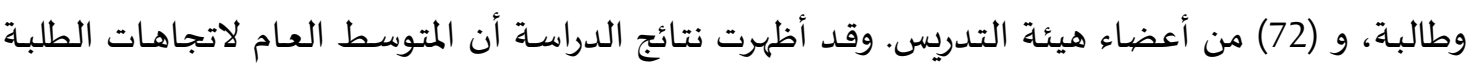
وأعضياء هيئة التدريس نحو استخدام نظام إدارة التعلم الإلكتروني كان إيجابياً.

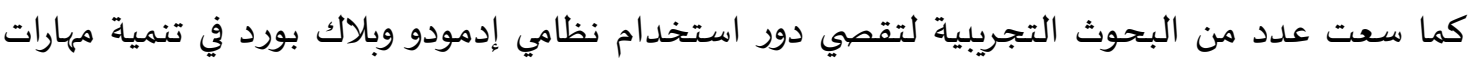

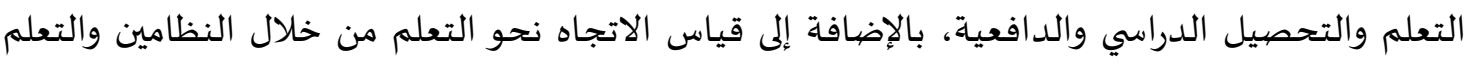

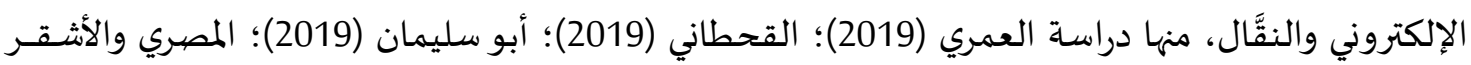
(2018)؛ (2018) Genedy\&Mabrouk)، القطعان (2108)؛ عمر والمصعبي (2017)؛ العصييمي (2016)؛ قلجة (2015)؛ العبد الكريم والرويس (2015)؛ الشهري وجلال (2014). وقد توصلت جميعها إلى ارتفاع

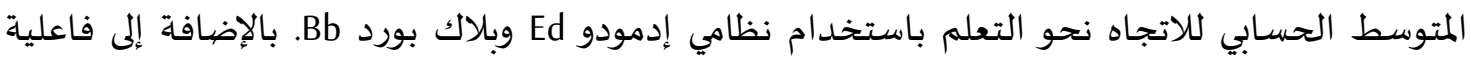

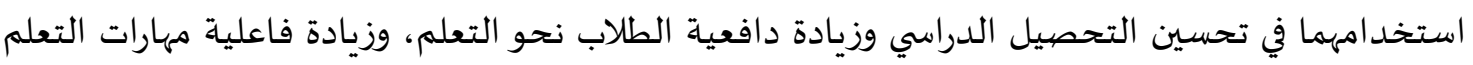

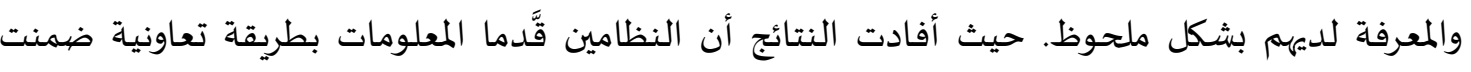

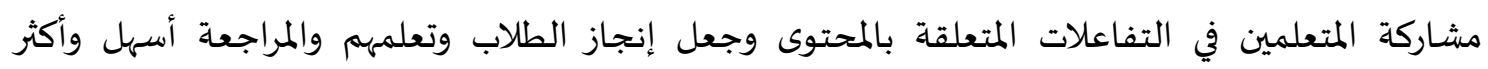

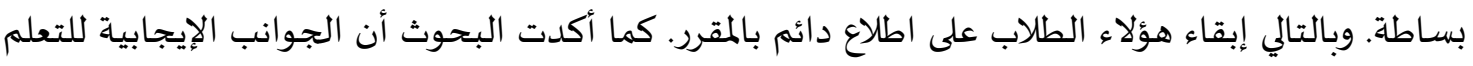
عبر النظامين عملت على تحسين مواقف الطلاب تجاه التعلم من خلاله، وبالتالي يمكن استخدادهماليما في التعليم العالي لتحسين مواقف المتعلمين فيما يتعلق بالتعلم من خلال المنصات التعلين موليمية.

\section{تعليق على الدراسـات السـابقة:}

- اتفقت الدراسة الحالية مع جميع الدراسات السابقة في اختيار طلاب الجامعة كعينة للدراسة باستثناء دراسة كلٍ من (أبو سليمان2019؛ العصيهي 2019؛ المصري والأشقر 2018) والتي اعتمدت على العيار طلى طلاب مرحلة التعليم

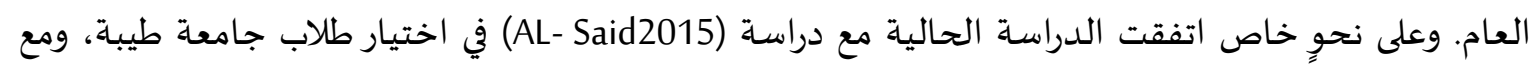

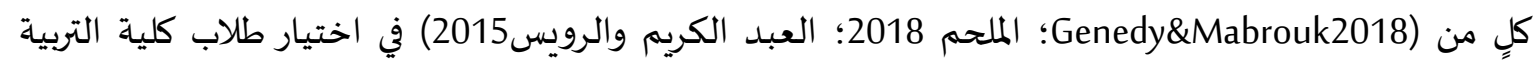
كعينة للدراسة. كما تتفق الدراسة الحالية في بناء مقياس اتجاه نحو التعلم مع دراسة كلٍ من (القحطاني

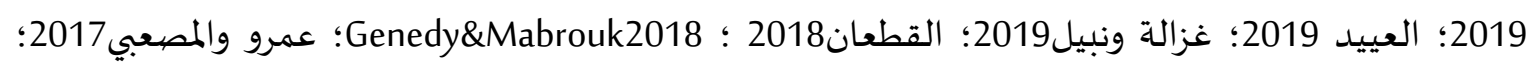
الجراح2011). كذلك اختارت الدراسة الحالية المنهج الوصفي للتطبيق بما يتفق مع دراسة كلٍ من (أبو الحاج

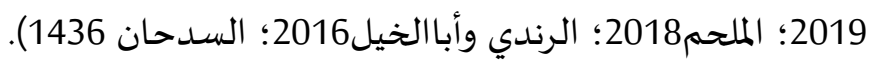


- وتميزت الدراسة الحالية عن الدراسات السابقة ببنائها وتطبيقها لاستبانتين كأدوات للدراسة، والعمل على المقارنة بين منصتين من منصات التعلم الإلكترونياة. - - ساعدت الدراسات السابقة الباحثة على تكوين تصور شامل عن كيفية بناء الأدوات وطرق استخدامها. كما ماندان ساعدتها في تدعيم الإطار النظري للدراسة الحالية، وكذلك في اختيار المنهجية الملائمة للدراسـة.

\section{3- منهجية البحث وإجراءاته.}

$$
\text { منهبج البحث: }
$$

تنتهي هذه الدراسة إلى الدراسات الوصفية المسحية التي تهدف إلى وصف ظاهرة ما، وجمع المعلومات عنها،

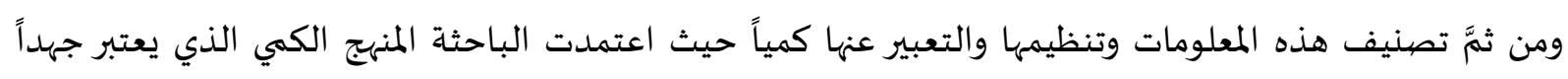

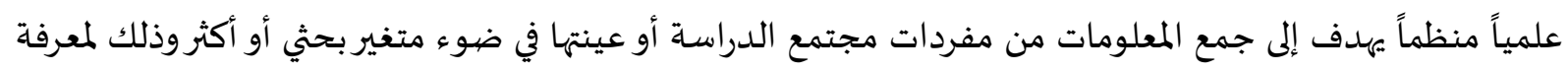

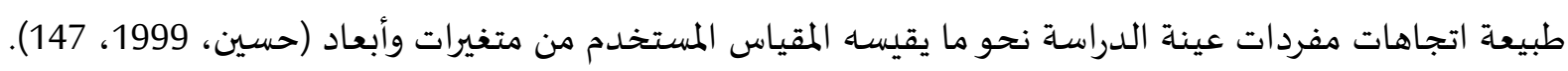

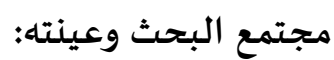

تكون مجتمع البحث من جميع الطالبات المسجلات لمقرر التعلم الإلكتروني (EDTE101) في كلية التربية

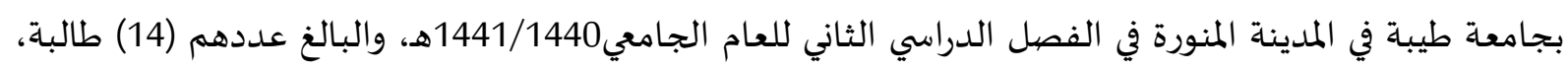

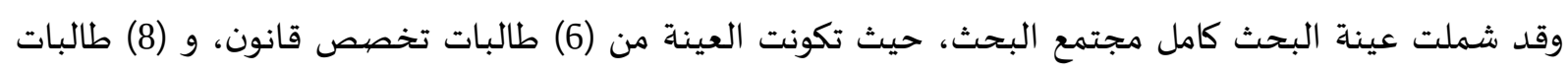
تخصص التربية الخاصية، وفينه وجميعهن يدرس الكثير من المقررات عن طريق نظام البلاك بورد، ومن هنا عملت الباحثة على استخدام منصية إدمودو Ed في دراستهن المقرر ليتسنّى لها المقارنة بين المنصتينين.

$$
\text { أدوات البحث: }
$$

لبناء أدوات الدراسة عملت الباحثة على:

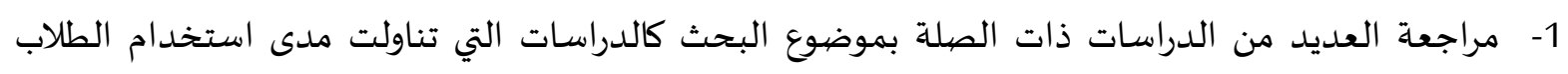

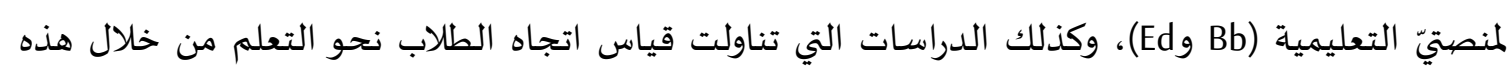

المنصتين.

2- - 2 - مياغة وبناء استبانتي الدراسة وهما:

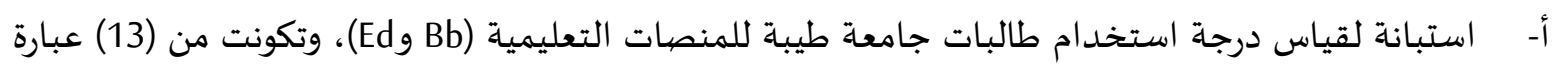

$$
\text { تراوحت بين (كثيراً - إلى حدٍ ما- قليلاً). }
$$

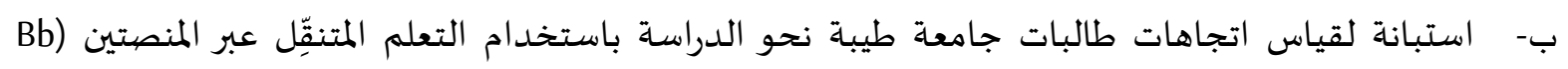

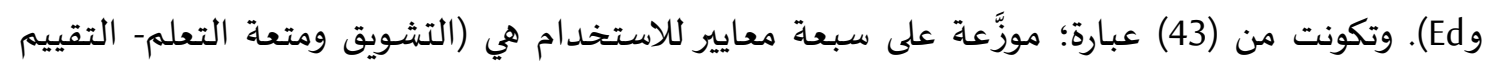

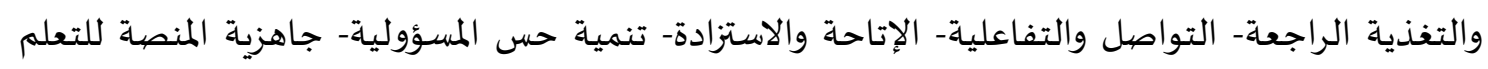
من خلاها- الرضا وقبول التعلم المتنقِّل). 3- تحكيم الأدوات وإجراء الصددق والثبات لها، ومن ثم إجراء التعديلات اللازمة في ضوء رأي المحكمين. 


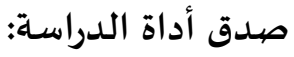

يقصد بالصدق" شمول الاستبانة لكل العناصر التي يجب أن تدخل في التحليل من ناحية، ووضوح فقراتها ومفرداتها من ناحية ثانية، بحيث تكون مفهومة لكل من يستخدمها (عبيدات وآخرون، 2001). وقد قامت الباحثة بالتأكد من صددق أداة الدراسة من خلال: أ. الصبدق الظاهري لأداتي الدراسة:

قامت الباحثة بعرض أداتيً الدراسة بعد الانتهاء منهما على مجموعة من المحكمين المتخصيّصين في المجال وعددهم (5) من أعضاء هيئة التدريس في تخصص تقنيات التعليم. للتأكد من صحة عباراتها وبناءها اللغوي، وكذلك للتأكد من مدى اتصالها بالموضوع، وبعد الاطلاع على ملاحظات ومقترحات الأسـاتذة المحكمين والأخذ بها، قامت الباحثة بالتعديل والحذف والإضافة حتى تم بناء الأداتين في صورتهما النهائية.

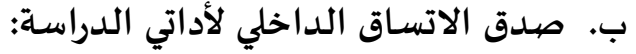
بعد التأكد من الصدق الظاهري لأداة الدراسة قامت الباحثة بتطبيقهما ميدانياً على عينة استطلاعية تكونت من (30) طالبة في كلية التربية بجامعة طيبة، وبعد تجميع الاستبانات قامت الباحثة باستخدام برنامج الحزم الإحصائية للعلوم الاجتماعية (SPSS)، ومن ثم قامت باستخدام معامل الارتباط بيرسون"Pearson Correlation" لحساب معامل الارتباط بين درجة كل عبارة والدرجة الكلية للمقياس. وتبين أن هناك عبارة واحدة يجب حذفها

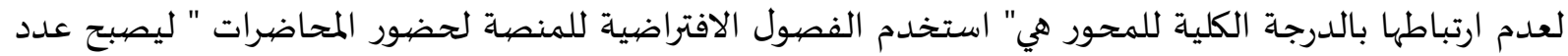
عبارات الاستبانة (12) عبارة، وتم إعادة التحليل بعد حذف العبارة وجاءت النتائج كما يوضحها الجدول أدناه: جدول (1) معاملات ارتباط بيرسون لعبارات استخدام طالبات جامعة طيبة للمنصات التبات التعليمية بالدرجة الكلية للمقياس

\begin{tabular}{|c|c|c|c|}
\hline معامل الارتباط & $\hat{\hat{\imath}}$ & معامل الارتباط & $\hat{\imath}$ \\
\hline $.807^{* *}$ & 7 & $.867^{* *}$ & 1 \\
\hline $.883^{* *}$ & 8 & $.686^{* *}$ & 2 \\
\hline $.885^{* *}$ & 9 & $.913^{* *}$ & 3 \\
\hline $.579 *$ & 10 & $.937^{* *}$ & 4 \\
\hline $.626^{*}$ & 11 & $.727 * *$ & 5 \\
\hline $.886^{* *}$ & 12 & $.687^{* *}$ & 6 \\
\hline
\end{tabular}

يبين الجدول أعلاه أن قيم معامل ارتباط العبارات بالدرجة الكلية للاستبانة دالة إحصائياً عند مستوى دلالة (0.01).

جدول (2) يوضح معاملات ارتباط بيرسون لعبارات محاور استبانة اتجاهات طالبات جامعة طيبة نحو الدراسة باستخدام التعلم المتنقل بالدرجة الكلية للمحور

\begin{tabular}{|c|c|c|c|c|c|c|c|}
\hline الاترتباط & رقم الفقرة & الارتباط معامل & رقم الفقرة & الارتباط معامل & رقم الفقرة & الارتباط معامل & رقم \\
\hline $.913^{* *}$ & 25 & $.836^{* *}$ & 17 & .a & 9 & $.939 * *$ & 1 \\
\hline $.747^{* *}$ & 26 & $.535^{*}$ & 18 & $.597^{*}$ & 10 & $.731^{* *}$ & 2 \\
\hline $.854^{* *}$ & 27 & $.620^{*}$ & 19 & $.792^{* *}$ & 11 & $.924^{* *}$ & 3 \\
\hline $.575^{*}$ & 28 & $.717^{* *}$ & 20 & $.882^{* *}$ & 12 & $.952^{* *}$ & 4 \\
\hline
\end{tabular}


المجلة العربية للطوم ونشر الأبحاث ـ مجلة العلوم التربوية والنفسية ـ المجلد الساس ـ العلد التاسع ـ فبراير 2022م

\begin{tabular}{|c|c|c|c|c|c|c|c|}
\hline الارتباط معامل & رقم الفقرة & معامل الارتباط & رقم الفقرة & الارتباط & رقم الفقرة & الارتباط & الفقرة \\
\hline \multirow[t]{4}{*}{$.854^{* *}$} & 29 & $.738^{* *}$ & 21 & $.759 * *$ & 13 & $.745^{* *}$ & 5 \\
\hline & & $.601^{*}$ & 22 & .509 & 14 & $.730^{* *}$ & 6 \\
\hline & & $.839 * *$ & 23 & $.853^{* *}$ & 15 & .a & 7 \\
\hline & & $.877^{* *}$ & 24 & $.633^{*}$ & 16 &.$a$ & 8 \\
\hline
\end{tabular}

يبين الجدول أعلاه أن قيم معامل ارتباط عبارات محاور استبانة اتجاهات طالبات جامعة طيبة نحو

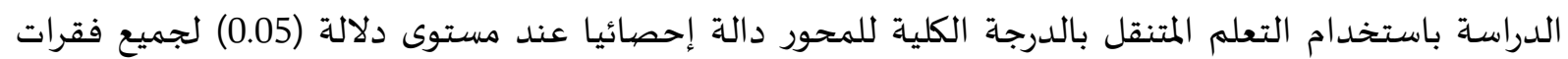

ثبات الأداتين:

لقياس مدى ثبات أداتي الدراسـة استخدمت الباحثة معادلة ألفا كرونباخ (Cronbach's Alpha)، حيث بلغ معامل الثبات العام لاستبانة استخدام طالبات جامعاة طيبة للمنصات التعليمية بلغ (0.94)، وقيمة معامل الثبات العام لاستبانة اتجاهات الطالبات نحو الدراسة عبر المنصات التعليمية بلغ (0.90)، وهذه قيم يمكن الاعتماد عليها في التطبيق الميداني للدراسـة.

أساليب المعالجة الإحصيائية:

لتحقيق أهداف الدراسة وتحليل البيانات التي تم تجميعها استخلدِمَت العديد من الأساليب الإحصائية

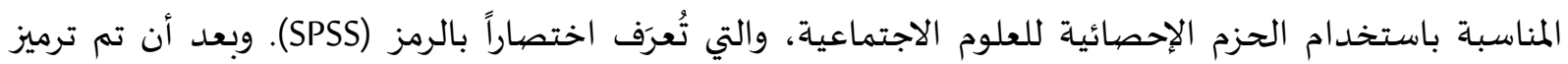

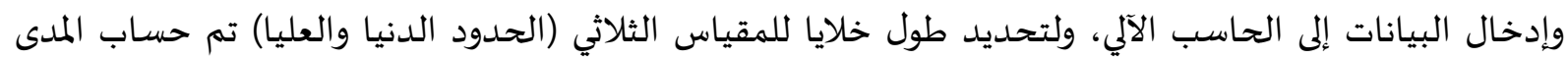

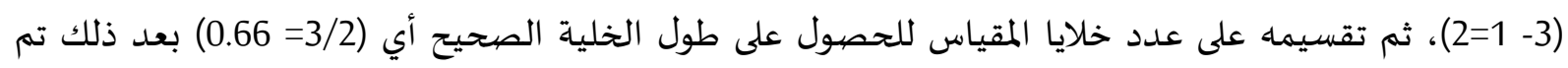

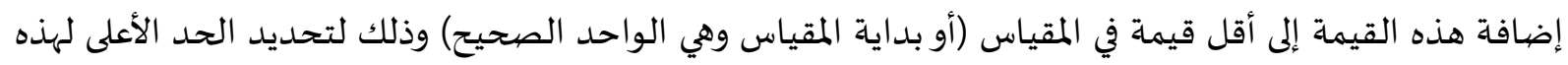
الخلية، وهكذا أصبح طول الخلايا كما يأتي:

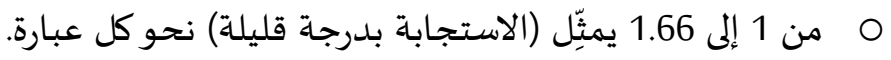

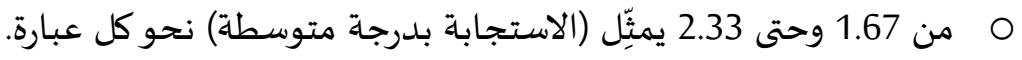

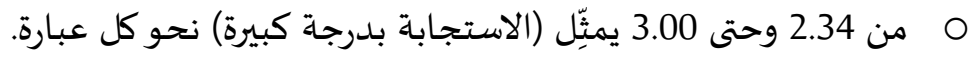
وبعد ذلك تم حساب الإحصائية التالية:

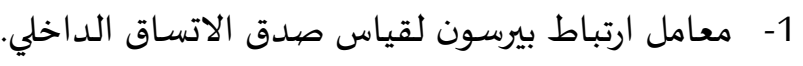

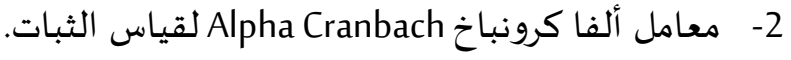
3- التكرارات والمتوسط الحسابي لمعرفة استجابات الأفراد على الاستبانتين.

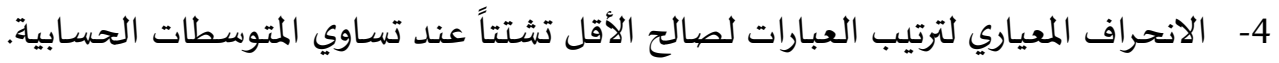

4- نتائج البحث ومناقشتها. النتائج المتعلقة بالإجابة عن السؤال الأول: ما مدى استخدام طالبات كلية التربية المسجلات لمقرر التعلم

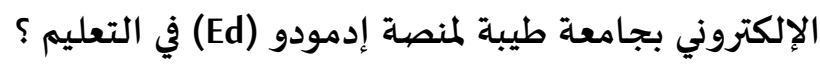


وللإجابة عن السؤال تم حساب التكرارات والمتوسط الحسابي والانحراف المعياري لمدى استخدام طالبات

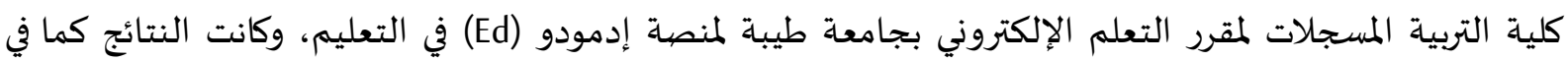

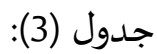

جدول رقم (3) يوضِّح مدى استخدام طالبات كلية التربية المسجلات لمقرر التعلم الإلكتروني بجامعة طيبة لمنصية إدمودو (Ed) في التعليم

\begin{tabular}{|c|c|c|c|c|c|c|c|}
\hline 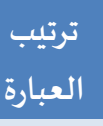 & 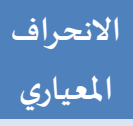 & الحسبط المتوسط & قليلاً & إلى حلٍ ما & كثيراً & & \\
\hline \multirow{2}{*}{7} & \multirow{2}{*}{0.83} & \multirow{2}{*}{1.93} & 5 & 5 & 4 & ك & \multirow{2}{*}{ استخدم المنصية لتصفح أدوات المقرر } \\
\hline & & & 35.7 & 35.7 & 28.6 & $\%$ & \\
\hline \multirow{2}{*}{9} & \multirow{2}{*}{0.83} & \multirow{2}{*}{1.71} & 7 & 4 & 3 & ك & \multirow{2}{*}{ استخدم المنصبة لتحميل المحاضرات } \\
\hline & & & 50.0 & 28.6 & 21.4 & $\%$ & \\
\hline \multirow{2}{*}{2} & \multirow{2}{*}{0.85} & \multirow{2}{*}{2.43} & 3 & 2 & 9 & ك & \multirow{2}{*}{ استخدم المنصبة لإرسال الواجبات والتكليفات } \\
\hline & & & 21.4 & 14.3 & 64.3 & $\%$ & \\
\hline \multirow{2}{*}{5} & \multirow{2}{*}{0.92} & \multirow{2}{*}{2.07} & 5 & 3 & 6 & ك & \multirow{2}{*}{ استخدم المنصية لأداء الاختبارات الإلكترونية } \\
\hline & & & 35.7 & 21.4 & 42.9 & $\%$ & \\
\hline \multirow{2}{*}{10} & \multirow{2}{*}{0.91} & \multirow{2}{*}{1.71} & 8 & 2 & 4 & ك & \multirow{2}{*}{ استخدم المنصية للنقاشـات والحوارات مع أستاذ } \\
\hline & & & 57.1 & 14.3 & 28.6 & $\%$ & \\
\hline \multirow{2}{*}{12} & \multirow{2}{*}{0.58} & \multirow{2}{*}{1.21} & 12 & 1 & 1 & ك & \multirow{2}{*}{ استخدم المنصية للنقاشات والحوارات مع زميلاتي } \\
\hline & & & 85.7 & 7.1 & 7.1 & $\%$ & \\
\hline \multirow{2}{*}{7} & \multirow{2}{*}{0.83} & \multirow{2}{*}{1.93} & 5 & 5 & 4 & ك & \multirow{2}{*}{ استخدم المنصية للحصهول على التغذية الراجعة } \\
\hline & & & 35.7 & 35.7 & 28.6 & $\%$ & \\
\hline \multirow{2}{*}{3} & \multirow{2}{*}{0.74} & \multirow{2}{*}{2.36} & 2 & 5 & 7 & ك & \multirow{2}{*}{ استخدم المنصة لتبادل المحتوى المعرفي مع } \\
\hline & & & 14.3 & 35.7 & 50.0 & $\%$ & \\
\hline 1 & 0.76 & 2.43 & 2 & 4 & 8 & ك & استخدم المنصهة في العمل على إثراء المحتوى \\
\hline & & 2.40 & 14.3 & 28.6 & 57.1 & $\%$ & العلمي للمقرر \\
\hline 6 & 0.73 & 193 & 4 & 7 & 3 & ك & 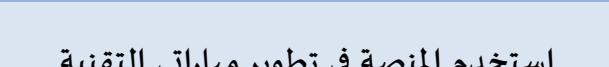 \\
\hline & 0.13 & 1.50 & 28.6 & 50.0 & 21.4 & $\%$ & 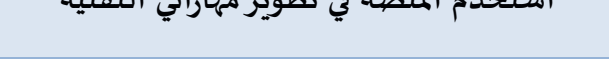 \\
\hline 11 & 0.74 & 1.64 & 7 & 5 & 2 & ك & استخدم المنصية في تطوير مهارتي في البحث وجمع \\
\hline 11 & 0.14 & 1.07 & 50.0 & 35.7 & 14.3 & $\%$ & المعلومات \\
\hline 4 & 0.95 & 214 & 5 & 2 & 7 & ك & استخدم المنصية في الرجوع إلى المحاضرات \\
\hline 4 & - & 2.14 & 35.7 & 14.3 & 50.0 & $\%$ & والنقاشات وقت الحاجة \\
\hline & 1.96 & & & & & ابي & المتوسط الح \\
\hline
\end{tabular}

بالنظر إلى المتوسط العام لمحور مدى استخدام طالبات جامعة طيبة للمنصة التعليمية Ed يتضح أهنن

بصورة عامة يستخدمن المنصية بدرجة متوسطة، حيث بلغ المتوسط الحسابي العام لجميع عبارات الاستبانة (1.96)

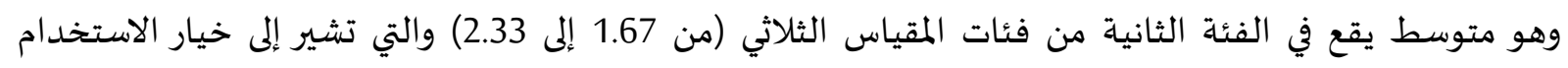

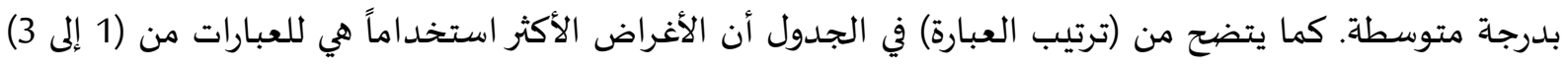

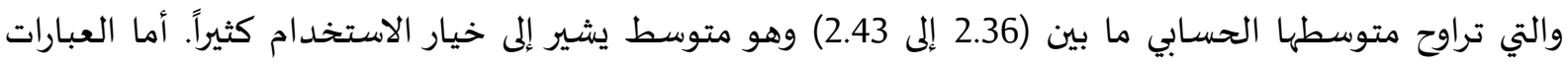

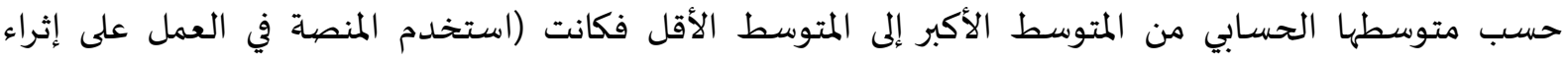


المحتوى العلمي للمقرر "2.43". استخدم المنصة لإرسال الواجبات والتكليفات "2.43". استخدم المنصية لتبادل

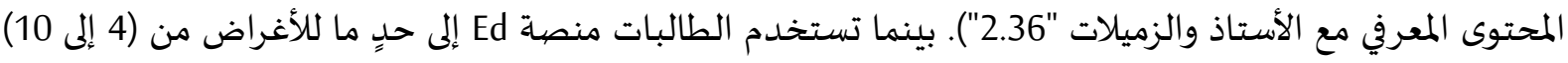

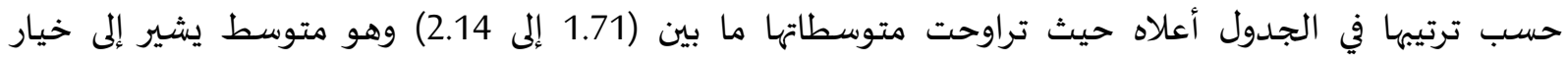

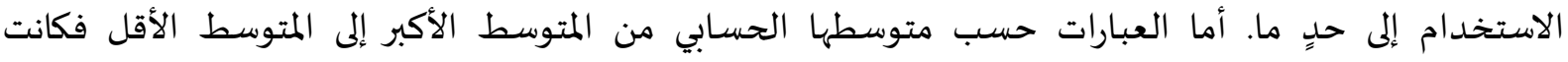

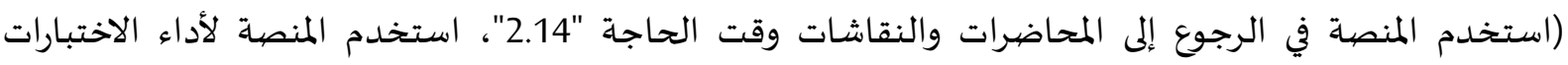

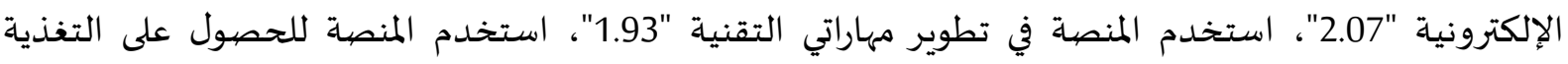

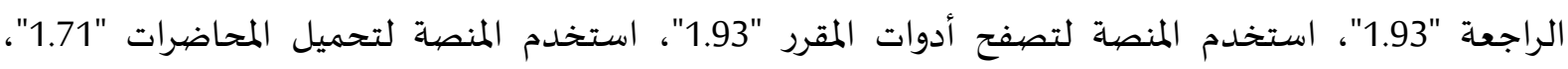

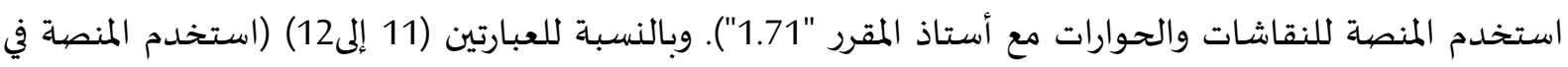

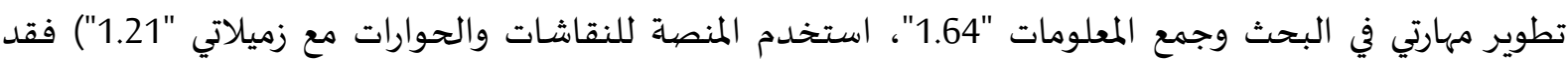
كانت قليلة الاستخدام حسب ترتيبها في الجدول أعلاه)، حيث تراوحت متوسطاتها ما بين (1.21 إلى 1.64) وهو متوسط يشير إلى خيار قليلاً.

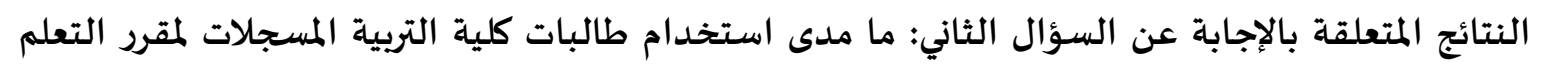

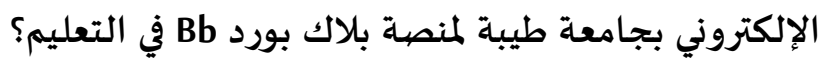

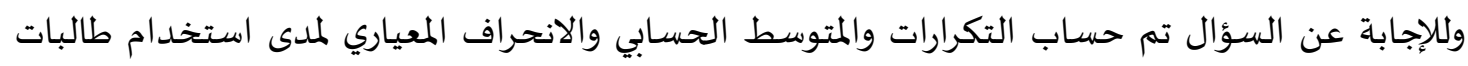

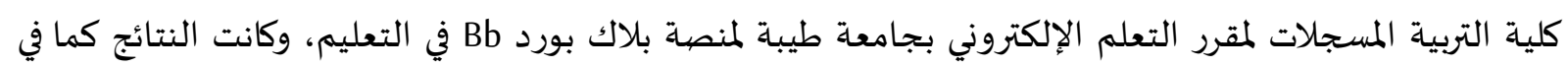

جدول (4):

جدول رقم (4) يوضِّح مدى استخدام طالبات كلية التربية المسجلات لمقرر التعلم الإلكتروني بجامعة طيبة لمنصية بلاك بورد Bb في التعليم

\begin{tabular}{|c|c|c|c|c|c|c|c|}
\hline ترتيب & الانعراف & المتوسط الحسابي & قليلاً & ما مالى حل & كثيراً & & \\
\hline \multirow{2}{*}{4} & \multirow{2}{*}{0.36} & \multirow{2}{*}{2.86} & & 2 & 12 & ك & \multirow{2}{*}{ استخدم المنصية لتصفح أدوات المقرر } \\
\hline & & & & 14.3 & 85.7 & $\%$ & \\
\hline \multirow{2}{*}{5} & \multirow{2}{*}{0.61} & \multirow{2}{*}{2.71} & 1 & 2 & 11 & ك & \multirow{2}{*}{ استخدم المنصية لتحميل المحاضرات } \\
\hline & & & 7.1 & 14.3 & 78.6 & $\%$ & \\
\hline \multirow{2}{*}{1} & \multirow{2}{*}{0} & \multirow{2}{*}{3} & & & 14 & ك ك & \multirow{2}{*}{ استخدم المنصية لإرسال الواجبات والتكليفات } \\
\hline & & & & & 100.0 & $\%$ & \\
\hline \multirow{2}{*}{1} & \multirow{2}{*}{0} & \multirow{2}{*}{3} & & & 14 & ك & \multirow{2}{*}{ استخدم المنصية لأداء الاختبارات الإلكترونية } \\
\hline & & & & & 100.0 & $\%$ & \\
\hline \multirow{2}{*}{7} & \multirow{2}{*}{0.76} & \multirow{2}{*}{2.57} & 2 & 2 & 10 & ك & \multirow{2}{*}{ استخدم المنصة للنقاشـات والحوارات مع أستاذ المقرر } \\
\hline & & & 14.3 & 14.3 & 71.4 & $\%$ & \\
\hline \multirow{2}{*}{12} & \multirow{2}{*}{0.88} & \multirow{2}{*}{2} & 5 & 4 & 5 & ك & \multirow{2}{*}{ استخدم المنصية للنقاشـات والحوارات مع زميلاتي } \\
\hline & & & 35.7 & 28.6 & 35.7 & $\%$ & \\
\hline \multirow{2}{*}{5} & \multirow{2}{*}{0.61} & \multirow{2}{*}{2.71} & 1 & 2 & 11 & ك & \multirow{2}{*}{ استخدم المنصية للحصيول على التغذية } \\
\hline & & & 7.1 & 14.3 & 78.6 & $\%$ & \\
\hline \multirow{2}{*}{7} & \multirow{2}{*}{0.76} & \multirow{2}{*}{2.57} & 2 & 2 & 10 & ك & \multirow{2}{*}{$\begin{array}{c}\text { استخدم المنصية لتبادل المتحتوى المعرفي مع المعتاذ والزميلات } \\
\text { المعتات }\end{array}$} \\
\hline & & & 14.3 & 14.3 & 71.4 & $\%$ & \\
\hline 11 & 0.63 & 2.36 & 1 & 7 & 6 & ك & استخدم المنصية في العمل على إثراء المحتوى \\
\hline
\end{tabular}




\begin{tabular}{|c|c|c|c|c|c|c|c|}
\hline ترتيب & الاندراف & المتوسط الحسابي & قليلاً & إلى حادٍ & كثيراً & & \\
\hline & & & 7.1 & 50.0 & 42.9 & $\%$ & العلمي للمقرر \\
\hline \multirow{2}{*}{9} & \multirow{2}{*}{0.76} & \multirow{2}{*}{2.5} & 2 & 3 & 9 & ك & \multirow{2}{*}{ استخدم المنصية في تطوير مهاراتي التقنية } \\
\hline & & & 14.3 & 21.4 & 64.3 & $\%$ & \\
\hline \multirow{2}{*}{10} & \multirow{2}{*}{0.76} & \multirow{2}{*}{2.43} & 2 & 4 & 8 & ك & \multirow{2}{*}{ استخدم المنصية في تطوير مهارتي في البحث } \\
\hline & & & 14.3 & 28.6 & 57.1 & $\%$ & \\
\hline \multirow{2}{*}{3} & \multirow{2}{*}{0.27} & \multirow{2}{*}{2.93} & & 1 & 13 & ك & \multirow{2}{*}{$\begin{array}{c}\text { استخدم المنصية في الرجوع إلى المحاضرات } \\
\text { والنقاشـات وقت الحاجة }\end{array}$} \\
\hline & & & & 7.1 & 92.9 & $\%$ & \\
\hline \multicolumn{3}{|c|}{2.64} & \multicolumn{5}{|c|}{ المتوسط الحسابي } \\
\hline
\end{tabular}

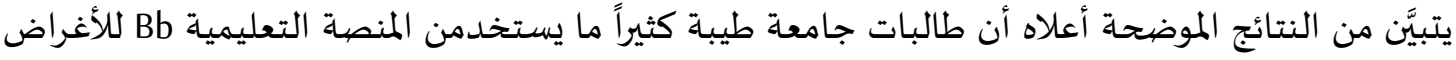

من (1 إلى 11) حسب ترتيبها في الجدول أعلاه حيث تراوح متوسطها الحسابي بين (2.36 إلى 3.00) وهو متوسط يقع

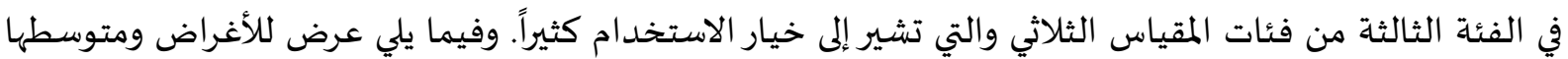

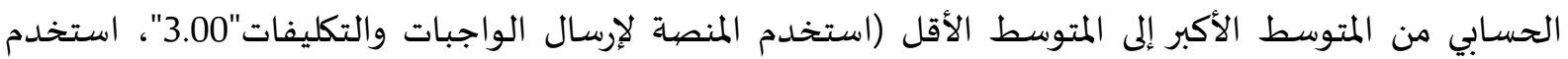

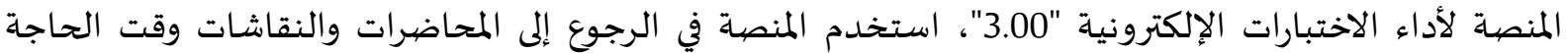

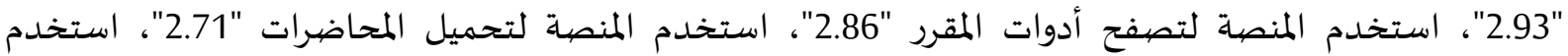
المنصة للحصول على التغذية الراجعة "2.71"، استخدم المنصية للنقاشات والحوارات مع أستاذ المقرر "2.57"،

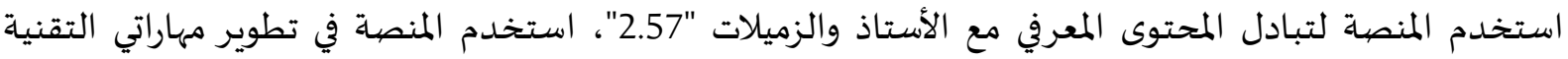

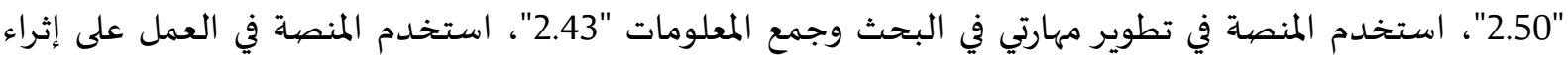

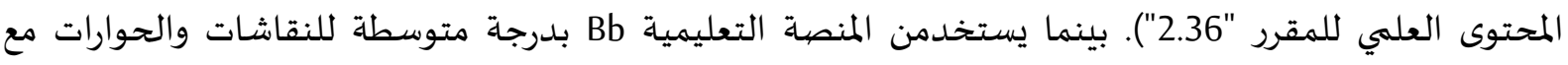

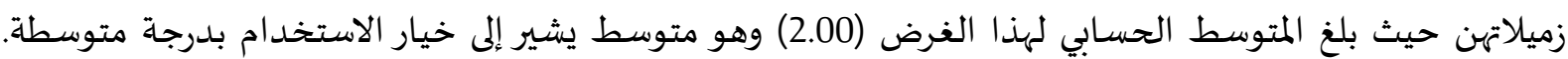

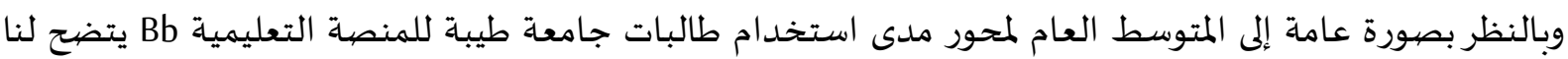

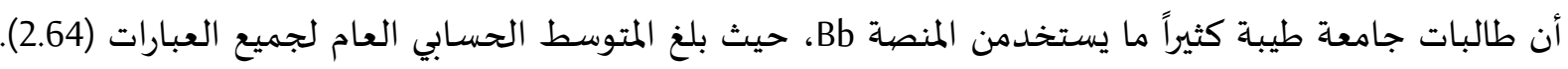

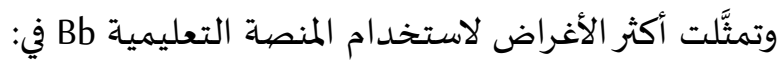
1- استخدم المنصية لإرسال الواجبات والتكليفات "3.00". 2- استخدم المنصية لأداء الاختبارات الإلكترونية "3.00".

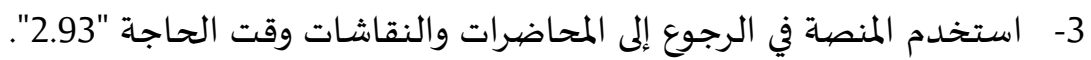

تفسير نتائج السؤالين الأول والثاني: بالمقارنة بين المتوسطين العامين لمدى مدى استخدام طالبات جامولئ الماولئ طيبة للمنصة التعليمية للمنصتين إدمودو Ed و Bb نجد أن الطالبات يستخدمن منصة Ed بلدرجة متوسطة بصورة عامة، حيث بلغ المتوسط الحسابي ملئي

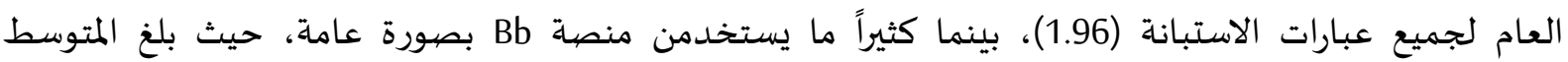

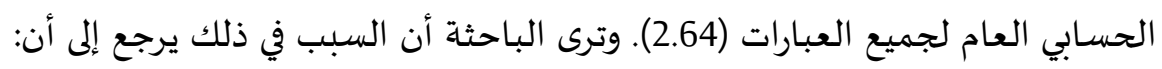

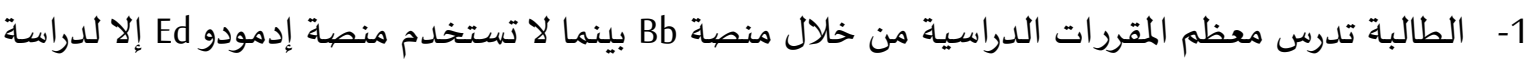

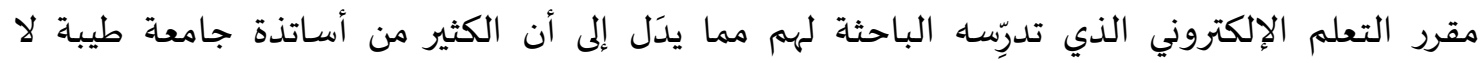


يستخدمون منصة Ed؛ إما لاكتفائهم بمنصة Bb الذي قررته جامعة طيبة كمنصة رئيسة لها، أو لعدم معرفتهم بمنصية إدمودو Ed، أو لجهلهم بمزاياها التعليمية.

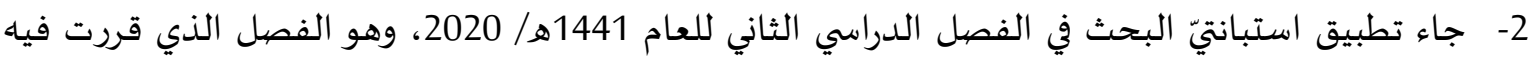

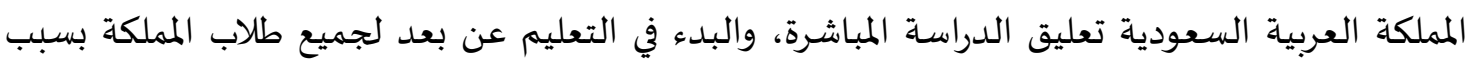

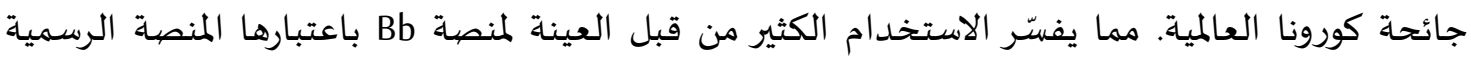

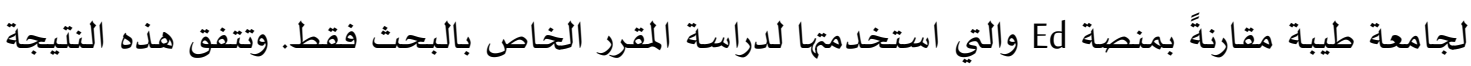

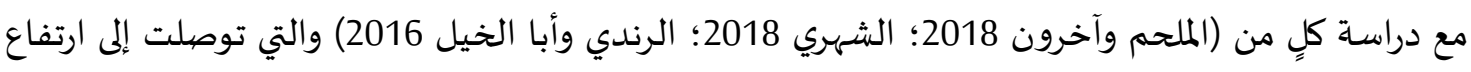
المتوسط الحسابي لاستخدام العينة لمنصية بلاك بورد في عملية التعلم. النتائج المتعلقة بالإجابة عن السؤال الثالث: ما اتجاهات طالبات كلية التربية المسججلات لمقرر التعلم

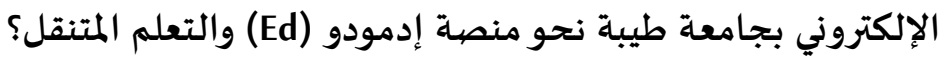

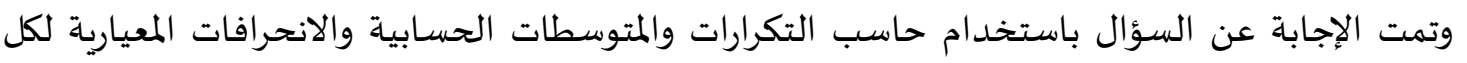

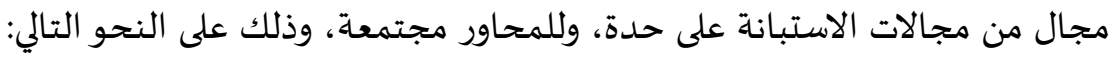

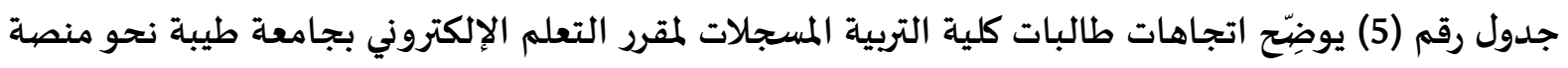
إدمودو (Ed) والتعلم المتنقل من حيث التشويق ومتعة التعلم

\begin{tabular}{|c|c|c|c|c|c|c|c|}
\hline ترتيب & الالانحراف & الحستوسط الحسبي & موافق & 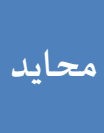 & 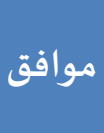 & & العبارة \\
\hline \multirow{2}{*}{1} & \multirow{2}{*}{0.36} & \multirow{2}{*}{2.86} & & 2 & 12 & ك & \multirow{2}{*}{ تشكل المنصية بيئة فعالة للتعلم } \\
\hline & & & & 14.3 & 85.7 & $\%$ & \\
\hline \multirow{2}{*}{2} & \multirow{2}{*}{0.63} & \multirow{2}{*}{2.64} & 1 & 3 & 10 & ك & \multirow{2}{*}{ تقدّم المنصية المحتوى بطريقة شيقة } \\
\hline & & & 7.1 & 21.4 & 71.4 & $\%$ & \\
\hline \multirow{2}{*}{5} & \multirow{2}{*}{0.68} & \multirow{2}{*}{2.00} & 3 & 8 & 3 & ك & \multirow{2}{*}{ أشعر بالحماس والاستثارة أثناء تعلم المقرر } \\
\hline & & & 21.4 & 57.1 & 21.4 & $\%$ & \\
\hline \multirow{2}{*}{3} & \multirow{2}{*}{0.70} & \multirow{2}{*}{2.21} & 2 & 7 & 5 & ك & \multirow{2}{*}{ تزيد الدراسـة من خلال المنصية من دافعيتي } \\
\hline & & & 14.3 & 50.0 & 35.7 & $\%$ & \\
\hline \multirow{2}{*}{3} & \multirow{2}{*}{0.70} & \multirow{2}{*}{2.21} & 2 & 7 & 5 & ك & \multirow{2}{*}{ يشعرني العمل والمشاركة في المنصية بالألفة } \\
\hline & & & 14.3 & 50.0 & 35.7 & $\%$ & \\
\hline \multicolumn{3}{|c|}{2.38} & \multicolumn{5}{|c|}{ المتوسط الحسابي } \\
\hline
\end{tabular}

بلغ المتوسط الحسابي العام لجميع عبارات محور اتجاهات طالبات جامعة طيبة نحو الدراسة عبر منصية

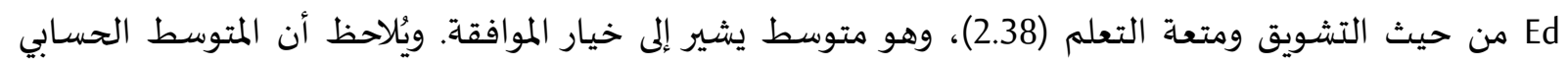

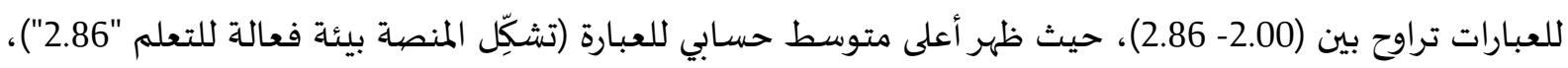

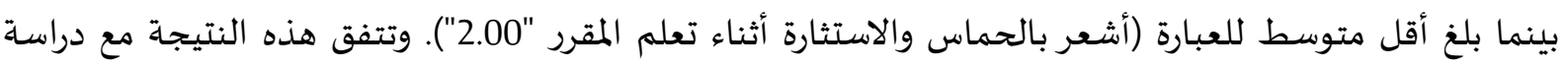

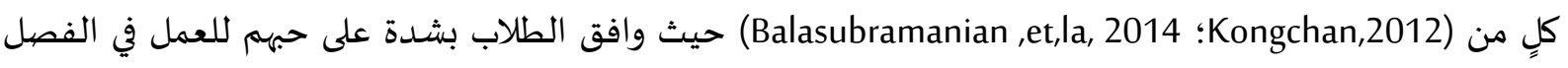

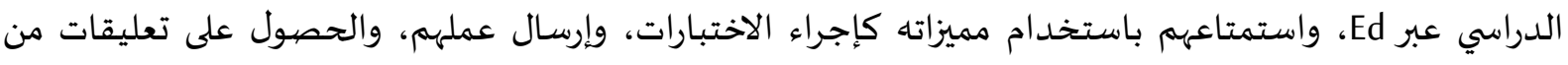

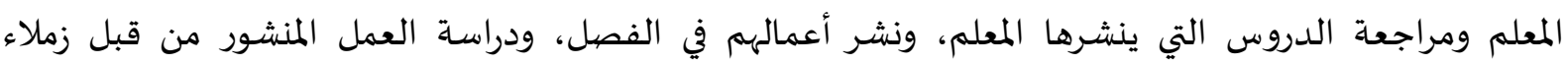

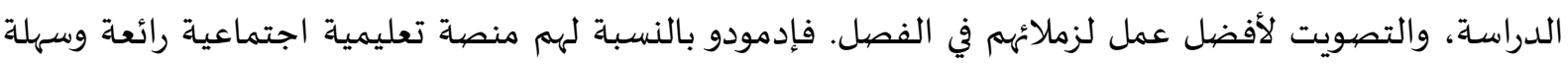


الاستخدام، كما وأن هذه النتائج قد تلهم المعلمين في أي مكان لإعادة تقييم الطريقة التي يديرون بها فصولهم. وعلى الطي

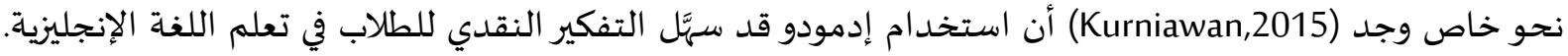
كما وجد (Batsila,2014) أن معظم المعلمين يرون Ed محفز تمامًا للمتعلمين؛ حيث جعلهم أكثر مشاركة في دروسهيم،

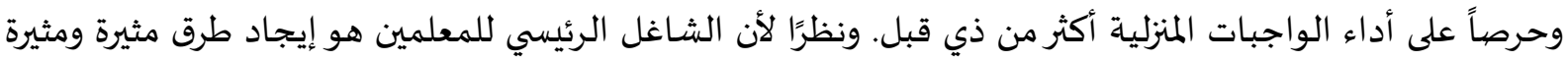

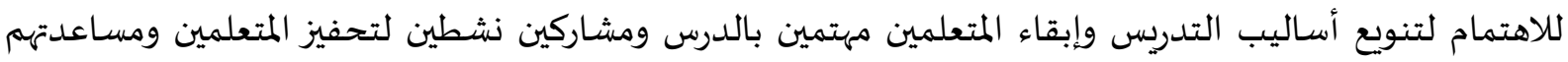

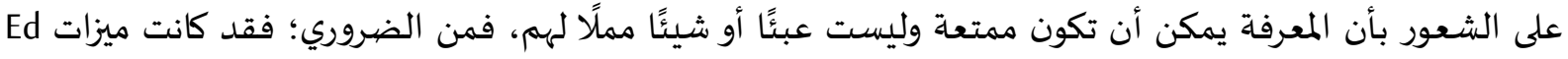
مفيدة للغاية من أجل إثارة اهتمام المتعلمين.

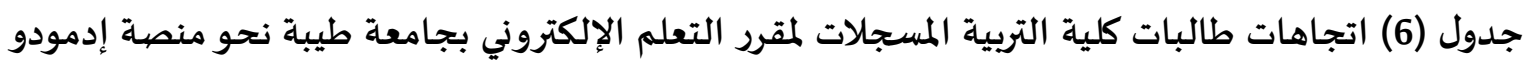
والتعلم المتنقل من حيث التقييم والتغذية الراجعة (Ed)

\begin{tabular}{|c|c|c|c|c|c|c|c|}
\hline 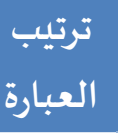 & الانعراف & المتوسط الحسابي & 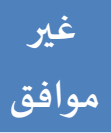 & مجحايد & موافق & & العبارة \\
\hline \multirow{2}{*}{1} & \multirow{2}{*}{0.27} & \multirow{2}{*}{2.93} & 00 & 1 & 13 & ك ك & \multirow{2}{*}{ توفِّرلي المنصة تقييماً مستمراً لمهامي الخاصية } \\
\hline & & & 00 & 7.1 & 92.9 & $\%$ & \\
\hline \multirow{2}{*}{1} & \multirow{2}{*}{0.27} & \multirow{2}{*}{2.93} & 00 & 1 & 13 & ك & \multirow{2}{*}{ توفِّر المنصة أدوات لمعرفة درجاتي كاملة في } \\
\hline & & & 00 & 7.1 & 92.9 & $\%$ & \\
\hline \multirow{2}{*}{1} & \multirow{2}{*}{0.27} & \multirow{2}{*}{2.93} & 00 & 1 & 13 & ك & \multirow{2}{*}{$\begin{array}{c}\text { تمكِنَني المنصية من متابعة التنبيهات والإعلانات الخاصة بالمقرر الدراسي } \\
\text { المِاسيات }\end{array}$} \\
\hline & & & 00 & 7.1 & 92.9 & $\%$ & \\
\hline \multirow{2}{*}{1} & \multirow{2}{*}{0.27} & \multirow{2}{*}{2.93} & 00 & 1 & 13 & ك & \multirow{2}{*}{ تلِّيّل لي المنصـة إرسال الواجبات والتكليفات ألمقرر في أي وقت ومن أي مكان } \\
\hline & & & 00 & 7.1 & 92.9 & $\%$ & \\
\hline \multirow{2}{*}{5} & \multirow{2}{*}{0.43} & \multirow{2}{*}{2.79} & 00 & 3 & 11 & ك ك & \multirow{2}{*}{ 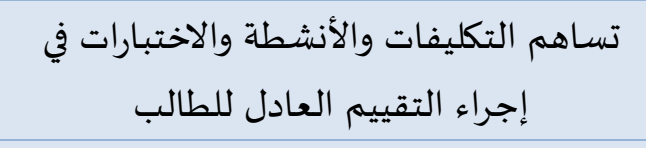 } \\
\hline & & & 00 & 21.4 & 78.6 & $\%$ & \\
\hline \multirow{2}{*}{5} & \multirow{2}{*}{0.43} & \multirow{2}{*}{2.79} & 00 & 3 & 11 & ك & \multirow{2}{*}{ 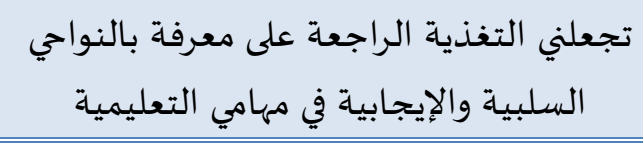 } \\
\hline & & & 00 & 21.4 & 78.6 & $\%$ & \\
\hline \multicolumn{3}{|c|}{2.88} & \multicolumn{5}{|r|}{ 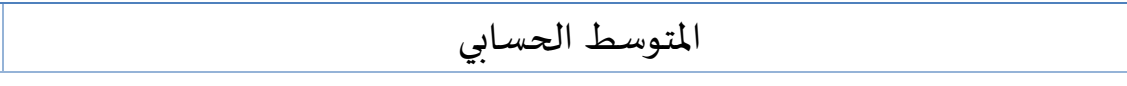 } \\
\hline
\end{tabular}

بلغ المتوسط الحسابي العام لجميع عبارات محور اتجاهات طالبات جامعة طيبة نحو الدراسة عبر منصية Ed من حيث التقييم والتغذية (2.88)، وهو متوسط يشير إلى خيار الموافقة. حيث وافقن على جميع العبارات بمتوسط حسابي مرتفع تراوح بين (2.79 إلى 2.93)، فقد ظهر المتوسط الحسابي الأعلى (2.93) للعبارات (توفِّرِ لي

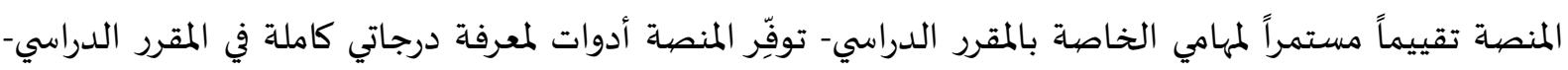

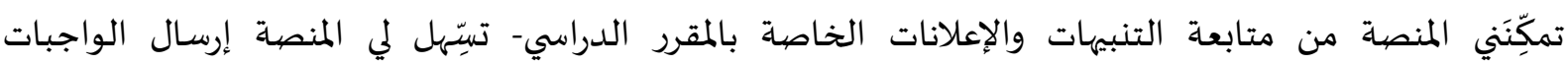

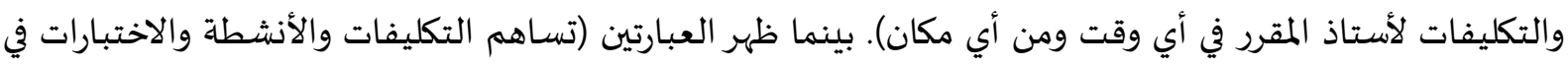

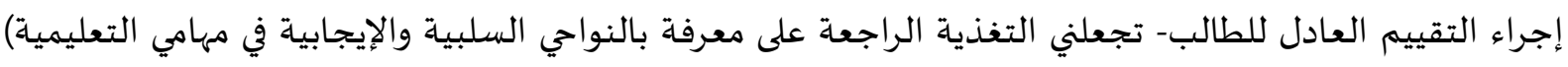

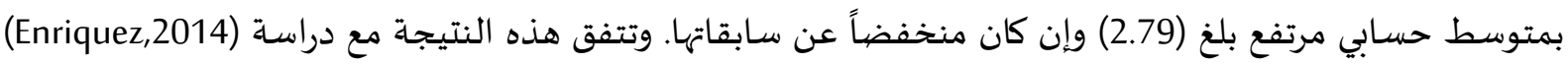

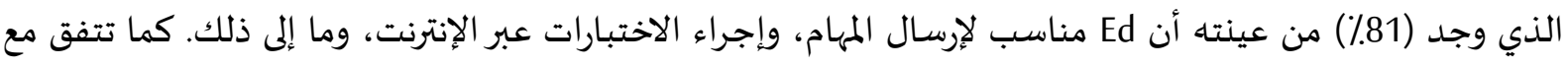

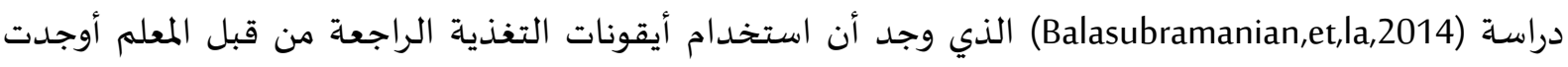

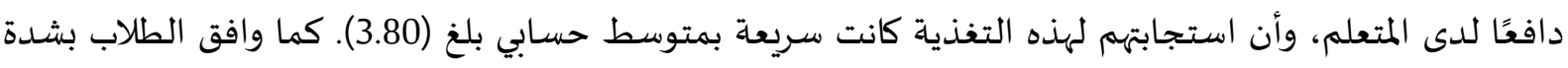


(3.96) على أن النظام الأساسي في Ed لتقديم المهام (مثل التقارير، المحفظة، كان مفيداً لهم. كما أيدَّت العينة بشدة استخدام Ed للاختبارات عبر الإنترنت بمتوسط درجة بلغ (4.08)، وهي الاختبارات القصيرة واستفسارات المعلومات.

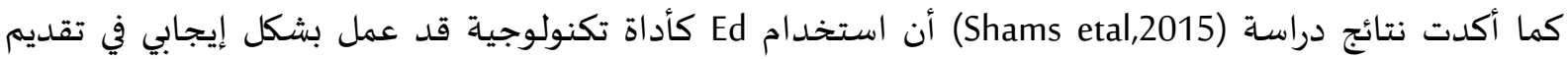
الملاحظات مثل إعادة الصياغة مما سـاعد المتعلمين على إدراك أخطائهم لفهم نقطة التغذية الراجعة. كذلك الك وجداه

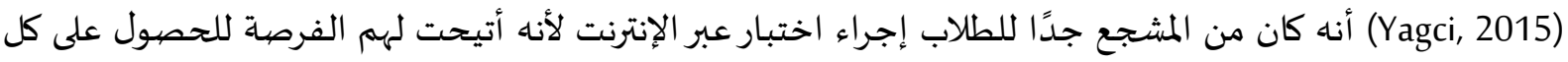

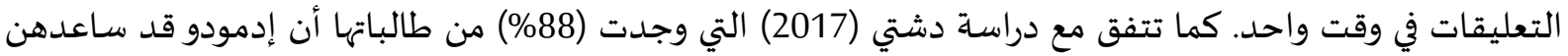

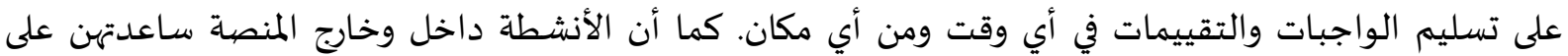
إجراء التعديلات اللازمة للتكليفات.

جدول رقم (7) اتجاهات طالبات كلية التربية المسجاتلات لمقرر التعلم الإلكتروني بجامعة طيبة نحو منصية إدمودو (Ed) والتعلم المتنقل من حيث التواصل والتفاعلية

\begin{tabular}{|c|c|c|c|c|c|c|c|}
\hline ت ت ت العبارة & 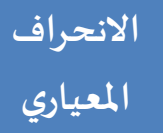 & المتوسط الحسابي & 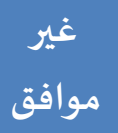 & محايد & موافق & & العبارة \\
\hline \multirow{2}{*}{1} & \multirow{2}{*}{0.43} & \multirow{2}{*}{2.79} & 00 & 3 & 11 & ك & \multirow{2}{*}{ 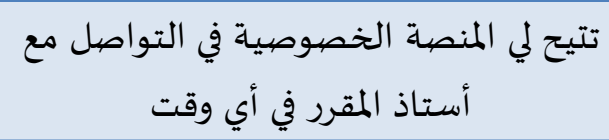 } \\
\hline & & & 00 & 21.4 & 78.6 & $\%$ & \\
\hline \multirow{2}{*}{1} & \multirow{2}{*}{0.43} & \multirow{2}{*}{2.79} & 1 & 1 & 12 & ك & \multirow{2}{*}{ 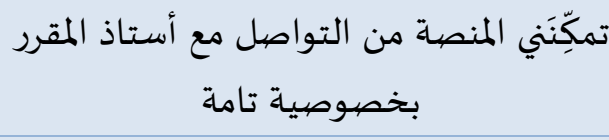 } \\
\hline & & & 7.1 & 7.1 & 85.7 & $\%$ & \\
\hline \multirow{2}{*}{4} & \multirow{2}{*}{0.83} & \multirow{2}{*}{2.07} & 4 & 5 & 5 & ك & \multirow{2}{*}{ تمكِنَني المنصية من التواصل مع زميلاتي في } \\
\hline & & & 28.6 & 35.7 & 35.7 & $\%$ & \\
\hline \multirow{2}{*}{3} & \multirow{2}{*}{0.74} & \multirow{2}{*}{2.36} & 2 & 5 & 7 & ك & \multirow{2}{*}{ 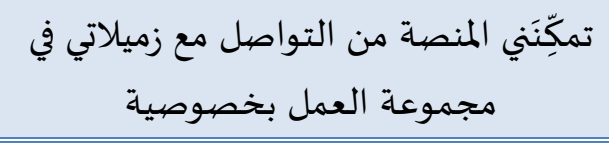 } \\
\hline & & & 14.3 & 35.7 & 50.0 & $\%$ & \\
\hline \multicolumn{3}{|c|}{2.50} & \multicolumn{5}{|c|}{ المتوسط الحسابي } \\
\hline
\end{tabular}

بالنظر إلى المتوسط العام لمحور اتجاهات طالبات جامعة طيبة نحو الدراسة عبر منصة Ed من حيث

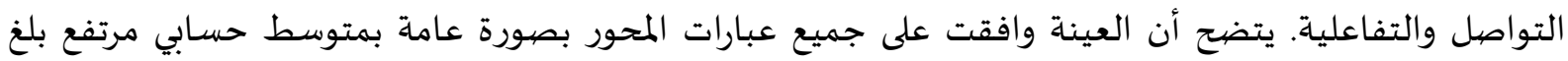
(2.50)، بينما تراوح للعبارات بين (2.36 إلى 2.79). حيث كان المتوسط الأعلى (2.79) للعبارتين: (تتيح لي المنصية

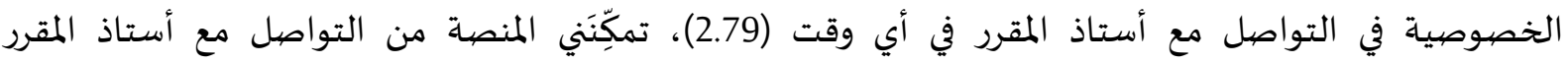

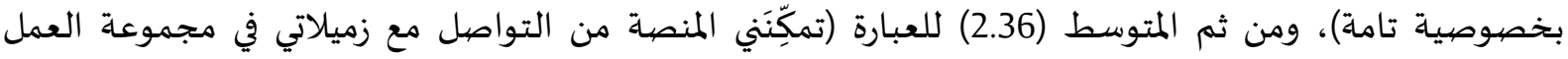

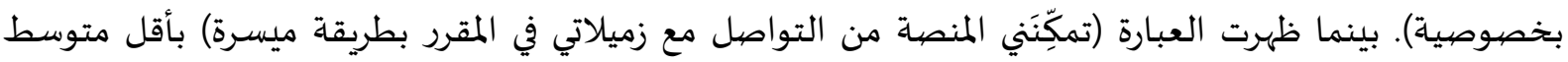

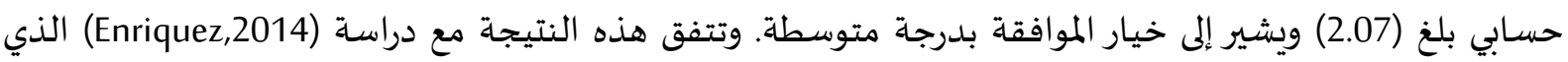

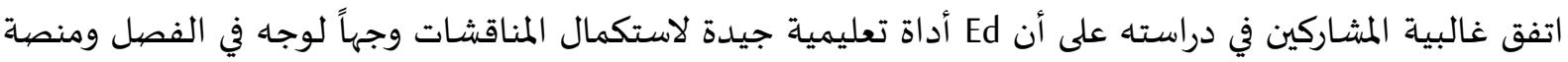

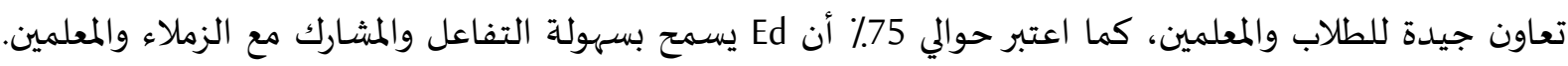
كذلك تتفق مع نتيجة (Balasubramanian,et,la,2014) الذي اتفقت عينته بشدة (4.14) على أن التواصل معاصل وتلقي

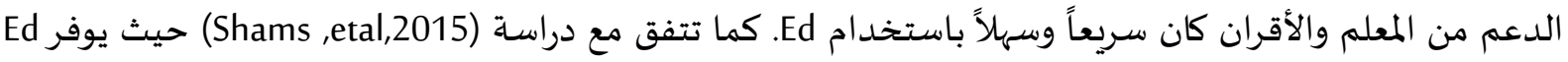

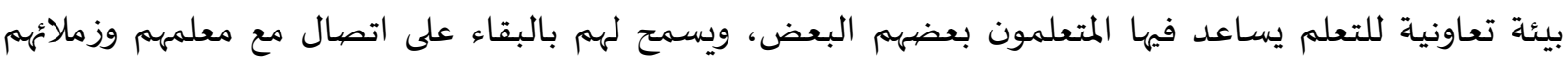
الآخرين خلال الأسبوع خارج الفصل. فلا يقتصر التعلم على وقت الفصل خلال الأسبوع. مما جعلهم أكثر تحفيزاً

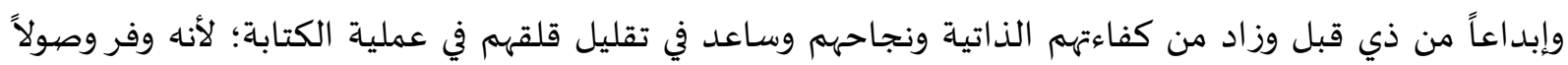




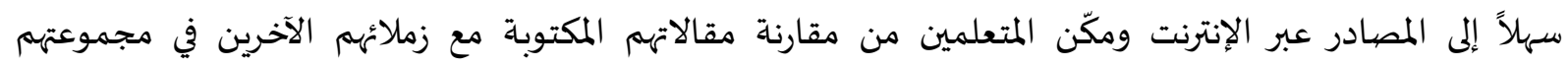

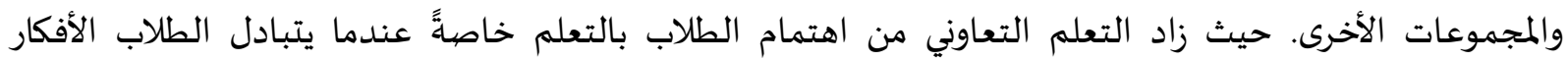

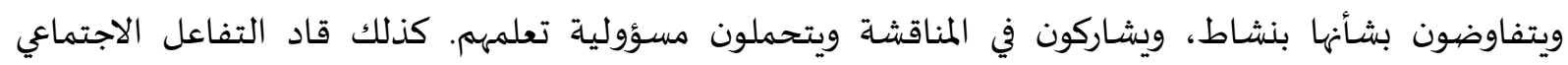

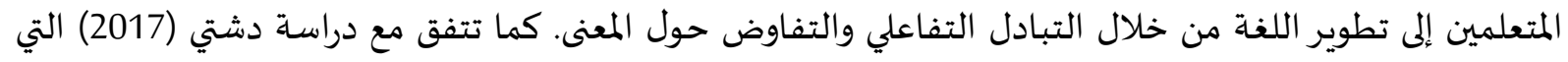

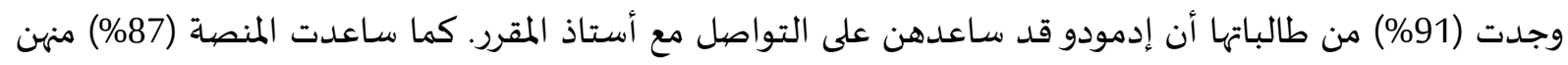

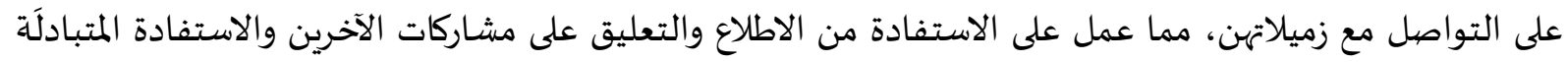

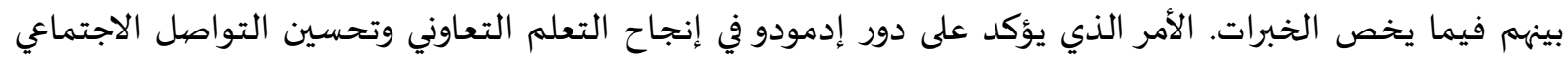
داخل وخارج المنصية.

جدول (8) اتجاهات طالبات كلية التربية المسجلات لمقرر التعلم الإلكتروني بجامعة طيبة نحو منصة إدمودو والتعلم المتنقل من حيث الإتاحة والاستزادة

\begin{tabular}{|c|c|c|c|c|c|c|c|}
\hline 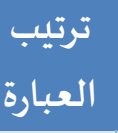 & الانحراف & المتوسط المسابي & 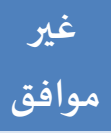 & 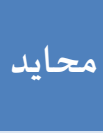 & 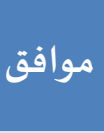 & & 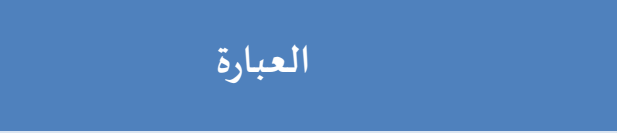 \\
\hline \multirow{2}{*}{4} & \multirow{2}{*}{0.65} & \multirow{2}{*}{2.43} & 1 & 6 & 7 & ك & \multirow{2}{*}{ توفِّرِلي المنصية مكتبة متعددة لمصيادر التعلم } \\
\hline & & & 7.1 & 42.9 & 50.0 & $\%$ & \\
\hline \multirow{2}{*}{2} & \multirow{2}{*}{0.51} & \multirow{2}{*}{2.57} & 00 & 6 & 8 & ك & \multirow{2}{*}{ يساعد استخدام المنصية على إثراء المقرر } \\
\hline & & & 00 & 42.9 & 57.1 & $\%$ & \\
\hline \multirow{2}{*}{1} & \multirow{2}{*}{0.61} & \multirow{2}{*}{2.71} & 1 & 2 & 11 & ك & \multirow{2}{*}{$\begin{array}{c}\text { يوفرلي استخدام المنصلة تصفح المحاضرات } \\
\text { بطريقة سهلة ومنظمة }\end{array}$} \\
\hline & & & 7.1 & 14.3 & 78.6 & $\%$ & \\
\hline \multirow{2}{*}{2} & \multirow{2}{*}{0.51} & \multirow{2}{*}{2.57} & 00 & 6 & 8 & ك & \multirow{2}{*}{ معلومرات إضتخدافية المنصية الحصول عفردات المقرر } \\
\hline & & & 00 & 42.9 & 57.1 & $\%$ & \\
\hline \multicolumn{3}{|c|}{2.57} & \multicolumn{5}{|c|}{ المتوسط الحسابي } \\
\hline
\end{tabular}

بالنظر إلى المتوسط العام لمحور اتجاهات طالبات جامعة طيبة نحو الدراسة عبر منصة Ed من حيث

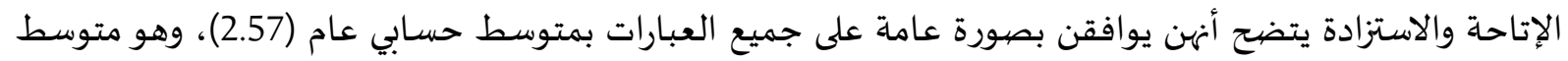

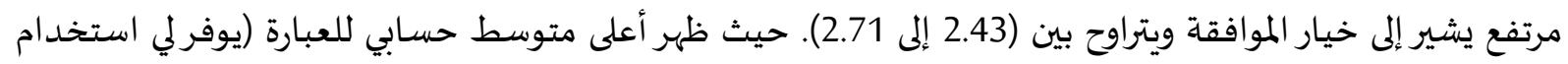

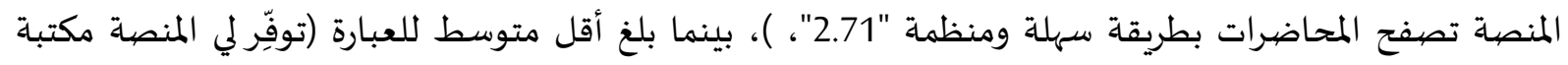

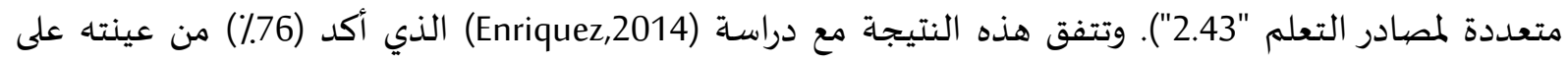

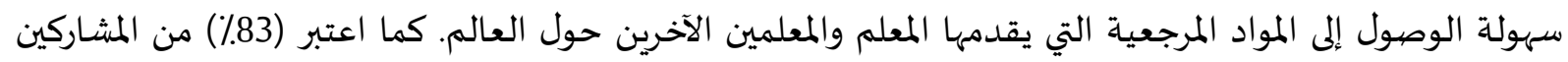
أن هذه المواد مفيدة في فهم المحتويات (موضوعات المقرر). وأضاف (et,Balasubramanianal,2014) أن تفضيل المنيل الطالب تجاه خيار استخدام وظائف مشاركة الموارد في Ed بمتوسط قيمة أعلى بلغ (4.14) لأنه يمكّههم من الوصول

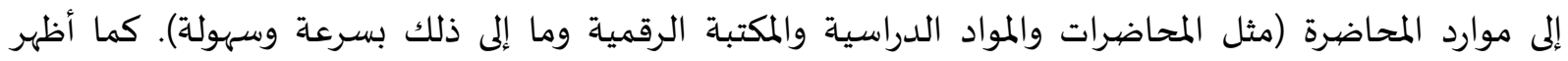

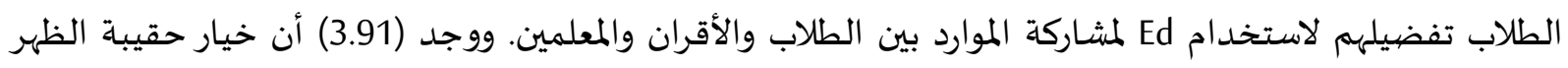

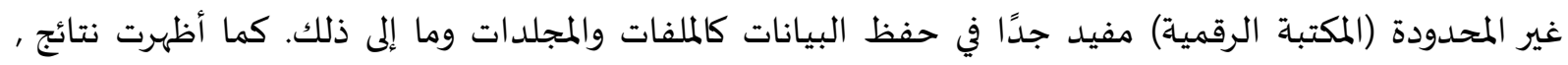

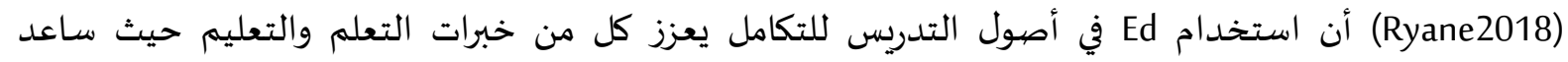

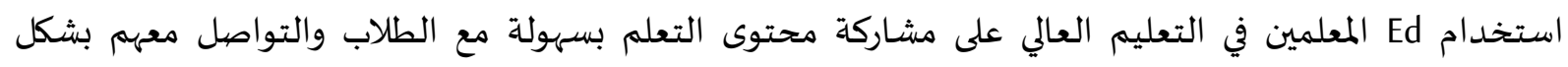


جدول (9) اتجاهات طالبات كلية التربية المسجلات لمقرر التعلم الإلكتروني بجامعة طيبة نحو منصة إدمودو

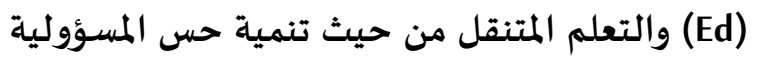

\begin{tabular}{|c|c|c|c|c|c|c|c|}
\hline | ت ت ت العبارة & الالمعراف & المتوسط الحسابي & 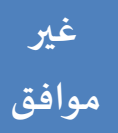 & محايد & موافق & & العبارة \\
\hline \multirow{2}{*}{3} & \multirow{2}{*}{0.65} & \multirow{2}{*}{2.57} & 1 & 4 & 9 & ك & \multirow{2}{*}{ تسـاعدني المنصة على تطوير مهارة التعلم الذاتي } \\
\hline & & & 7.1 & 28.6 & 64.3 & $\%$ & \\
\hline \multirow{2}{*}{4} & \multirow{2}{*}{0.63} & \multirow{2}{*}{2.36} & 1 & 7 & 6 & ك & \multirow{2}{*}{ تشعرني الدراسـة عبر المنصية بالرغبة الدائمة في } \\
\hline & & & 7.1 & 50.0 & 42.9 & $\%$ & \\
\hline \multirow{2}{*}{1} & \multirow{2}{*}{0.36} & \multirow{2}{*}{2.86} & 00 & 2 & 12 & ك & \multirow{2}{*}{ تساعدني المشاركة في تزويد المنصية بالوسائط } \\
\hline & & & 00 & 14.3 & 85.7 & $\%$ & \\
\hline \multirow{2}{*}{2} & \multirow{2}{*}{0.51} & \multirow{2}{*}{2.57} & 00 & 6 & 8 & ك & \multirow{2}{*}{$\begin{array}{c}\text { يساعدني استخدام المنصية على تطوير مهارة } \\
\text { البحث وجمع المعلومات }\end{array}$} \\
\hline & & & 00 & 42.9 & 57.1 & $\%$ & \\
\hline \multicolumn{3}{|c|}{2.59} & \multicolumn{5}{|r|}{ المتوسط الحسابي } \\
\hline
\end{tabular}

يتضح من الجدول أعلاه أن الطالبات وافقن على جميع عبارات محور اتجاهات طالبات جامعة طيبة نحو

الدراسة عبر منصة Ed من حيث تنمية حس المسؤولية بمتوسط حسابي عام بلغ (2.59) وتراوح للعبارات بين (2.36

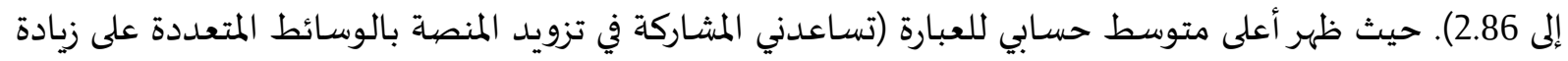

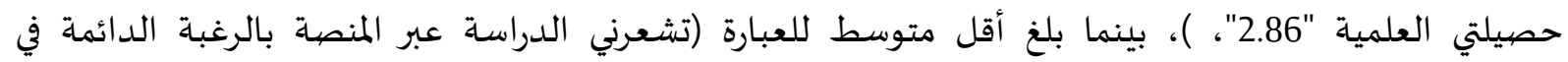

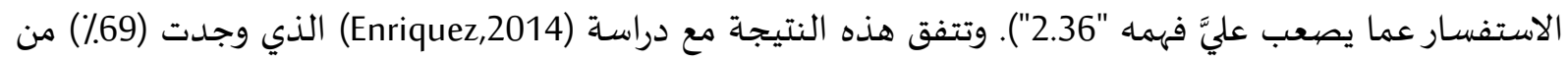

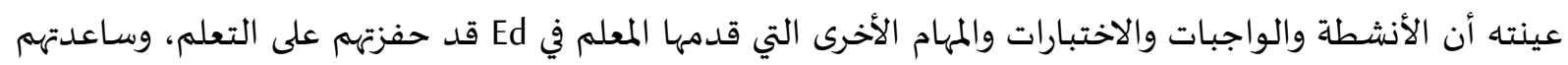

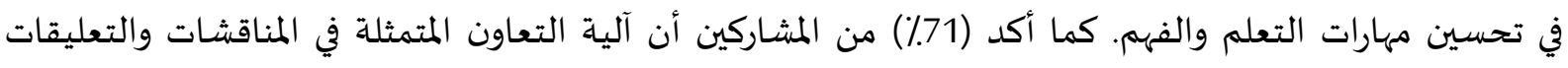

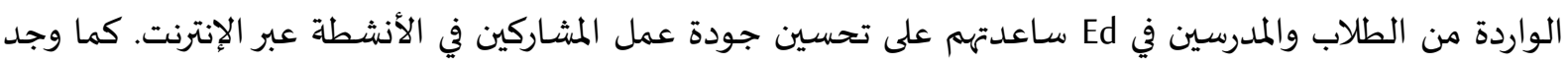

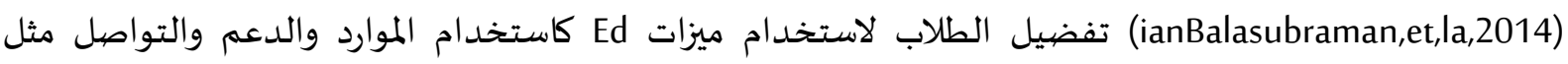

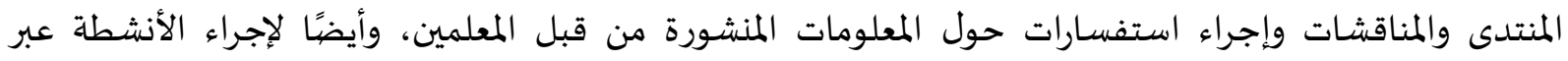

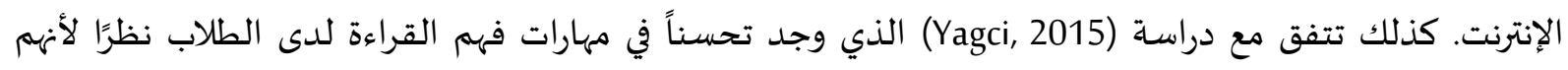
بدأوا في قراءة الكثير من نصوص القراءة في كل من الفصول الحقيقية والفصول الإفتراضية من خلال وسائل

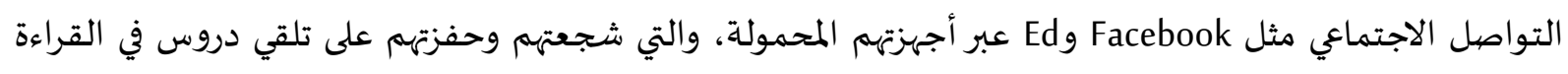

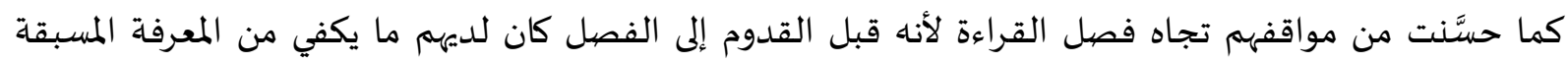

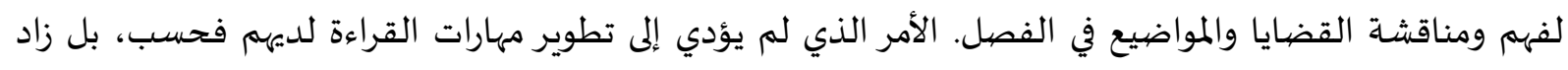

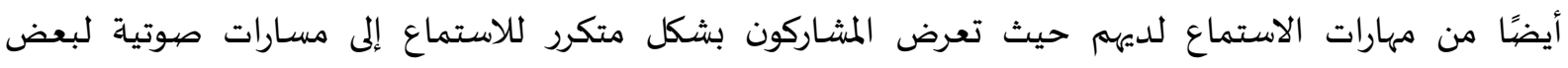
النصوص في الكتاب المدرسي. 
جدول (10) اتجاهات طالبات كلية التربية المسجلات لمقرر التعلم الإلكتروني بجامعة طيبة نحو منصية إدمودو (Ed) والتعلم المتنقل من حيث الرضيا وقبول التعلم المتنقِّل

\begin{tabular}{|c|c|c|c|c|c|c|c|}
\hline 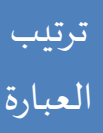 & 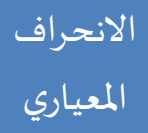 & المتوسط الحسابي & 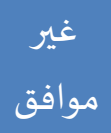 & محايد & 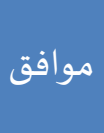 & & العبارة \\
\hline \multirow{2}{*}{2} & \multirow{2}{*}{0.63} & \multirow{2}{*}{2.36} & 1 & 7 & 6 & ك & \multirow{2}{*}{ استمتع بالتعلم المتنقِّل } \\
\hline & & & 7.1 & 50.0 & 42.9 & $\%$ & \\
\hline \multirow{2}{*}{2} & \multirow{2}{*}{0.63} & \multirow{2}{*}{2.36} & 1 & 7 & 6 & ك & \multirow{2}{*}{ استمتع بالتعلم من خلال الأجهزة الذكية } \\
\hline & & & 7.1 & 50.0 & 42.9 & $\%$ & \\
\hline \multirow{2}{*}{5} & \multirow{2}{*}{0.73} & \multirow{2}{*}{2.07} & 3 & 7 & 4 & ك & \multirow{2}{*}{ أفضل التعلم المتنقِّل على التعلم التقليدي } \\
\hline & & & 21.4 & 50.0 & 28.6 & $\%$ & \\
\hline \multirow{2}{*}{4} & \multirow{2}{*}{0.80} & \multirow{2}{*}{2.21} & 3 & 5 & 6 & ك & \multirow{2}{*}{ تعزز الدراسـة من خلال المنصة رأيي في التعلم } \\
\hline & & & 21.4 & 35.7 & 42.9 & $\%$ & \\
\hline \multirow{2}{*}{1} & \multirow{2}{*}{0.63} & \multirow{2}{*}{2.64} & 1 & 3 & 10 & ك & \multirow{2}{*}{ تختصر الدراسة من خلال التعلم المتنقِل } \\
\hline & & & 7.1 & 21.4 & 71.4 & $\%$ & \\
\hline \multirow{2}{*}{6} & \multirow{2}{*}{0.74} & \multirow{2}{*}{1.64} & 7 & 5 & 2 & ك & \multirow{2}{*}{ أفضل دراسة المقررات الأخرى من خلال } \\
\hline & & & 50.0 & 35.7 & 14.3 & $\%$ & \\
\hline \multicolumn{3}{|c|}{2.21} & \multicolumn{5}{|c|}{ المتوسط الحسابي } \\
\hline
\end{tabular}

وافقت العينة إلى حلٍ ما على محور الاتجاه نحو الدراسة عبر منصة Ed من حيث الرضا وقبول التعلم حيث

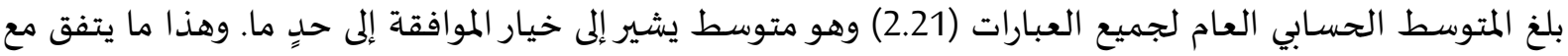

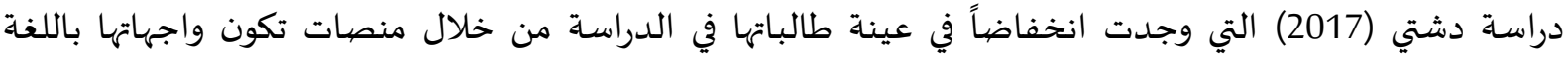
العربية لأن واجهة تطبيق إدمودو باللغة الإنجليزية لكناه يسمح بكتابة الملاحظات والواجبات باللغة العبية مقارنة باستخدام الطالبة لمنصاة بلاك بورد التي واجهة التطبيق فهيا باللغة العربية. وقد جاءت العبارة (تختصر الدراسة من

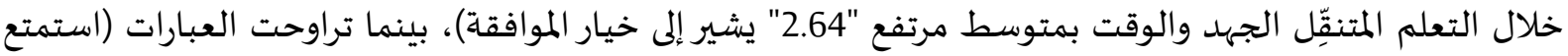

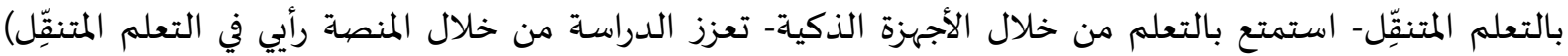

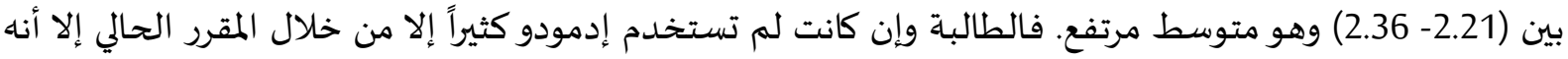

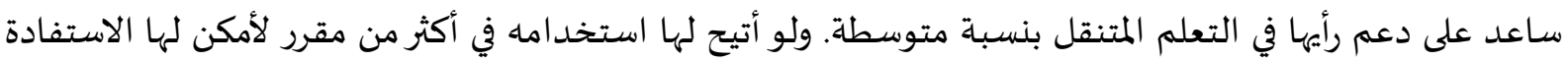

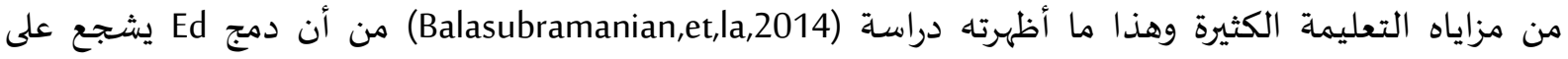

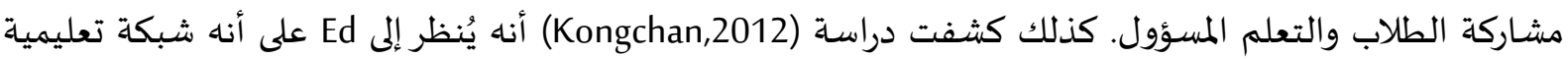

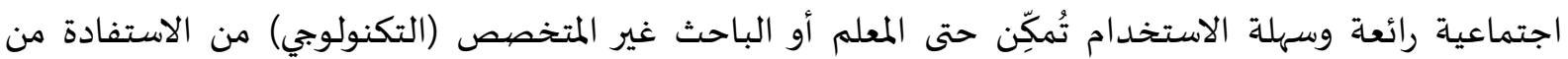

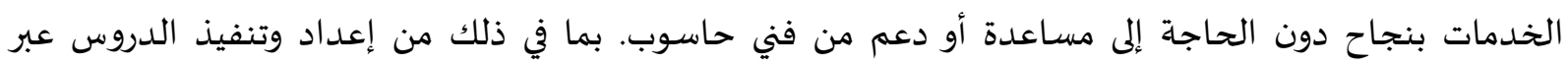

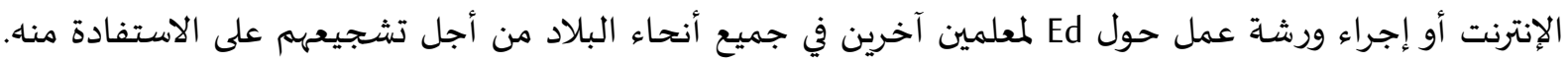

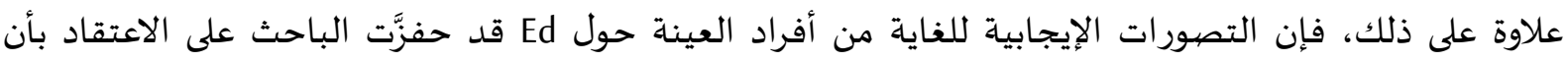
جميع المعلمين يجب أن يكونوا قادرين على استخدام Ed كأداة لإنشاء مجتمع الفصل الفيل الدراسي الإضافيافي عبر الإنترنت لطلابهم. 
جدول (11) ملخص اتجاهات طالبات كلية التربية المسبجلات لمقرر التعلم الإلكتروني بجامعة طيبة نحو منصية إدمودو (Ed) والتعلم المتنقل لجميع محاور الاستبانة مرتبة تنازليا بحسب المتوسطات

\begin{tabular}{|c|c|c|c|c|}
\hline الاتجاه & 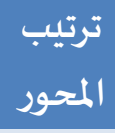 & المتوسط الحسبي & 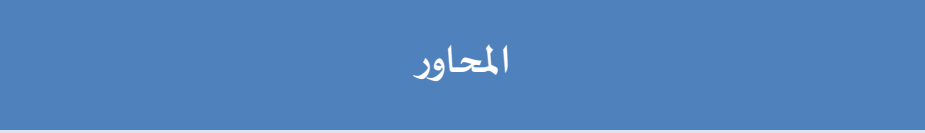 & r \\
\hline 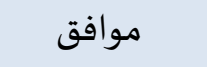 & 1 & 2.88 & اتجاهات طالبات جامعة طيبة من حيث التقييم والتغذية الراجعة & 2 \\
\hline 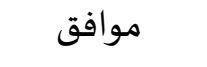 & 2 & 2.59 & اتجاهات طالبات جامعة طيبة من حيث تنمية حس المسؤولية & 5 \\
\hline 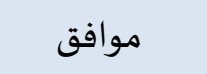 & 3 & 2.57 & اتجاهات طالبات جامعة طيبة من حيث الإتاحة والاستزادة & 4 \\
\hline 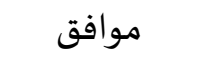 & 4 & 2.50 & اتجاهات طالبات جامعة طيبة من حيث التواصل والتفاعلية & 3 \\
\hline 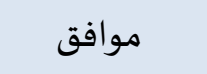 & 5 & 2.38 & اتجاهات طالبات جامعة طيبة من حيث التشويق ومتعة التعلم & 1 \\
\hline موافق إلى حد & 6 & 2.21 & اتجاهات طالبات جامعة طيبة من حيث الرضا وقبول التعلم & 6 \\
\hline \multicolumn{3}{|c|}{2.52} & المتوسط الحسابي & \\
\hline
\end{tabular}

النتائج المتعلقة بالإجابة عن السؤال الرابع ونصها: ما اتجاهات طالبات كلية التربية المسججلات لمقرر التعلم

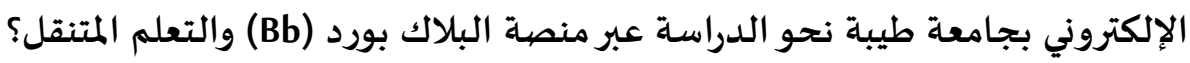

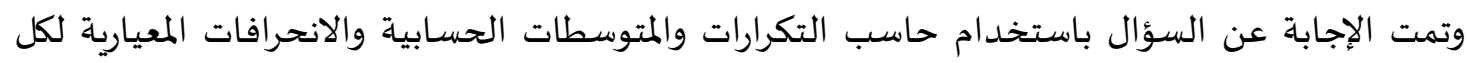
مجال من مجالات الاستبانة على حدة، وللمحاور مجتمعة وذلك على النحو النحو التالي:

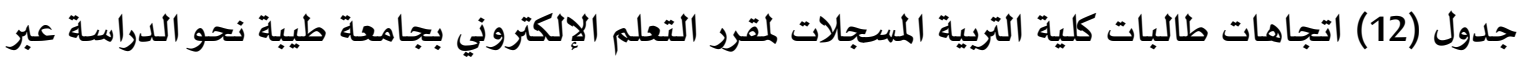
منصية البلاك بورد (Bb) والتعلم المتنقل من حيث التشويق ومتعة التعلم

\begin{tabular}{|c|c|c|c|c|c|c|c|}
\hline ت ت العبارة & 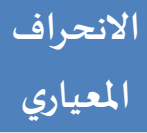 & المتوسط المسابي & 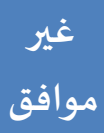 & 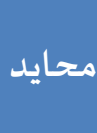 & 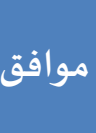 & & 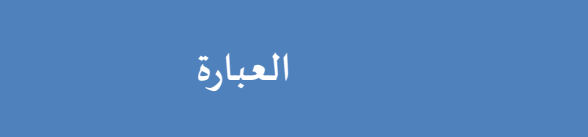 \\
\hline \multirow{2}{*}{1} & \multirow{2}{*}{0.43} & \multirow{2}{*}{2.79} & 00 & 3 & 11 & ك & \multirow{2}{*}{ تشكل المنصية بيئة فعالة للتعلم } \\
\hline & & & 00 & 21.4 & 78.6 & $\%$ & \\
\hline \multirow{2}{*}{2} & \multirow{2}{*}{0.51} & \multirow{2}{*}{2.57} & 00 & 6 & 8 & ك & \multirow{2}{*}{ تقدّم المنصية المحتوى بطريقة شيقة } \\
\hline & & & 00 & 42.9 & 57.1 & $\%$ & \\
\hline \multirow{2}{*}{5} & \multirow{2}{*}{0.80} & \multirow{2}{*}{2.21} & 3 & 5 & 6 & ك & \multirow{2}{*}{ أشعر بالحماس والاستثارة أثناء تعلم المقرر } \\
\hline & & & 21.4 & 35.7 & 42.9 & $\%$ & \\
\hline \multirow{2}{*}{4} & \multirow{2}{*}{0.84} & \multirow{2}{*}{2.36} & 3 & 3 & 8 & ك & \multirow{2}{*}{ تزيد الدراسة من خلال المنصية من دافعيتي } \\
\hline & & & 21.4 & 21.4 & 57.1 & $\%$ & \\
\hline \multirow{2}{*}{3} & \multirow{2}{*}{0.65} & \multirow{2}{*}{2.57} & 1 & 4 & 9 & ك & \multirow{2}{*}{ يشعرني العمل والمشاركة في المنصية بالألفة } \\
\hline & & & 7.1 & 28.6 & 64.3 & $\%$ & \\
\hline \multicolumn{3}{|c|}{2.50} & \multicolumn{5}{|c|}{ المتوسط الحسابي } \\
\hline
\end{tabular}


يتبين من النتائج الموضحة أعلاه أن طالبات جامعة طيبة يوافقن على العبارات التي تقيس اتجاهاتهن نحو

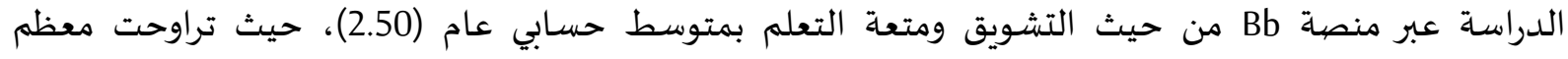

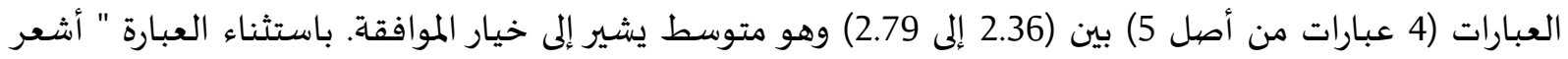

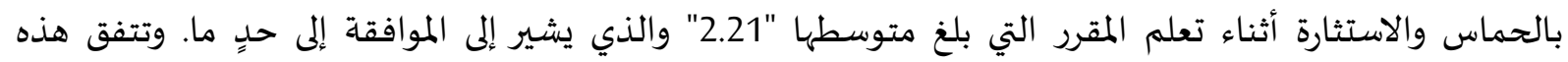

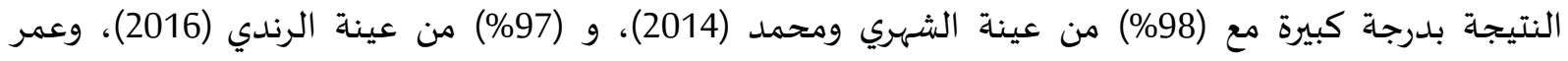
والمصعبي (2017) بمتوسط حسابي مرتفع بدرجة (2.88)، والتي شعرت بالسعادة في القيام بإنجاز الأنشطة

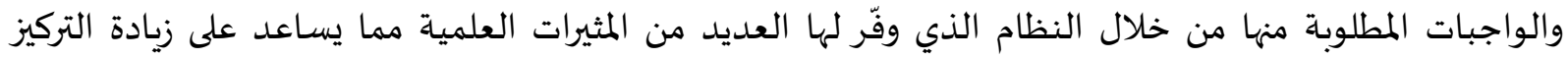

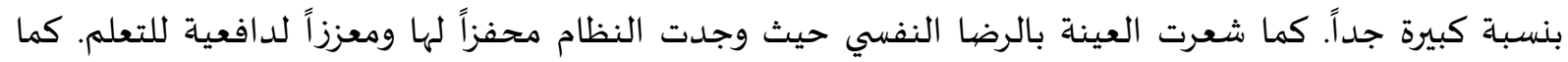

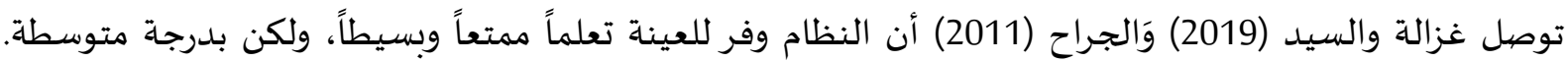

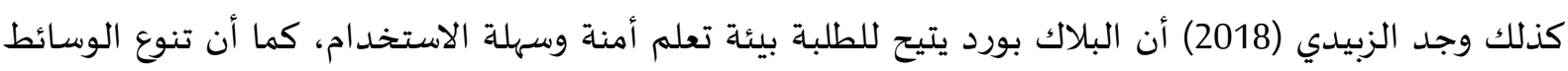

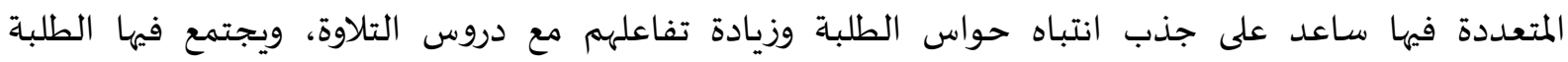

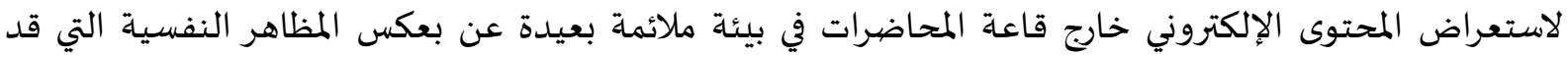

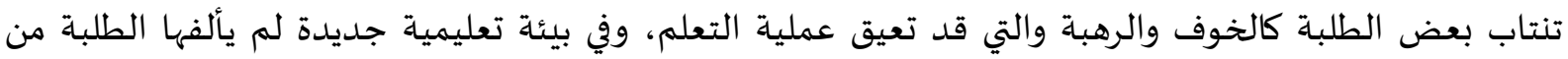

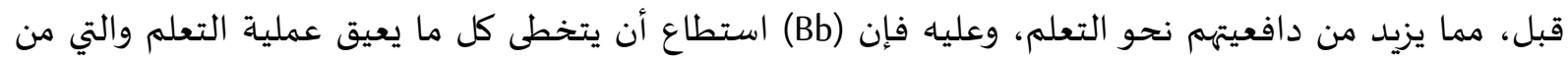

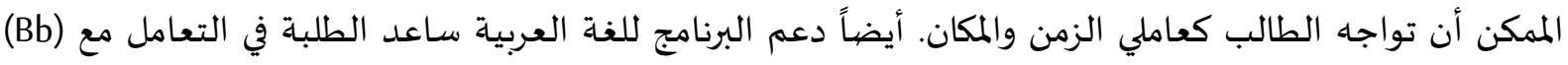
بسهولة ويسر. جدول (13) اتجاهات طالبات كلية التربية المسجلات لمقرر التعلم الإلكتروني بجامعة طيبة نحو الدراسة عبر

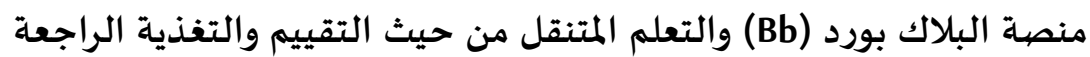

\begin{tabular}{|c|c|c|c|c|c|c|c|}
\hline ت ت ت العبارة & الانمراف & المتوسط المسابي & 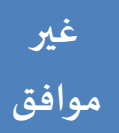 & متحايد & موافق & & العبارة \\
\hline \multirow{2}{*}{4} & \multirow{2}{*}{0.27} & \multirow{2}{*}{2.93} & 00 & 1 & 13 & ك & \multirow{2}{*}{ توفِرِلي المنصية تقييماً مستمراً لمهامي الخاصية } \\
\hline & & & 00 & 7.1 & 92.9 & $\%$ & \\
\hline \multirow{2}{*}{1} & \multirow{2}{*}{0.00} & \multirow{2}{*}{3.00} & 00 & & 14 & ك & \multirow{2}{*}{ توفّر المنصبة أدوات لمعرفة درجاتي كاملة في المقرر الدراسي } \\
\hline & & & 00 & & 100 & $\%$ & \\
\hline \multirow{2}{*}{1} & \multirow{2}{*}{0.00} & \multirow{2}{*}{3.00} & 00 & & 14 & ك & \multirow{2}{*}{ 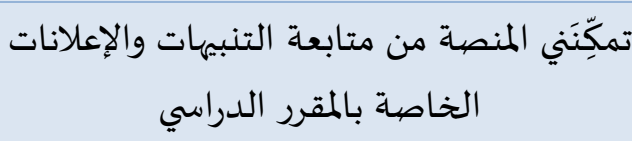 } \\
\hline & & & 00 & & 100 & $\%$ & \\
\hline \multirow{2}{*}{1} & \multirow{2}{*}{0.00} & \multirow{2}{*}{3.00} & 00 & & 14 & ك & \multirow{2}{*}{ تسِّهل لي المنصـة إرسال الواجبات والتكليفات المقرر في أي وقت ومن أي مكان } \\
\hline & & & 00 & & 100 & $\%$ & \\
\hline \multirow{2}{*}{5} & \multirow{2}{*}{0.43} & \multirow{2}{*}{2.79} & 00 & 3 & 11 & ك & \multirow{2}{*}{$\begin{array}{c}\text { تساهم التكليفات والأنشطة والاختبارات في التراء التقييم العادل للطالب }\end{array}$} \\
\hline & & & 00 & 21.4 & 78.6 & $\%$ & \\
\hline \multirow{2}{*}{5} & \multirow{2}{*}{0.43} & \multirow{2}{*}{2.79} & 00 & 3 & 11 & ك & \multirow{2}{*}{ تجعلني التغذية الراجعة على معرفة بالنواحي } \\
\hline & & & 00 & 21.4 & 78.6 & $\%$ & \\
\hline \multicolumn{3}{|c|}{2.92} & \multicolumn{5}{|r|}{ المتوسط الحسابي } \\
\hline
\end{tabular}

يتبين من النتائج الموضحة أعلاه أن طالبات جامعة طيبة يوافقن على جميع العبارات التي تقيس اتجاهاتهن نحو الدراسة عبر منصة Bb من حيث التقييم والتغذية الراجعة بمتوسط حسابي عام بلغ (2.92) وتراوح لجميع 
العبارات بين (2.79 إلى 3.00) وهو متوسط يشير إلى خيار الموافقة. حيث جاء المتوسط الحسابي"3.00" لثلاث من

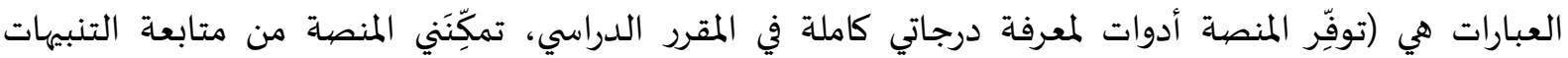

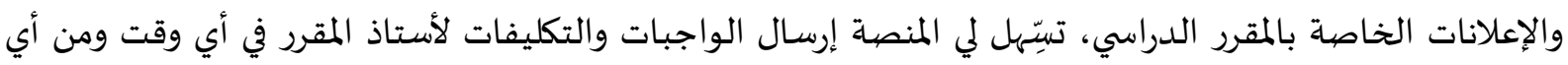

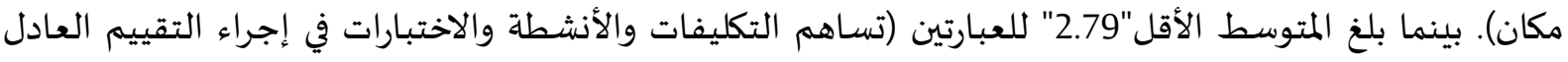
للطالب "2.79"، تجعلني التغذية الراجعة على معرفة بالنواحي السلبية والإيجابية في مهامي التعليمية). وتتفق هذه النتيجة مع الشهري ومحمد (2014) والتي وجدت أن 90\% من العينة ترى أن استخدام النظام ساعدها على إنجاز

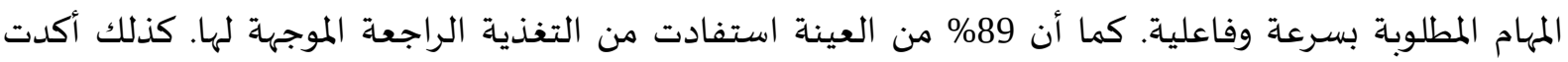

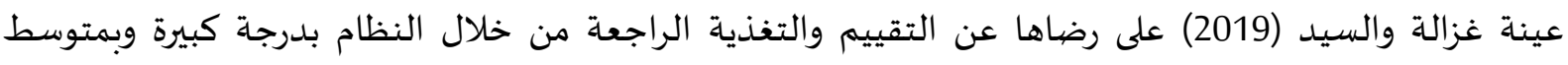

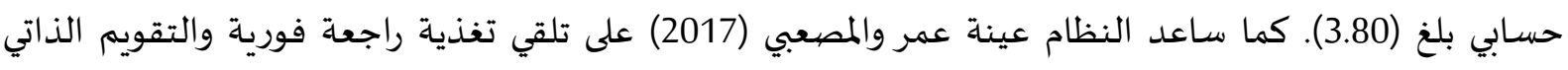

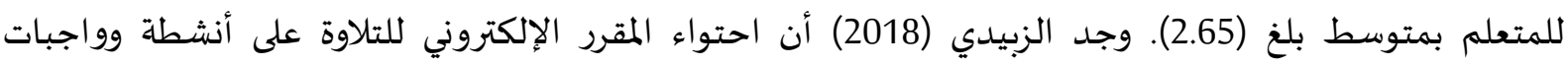

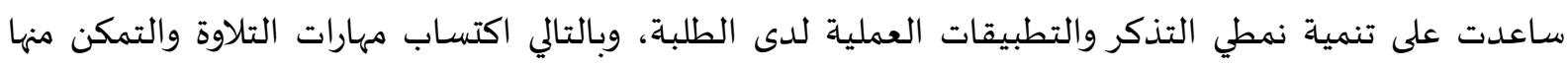

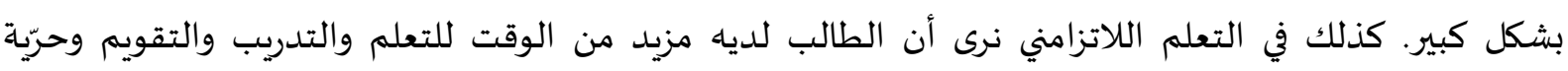
التجريب بخلاف الطالب في التعلم التقليدي فهو مقيد بوقت محدد جداً للقراءة والاستماع وتصحيح الأخطاء تحسن فئن

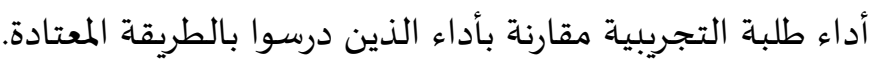

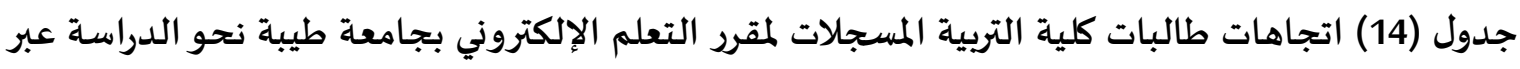

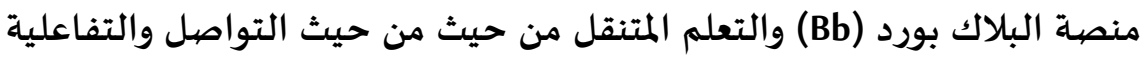

\begin{tabular}{|c|c|c|c|c|c|c|c|}
\hline 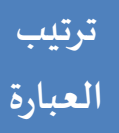 & الالمعراف & المتوسط الحسابي & 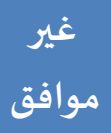 & مجحايد & موافق & & العبارة \\
\hline \multirow{2}{*}{2} & \multirow{2}{*}{0.65} & \multirow{2}{*}{2.57} & 1 & 4 & 9 & ك & \multirow{2}{*}{ 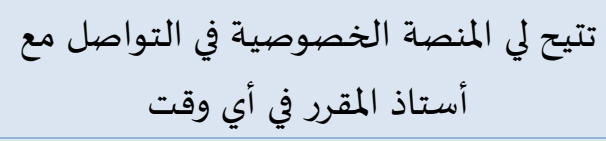 } \\
\hline & & & 7.1 & 28.6 & 64.3 & $\%$ & \\
\hline \multirow{2}{*}{1} & \multirow{2}{*}{0.63} & \multirow{2}{*}{2.64} & 1 & 3 & 10 & ك & \multirow{2}{*}{ تمكِنْني المنصية من التواصل مع أستاذ المقرر } \\
\hline & & & 7.1 & 21.4 & 71.4 & $\%$ & \\
\hline \multirow{2}{*}{4} & \multirow{2}{*}{0.80} & \multirow{2}{*}{2.21} & 3 & 5 & 6 & ك & \multirow{2}{*}{ 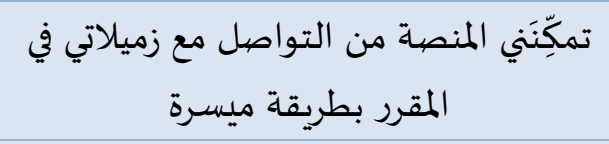 } \\
\hline & & & 21.4 & 35.7 & 42.9 & $\%$ & \\
\hline \multirow{2}{*}{3} & \multirow{2}{*}{0.74} & \multirow{2}{*}{2.36} & 2 & 5 & 7 & ك & \multirow{2}{*}{ 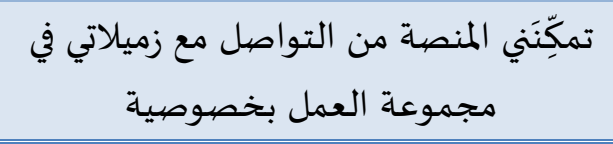 } \\
\hline & & & 14.3 & 35.7 & 50.0 & $\%$ & \\
\hline \multicolumn{3}{|c|}{2.45} & \multicolumn{5}{|c|}{ المتوسط الحسابي } \\
\hline
\end{tabular}

يتضح من جدول محور اتجاهات طالبات جامعة طيبة نحو الدراسة عبر منصة Bb من حيث التواصل

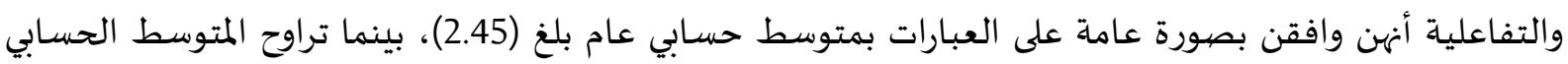

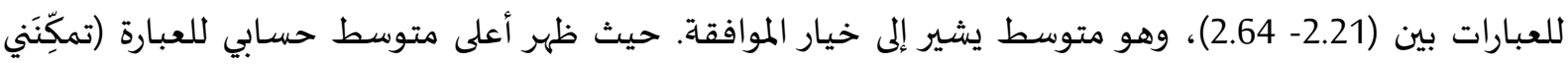

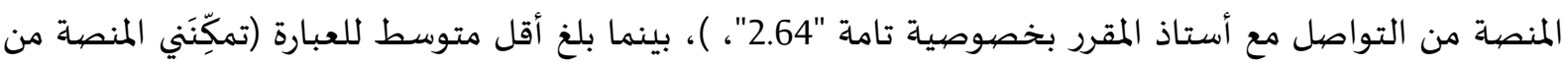

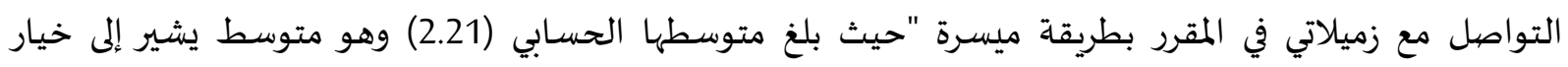

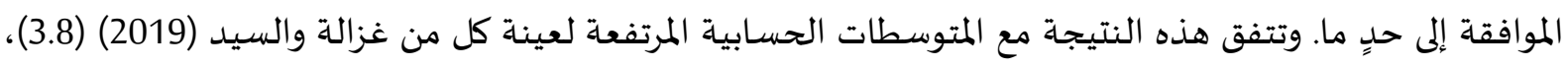

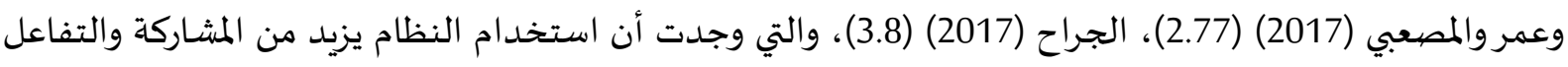
في العلمية التعليمية، ويسهِل تبادل الملفات بين المتعلمين والأساتذة. 
جدول (15) اتجاهات طالبات كلية التربية المسجلات لمقرر التعلم الإلكتروني بجامعة طيبة نحو الدراسة عبر منصية البلاك بورد (Bb) والتعلم المتنقل من حيث الإتاحة والاستزادة

\begin{tabular}{|c|c|c|c|c|c|c|c|}
\hline ت ت ت العببارة & 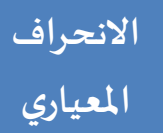 & المتوسط المسابي & 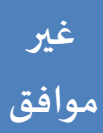 & متحايد & موافق & & العبارة \\
\hline \multirow{2}{*}{2} & \multirow{2}{*}{0.50} & \multirow{2}{*}{2.64} & & 5 & 9 & ك & \multirow{2}{*}{ توفِّر لي المنصية مكتبة متعددة لمصهادر التعلم } \\
\hline & & & & 35.7 & 64.3 & $\%$ & \\
\hline \multirow{2}{*}{4} & \multirow{2}{*}{0.65} & \multirow{2}{*}{2.50} & 1 & 5 & 8 & ك & \multirow{2}{*}{ يساعد استخدام المنصية على إثراء المقرر } \\
\hline & & & 7.1 & 35.7 & 57.1 & $\%$ & \\
\hline \multirow{2}{*}{1} & \multirow{2}{*}{0.27} & \multirow{2}{*}{2.93} & & 1 & 13 & ك & \multirow{2}{*}{$\begin{array}{c}\text { يوفرلي استخدام المنصة تصفح المحاضرات } \\
\text { بطريقة سهلة ومنظمة }\end{array}$} \\
\hline & & & & 7.1 & 92.9 & $\%$ & \\
\hline \multirow{2}{*}{3} & \multirow{2}{*}{0.65} & \multirow{2}{*}{2.57} & 1 & 4 & 9 & ك & \multirow{2}{*}{ يوفرلي استخدام المنصية الحصول على إضافية عن مفردات المقرر } \\
\hline & & & 7.1 & 28.6 & 64.3 & $\%$ & \\
\hline \multicolumn{3}{|c|}{2.66} & \multicolumn{5}{|c|}{ المتوسط الحسابي } \\
\hline
\end{tabular}

يتبين من النتائج الموضحة أعلاه أن الطالبات وافقن على جميع عبارات مقياس الاتجاه نحو الدراسة عبر منصة Bb من حيث الإتاحة والاستزادة حيث تراوح المتوسط الحسابي للعبارات بين (2.50 إلى 2.93) وهو متوسط

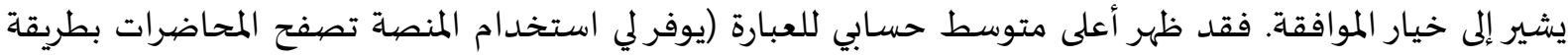
سهلة ومنظمة "2.93")، بينما بلغ أقل متوسط للعبارة (يساعد استخدام المنصية على إثلى إثراء المقرر الدراسي "2.50"). وتتفق هذه النتيجة مع أمل الشهري ومحمد (2014) والتي وجدت (99\%) من عينتها أن استخدام النظام في تلقي

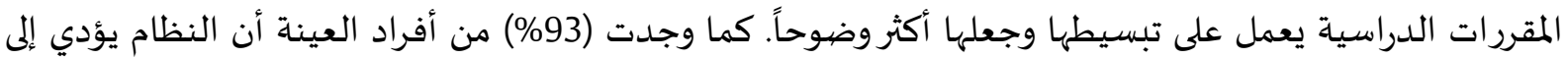
تنوع مصادر المعرفة، و90\% وجدت أنها يؤدي إلى توضيح المفاهيم الغامضية. كما وجدت عينة غزالة والئه والسيد (2019)، والجراح (2017) أن استخدام النظام ساعد على تسهيل وزيادة التحصيل الدراسي، بالإضافة إلى تكامل المصيادر

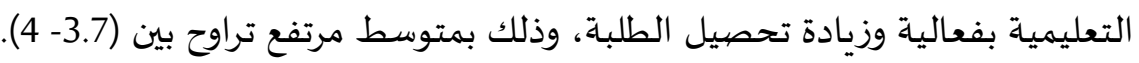

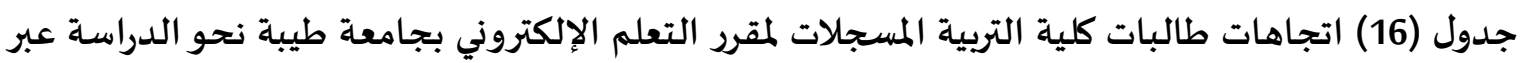

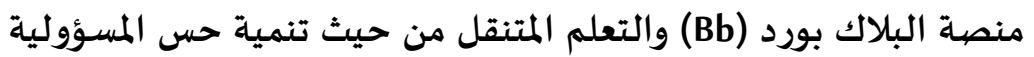

\begin{tabular}{|c|c|c|c|c|c|c|c|}
\hline 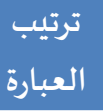 & 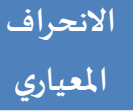 & الحتوسط & 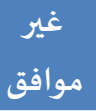 & مجحايد & موافق & & \\
\hline \multirow{2}{*}{2} & \multirow{2}{*}{0.85} & \multirow{2}{*}{2.50} & 3 & 1 & 10 & ك ك & \multirow{2}{*}{ تساعدني المنصية على تطوير مهارة التعلم الذاتي } \\
\hline & & & 21.4 & 7.1 & 71.4 & $\%$ & \\
\hline \multirow{2}{*}{3} & \multirow{2}{*}{0.73} & \multirow{2}{*}{2.29} & 2 & 6 & 6 & ك & \multirow{2}{*}{ 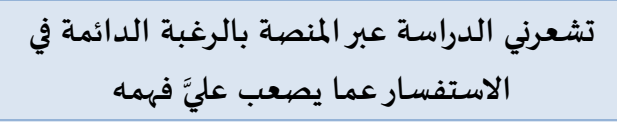 } \\
\hline & & & 14.3 & 42.9 & 42.9 & $\%$ & \\
\hline \multirow{2}{*}{1} & \multirow{2}{*}{0.76} & \multirow{2}{*}{2.50} & 2 & 3 & 9 & ك & \multirow{2}{*}{ تساعدني المشاركة في تزويد المنصية بالوسائط المتعددة على زيادة حصيلتي العلمية } \\
\hline & & & 14.3 & 21.4 & 64.3 & $\%$ & \\
\hline \multirow{2}{*}{4} & \multirow{2}{*}{0.83} & \multirow{2}{*}{2.29} & 3 & 4 & 7 & ك & \multirow{2}{*}{ يساعدني استخدام المنصية على تطوير مهارة البحث } \\
\hline & & & 21.4 & 28.6 & 50.0 & $\%$ & \\
\hline \multicolumn{3}{|c|}{2.40} & \multicolumn{5}{|c|}{ المتوسط الحسابي } \\
\hline
\end{tabular}


بلغ المتوسط الحسابي العام لجميع عبارات محور اتجاهات طالبات جامعة طيبة نحو الدراسة عبر منصية

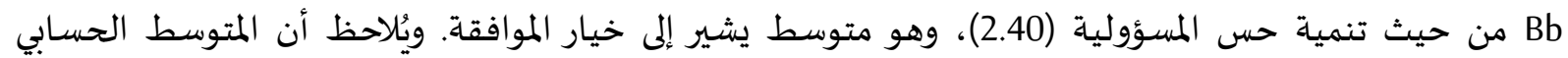

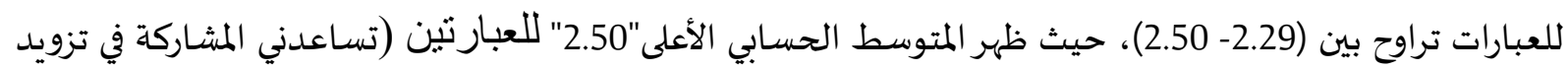

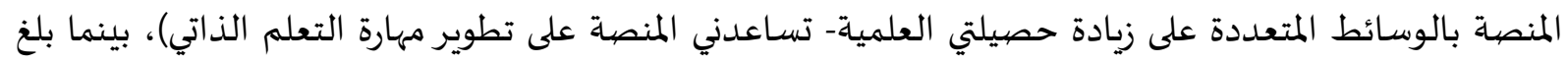

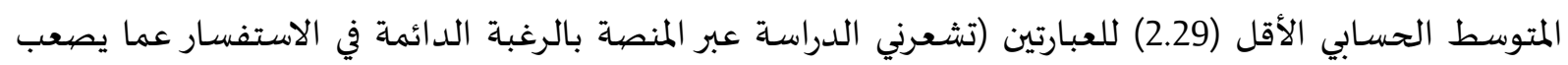

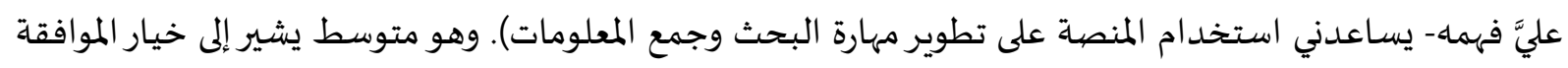

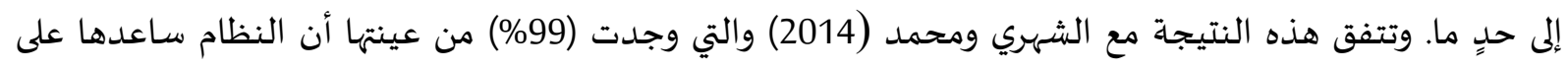

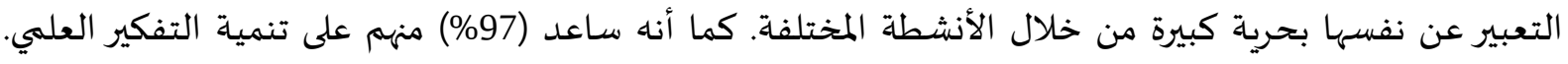
كما رأت عينة غزالة والسيد (2019) أن النظام يساعد في تسريع عملية التحصيل الدراسي بمتوسط كبير بلغئل

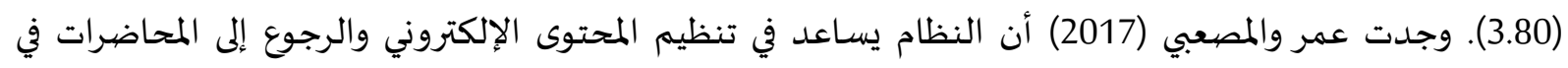
أوقات غير نظامية بمتوسط (2.85)، كذلك وجد الجراح (2017) أن النظام يساعد المعلم على تزويد المتعلم ببيئة

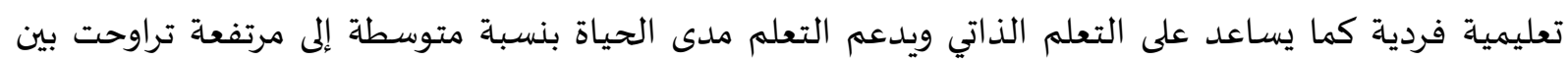

جدول (17) اتجاهات طالبات كلية التربية المسدجلات لمقرر التعلم الإلكتروني بجامعة طيبة نحو الدراسة عبر منصة البلاك بورد (Bb) والتعلم المتنقل من حيث الرضا وقبول التعلم المتنقِّل

\begin{tabular}{|c|c|c|c|c|c|c|c|}
\hline ت ت ترتيب & الانمراف & المتوسط الحسابي & 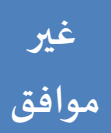 & 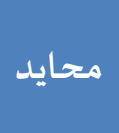 & موافق & & العبارة \\
\hline \multirow{2}{*}{2} & \multirow{2}{*}{0.74} & \multirow{2}{*}{2.36} & 2 & 5 & 7 & ك & \multirow{2}{*}{ استمتع بالتعلم المتنقِّل } \\
\hline & & & 14.3 & 35.7 & 50.0 & $\%$ & \\
\hline \multirow{2}{*}{3} & \multirow{2}{*}{0.73} & \multirow{2}{*}{2.29} & 2 & 6 & 6 & ك & \multirow{2}{*}{ استمتع بالتعلم من خلال الأجهزة الذكية } \\
\hline & & & 14.3 & 42.9 & 42.9 & $\%$ & \\
\hline \multirow{2}{*}{6} & \multirow{2}{*}{0.80} & \multirow{2}{*}{1.79} & 6 & 5 & 3 & ك & \multirow{2}{*}{ أفضل التعلم المتنقِّل على التعلم التقليدي } \\
\hline & & & 42.9 & 35.7 & 21.4 & $\%$ & \\
\hline \multirow{2}{*}{4} & \multirow{2}{*}{0.83} & \multirow{2}{*}{2.29} & 3 & 4 & 7 & ك & \multirow{2}{*}{ تعزز الدراسـة من خلال المنصية رأيي في } \\
\hline & & & 21.4 & 28.6 & 50.0 & $\%$ & \\
\hline \multirow{2}{*}{1} & \multirow{2}{*}{0.36} & \multirow{2}{*}{2.86} & & 2 & 12 & ك & \multirow{2}{*}{ تختصر الدراسـة من خلال التعلم المتنقِّل } \\
\hline & & & & 14.3 & 85.7 & $\%$ & \\
\hline \multirow{2}{*}{5} & \multirow{2}{*}{0.83} & \multirow{2}{*}{1.93} & 5 & 5 & 4 & ك & \multirow{2}{*}{ أفضّل دراسة المقررات الأخرى من خلال } \\
\hline & & & 35.7 & 35.7 & 28.6 & $\%$ & \\
\hline \multicolumn{3}{|c|}{2.25} & \multicolumn{5}{|c|}{ المتوسط الحسابي } \\
\hline
\end{tabular}

يتبين من النتائج الموضحة أعلاه أن طالبات جامعة طيبة يوافقن على العبارات التي تقيس اتجاهاتهن نحو

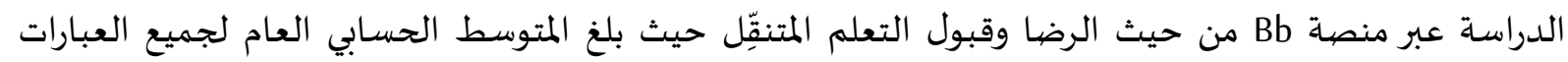

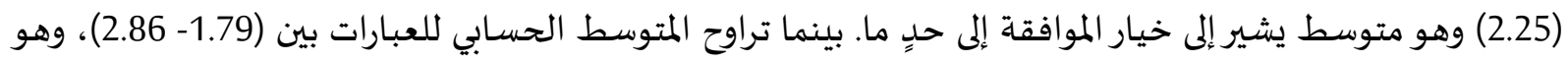

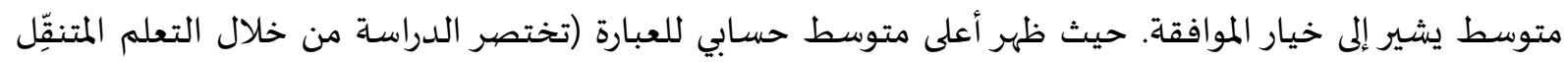

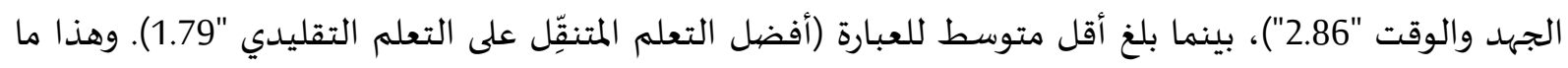


توصلت له عينة كل من أبو الحاج (2019) بنسبة 91\%، وعينة غزالة والسيد (2019) بمتوسط تراوح بين (3.45-

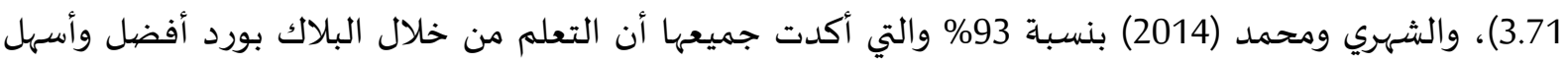

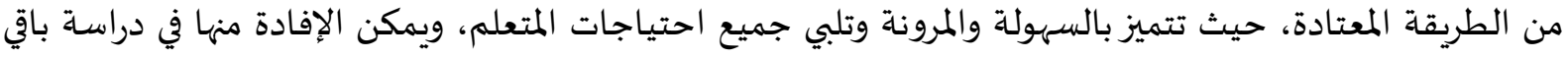

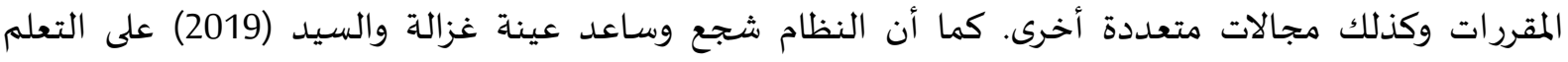

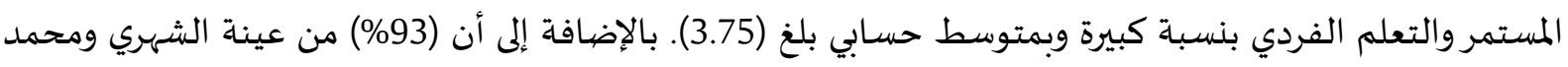

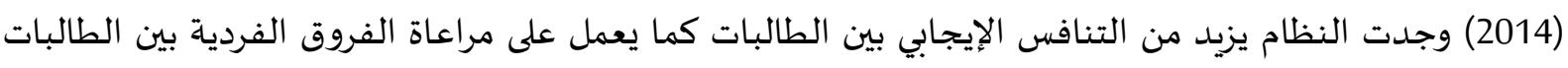
ويسهم في حل بعض المشكلات كزيادة عدد الطالبات المسجلات في مقرر ما. كما وجدت المدات عمر والمصنعبي (2017) بمتوسط (2.88- 2.92) أن التعلم من خلال Bb يساهم في دعم التعلم الإلكتروني كما فضلت العيلت العينة استخدام

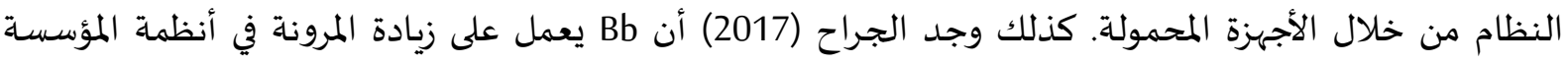

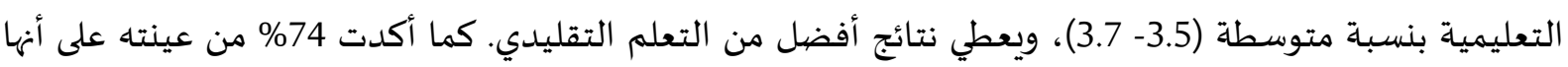

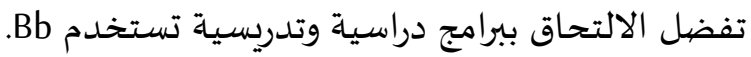

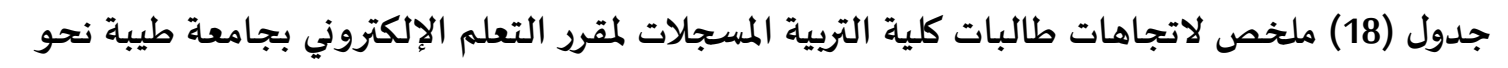
الدراسة عبر منصة البلاك بورد (Bb) والتعلم المتنقل لجميع محاور الاستبانة مرتبة تنازليا بحسب المتوسطات

\begin{tabular}{|c|c|c|c|c|}
\hline 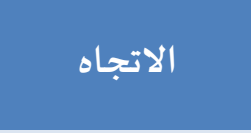 & ترتيب & لمتوسط الحسبي & المحاور & $\hat{\imath}$ \\
\hline 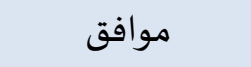 & 1 & 2.92 & اتجاهات طالبات جامعاة طيبة من حيث التقييم والتغذية الراجعة & 2 \\
\hline 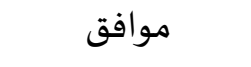 & 2 & 2.66 & اتجاهات طالبات جامعة طيبة من حيث الإتاحة والاستزادة & 4 \\
\hline 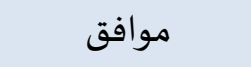 & 3 & 2.50 & اتجاهات طالبات جامعة طيبة من حيث التشويق ومتعة التعلم & 1 \\
\hline 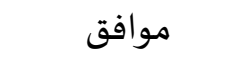 & 4 & 2.45 & اتجاهات طالبات جامعة طيبة من حيث التواصل والتفاعلية & 3 \\
\hline 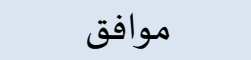 & 5 & 2.40 & اتجاهات طالبات جامعة طيبة من حيث تنمية حس المسؤولية & 5 \\
\hline 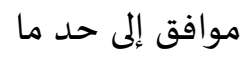 & 6 & 2.25 & اتجاهات طالبات جامعة طيبة من حيث الرضا وقبول التعلم المتنقل & 6 \\
\hline \multicolumn{3}{|c|}{2.53} & المتوسط الحسابي & \\
\hline
\end{tabular}

تفسير النتائج التي توصل لها السؤالان الثالث والرابع:

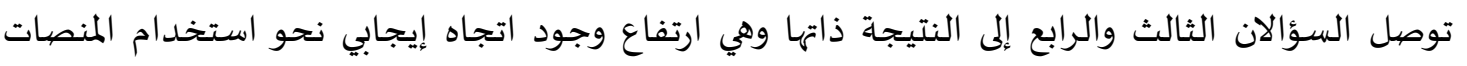

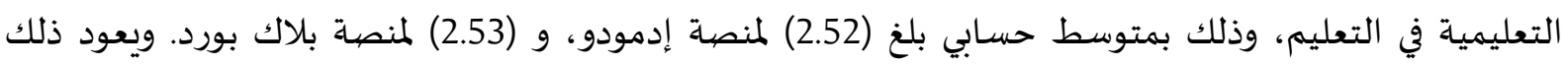
للأسباب التالية: يَسْهُل تحميل تطبيقي البلاك بورد وإدمودو على الأجهزة المتنقِّلة بدلاً من أجهزة الحاسوب مما يعمل على سهولة التنقل واستخدامه دون التقيد بمكان أو زمان. يصاحب استخدام التطبيق وجود إشعارات وتنبيهات تمكِّن المتعلم من معرفة ما يرسله الأستاذ مباشرة

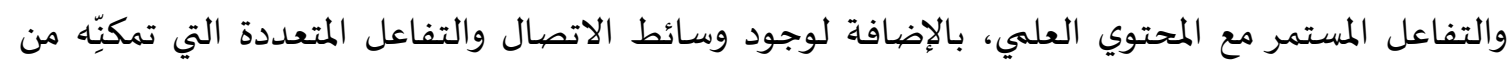
التفاعل المباشر مع زملائه وأستاذه بطريقة تزامنية المعرية ولا تزامنية. 


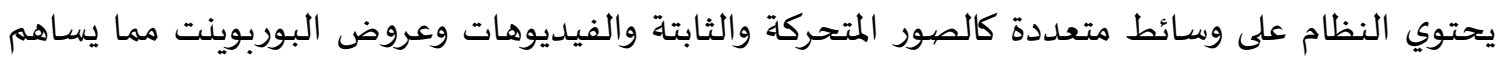
في تنوع المحتوى العلمي ومناسبته للأنماط المعرفية المختلفة للطالبة الأمر الذي يجعل عملية وعلية التعلم أكثر تشويقاً وتحفيزاً ويزيد من دافعية المتعلم للتعلم. يمكِِّن النظام المعلم من استخدام وسائل عديدة للتقييم منها (الاختبار اتـ النقاشـات الجماعية والفرديةالمنتديات- التكليفات والأنشطة- العروض الشخصية والجمعية)؛ حيث تعمل التغذية المباشرة بأشكالها المتعدِّدة على تحفيز الطالب لمتابعة سير عملية تقييمه بطريقة سريعة مما يسهل عليها إجراء التعديلات اللازمة. يحوي النظام على أدوات تساعد على البحث والاطلاع حسب الاحتياجات الفردية للمتعلم؛ فهو يوفِّر المصادر

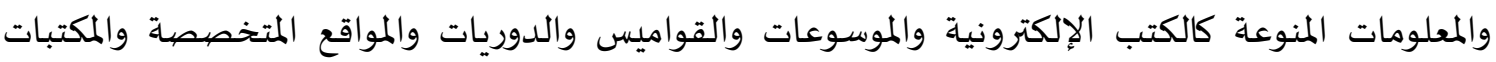
والمستودعات الرقمية. يُشَكِل النظام فصل دراسي متكامل على مدار الوقت فهو يحوي المقرر الدراسي، وأدوات التقييم والمتابعة من

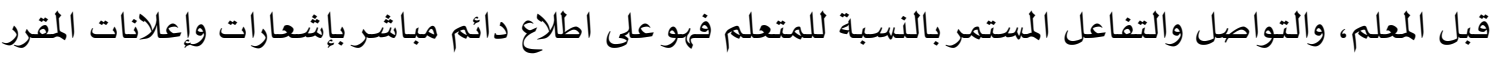
والتكليفات المطلوبة ووقت التسليم، والتغذية الراجعة لكل منها. وبالإضافة للتفاعل فيمكن لله القيام بالتكليفات والأنشطة المطلوبة منها في أي مكان كان. وجود هذا النظام المتكامل والمحفز على التعلم يزيد من دافعية الطالب، وثقته بنفساه، لأنه يعمل في إطار

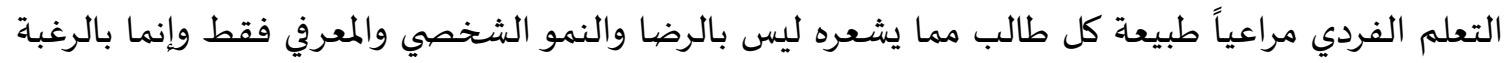

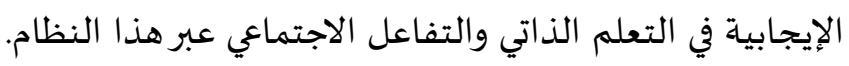

يعمل نظامي البلاك بورد وإدمودو على دعم التعلم التفاعلي القائم على إشراك الطالب في عملية التعلم،

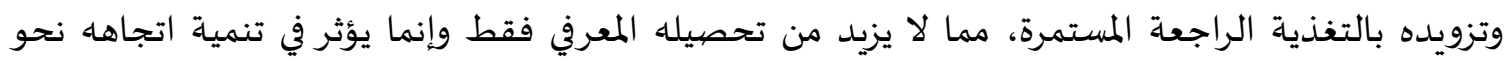

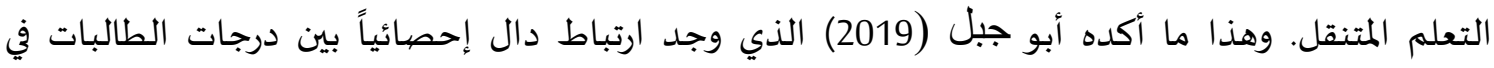
الاختبار التحصيلي ودرجاتهن في التطبيق البعدي لمقياس الاتجاه نحو التعلم عبر المنصة التعليمية.

التوصيات والمقترحات.

1- ضرورة أن يعمل الأستاذ الجامعي على دمج أكثر من منصية تعليمية في العملية التعليمية.

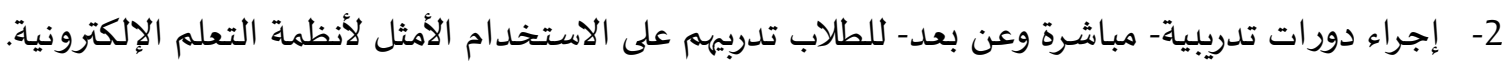

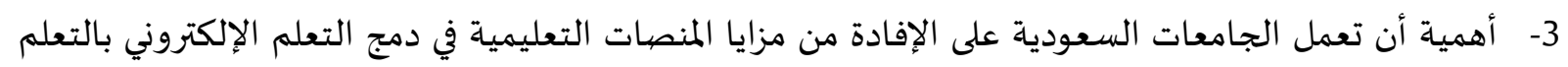
التقليدي. 4- أن تعمل الجامعات السعودية على تطوير بيئات إلكترونية توظِّف أنظمة التعلم التوظيف الأمثل لرفع الكفاءة العلمية والشخصية والمهنية للمتعلم. 5- ضرورة أن تعمل الجامعات السعودية على توفير الإمكانات (المادية والبشرية) اللازمة لتفعيل دور التعلم

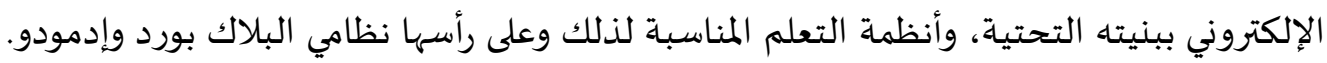

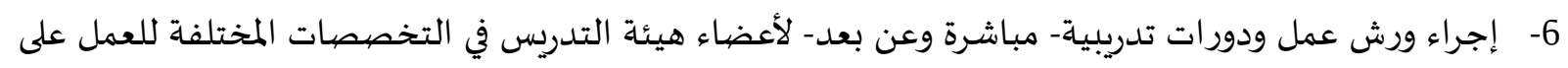

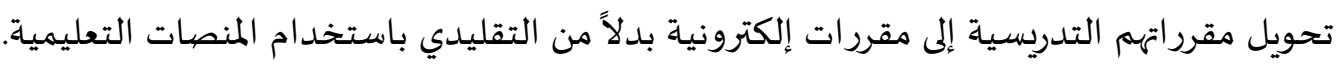

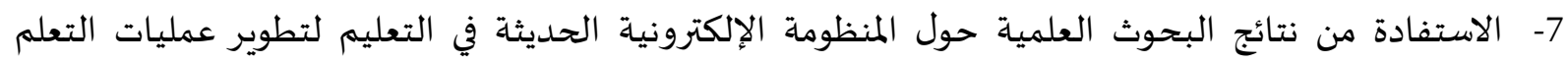

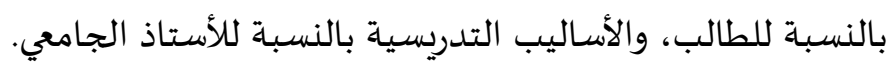
8- كما تقترح الباحثة إجراء مزيدا من الدراسات في الموضوعات الآتية: 
المزايا التعليمية لمنصتي إدمودو وبلاك بورد من وجهة نظر الطلاب وأعضاء هيئة التدريس (دراسة وصفية). أثر استخدام طالبات جامعة طيبة للمنصات التعليمية على التحصيل الدراسي واتجاهاتهن نحو الدراسة

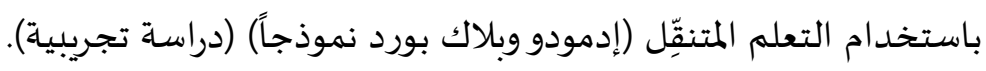

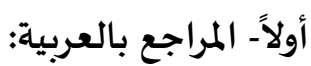

- أبو الحاج، عبد الرحمن (2019). واقع استخدام نظام إدارة التعلم البلاك بورد من وجهة نظر طلاب جامعة

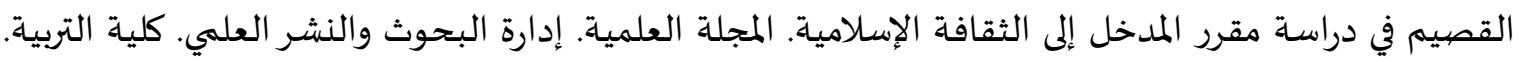
جامعة أسيوط. 35 (2)، 1- 28. - أبو جبل، مصطفى عبد الوهاب أحمد (2019). "فاعلية نظام إدارة التعلم البلاك بورد "Blackboard" في تنمية

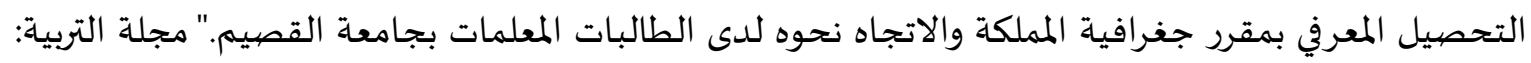
جامعة الأزهر- كلية التربية.184 (3). 1200- 1255.

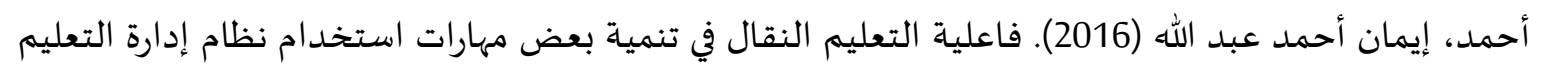
الإلكتروني بلاك بورد (Blackboard) لدى أعضاء هيئة التدريس بكلية التربية بالجبيل جامعة الدمام. مجلة كلية التربية: جامعة أسيوط- كلية التربية.32 (4)، 70- 109. بلغيث، سلطان. (2017). التعلم بوساطة الهواتف المحمولة: الخصائص، الخطوات، المزايا، المحاذير. مجلة أنسنة للبحوث والدراسات: جامعة زيان عاشور بالجلفة- كلية العلوم الاجتماعية والإنسانية. 8 (1). 198- 217.

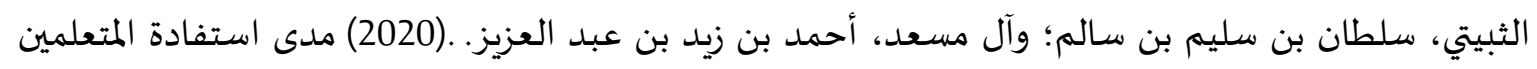

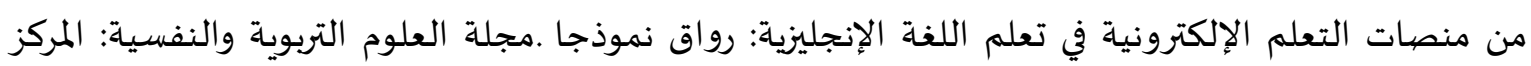

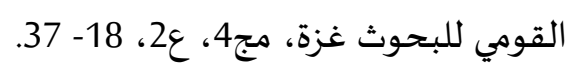
الجاسر، عفاف بنت محمد (2018). أثر استخدام الإدمودو "Edmodo" على التحصيل الدراسي والاتجاه نحوه

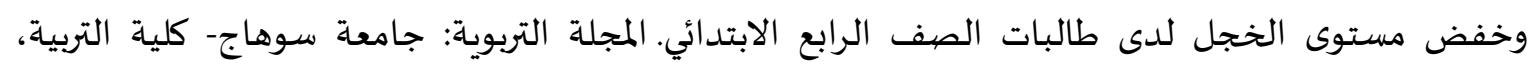
$808-777$ ، 803$)$

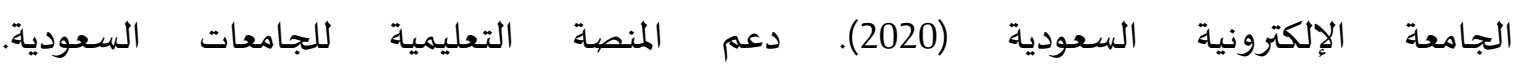
/https://seu.edu.sa/ar/blackboard- system

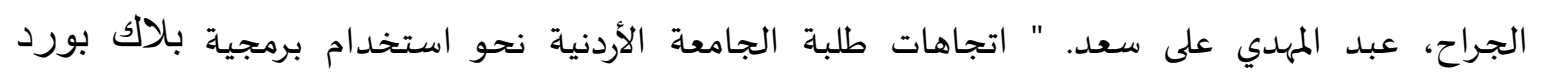
(Blackboard) .1304

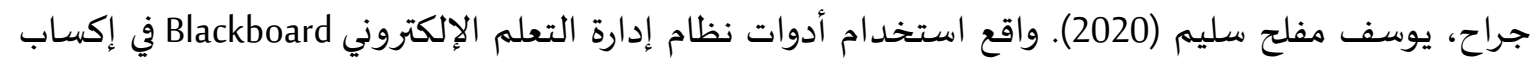

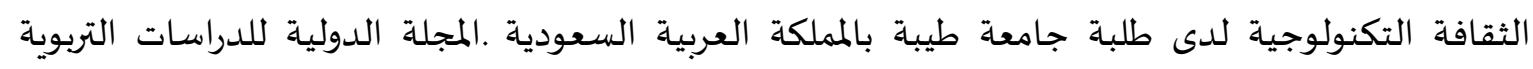

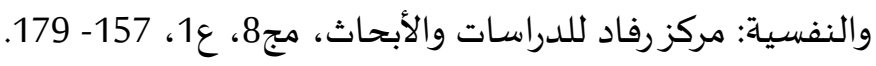

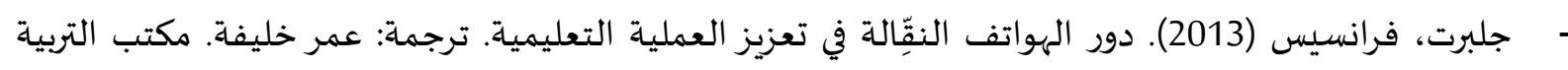

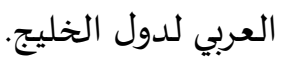


- الجهني، ليلى سعيد سويلم. (2019). تقييم منصة إدمودو الإلكترونية في ضوء معايير سهولة الاستخدام .المجلة

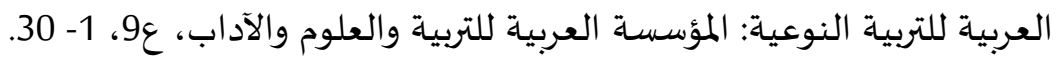

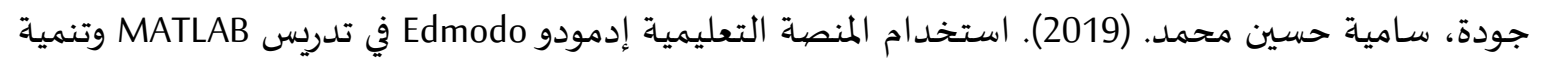

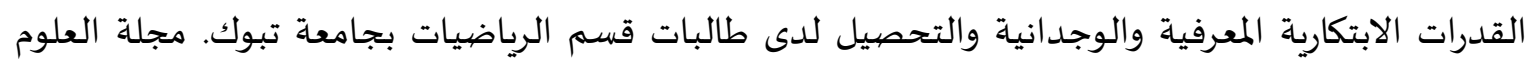
التربوية والنفسية: جامعة البحرين- مركز النشر العلمي، 20 (1). 282- 318. الحافظي، فهد بن سليم سالم (2019). "تصميم برنامج تعليمي قائم على نظام إدارة التعلم الإلكتروني "Blackboard"

في مدينة جدة." تكنولوجيا التربية- دراسات وبحوث: الجمعية العربية لتكنولوجيا التربية. (39)، 119- 174. الحسن، رياض والمطرودي، عائشة بنت صالح (2017). أثر التدريس بالتعلم التعاوني عبر الشبكة الاجتماعية

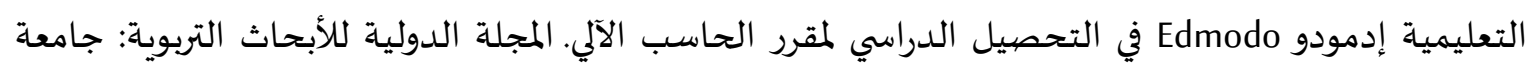

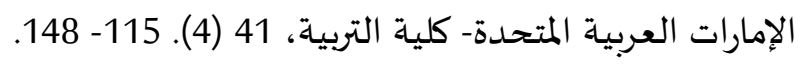
حسين، سمير1999م: بحوث الإعلام، القاهرة، الطبعة الثالثة. دشتي، فاطمة عبد الصمد (2017). اتجاهات الطالبة المعلمة نحو أنظمة إدارة التعلم من خلال استخدام تطبيق إدمودو. مجلة كلية التربية: جامعة طنطا- كلية التربية.67 (3). 332- 363 (2017. الرشيدي، منيرة شقير، والبراهيم، أمل. (2019). واقع استخدام معلمات الحاسب الآلآل للمنصات التهات التعليمية

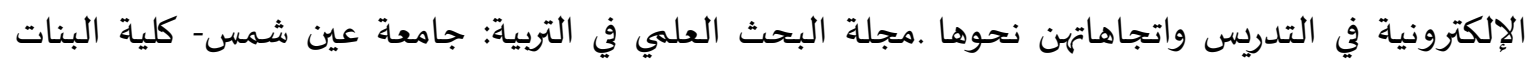

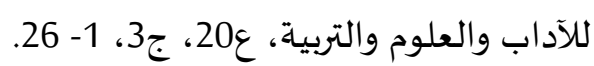
الرندي، بشاير سعود؛ وأبا الخيل، أحمد (2016). "اتجاهات الطلبة نحو استخدام نظام بلاك بولك بورد للتعلم

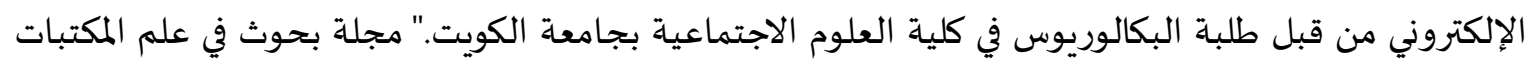

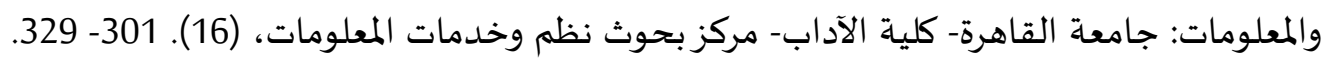

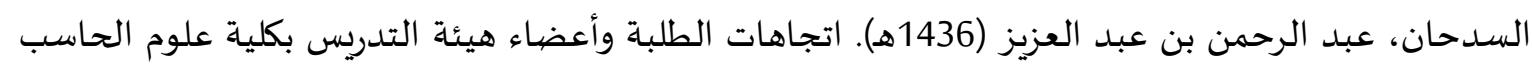

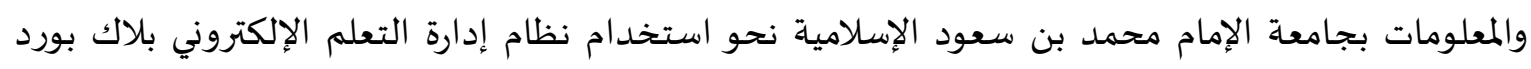
Blackboard وعلاقته ببعض المتغيرات. مجلة العلوم التربوية، (2)، 223- 278. السيد، عبد العال عبد الله (2015). المنصات التعليمية الإلكترونية - Edmodo رؤية مستقبلية لبيان التعليم الإلكتروني، ع 16، جامعة المنصورة.

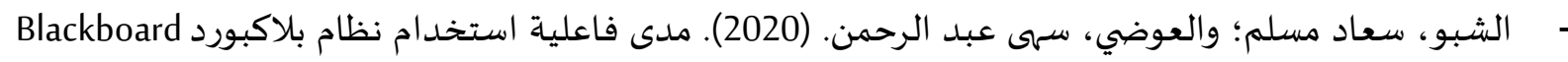

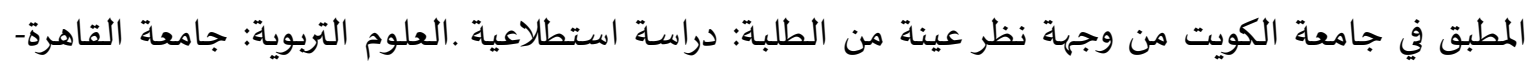

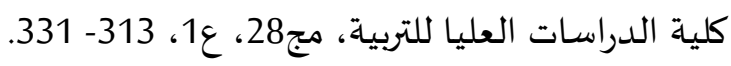
الشهري، أحمد عاطف عبد الرحمن (2018). "واقع استخدام الطلاب معلمي اللغة الانجليزية لمهام نظام البلاك

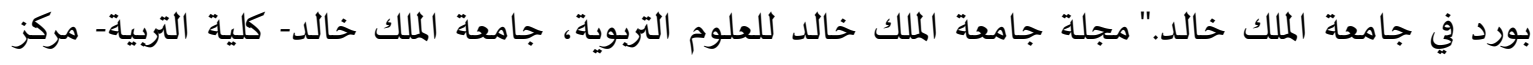

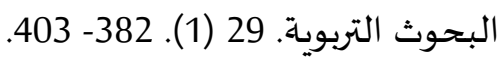

الشهري، أمل ظافر؛ محمد، لمياء جلال (2014). "فاعلية برنامج تدريبي لتدريب طالبات كلية التربية جامعة

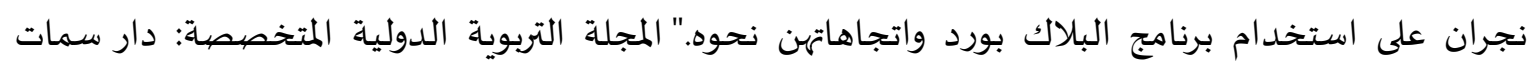

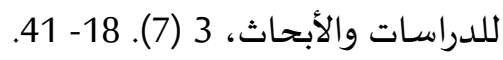


- الشواربة، داليه خليل عبد الكريم؛ السعيد، خليل محمود سعيد (2019)، درجة استخدام طلبة الدراسات

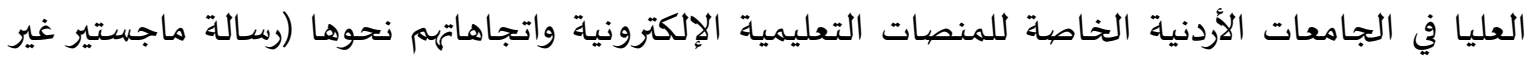
منشورة). جامعة الشرق الأوسط، عمان. العبد الكريم، راشد بن حسين؛ والرويس، عزيزة سعد علي (2015)." فاعلية تدريس مقرر مقدمة في التعلم

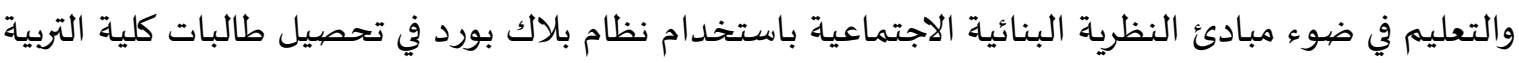

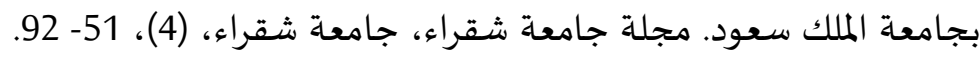

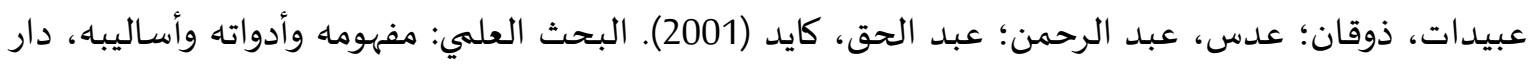

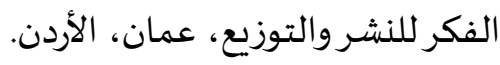
عثمان، محمود علي عثمان؛ الزبيدي، منير أحمد حسين (2018). أثر توظيف نظام إدارة التعلم (Blackboard)

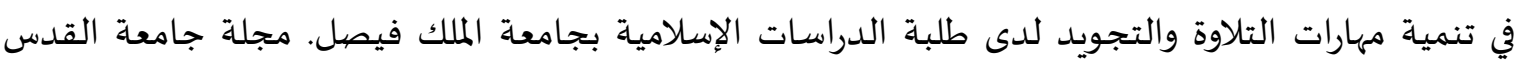
المفتوحة للبحوث الإنسانية والاجتماعية. 2 (44). 219- 233. العصيمي، وفاء بنت محمد (2016). فاعلية استخدام الشبكة الاجتماعية الإدمودو في تعزيز التعلم التشاركي

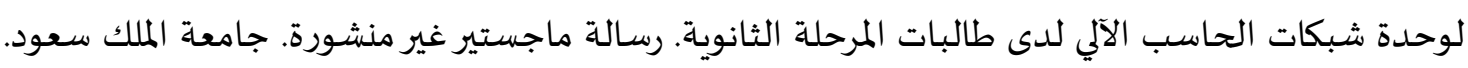

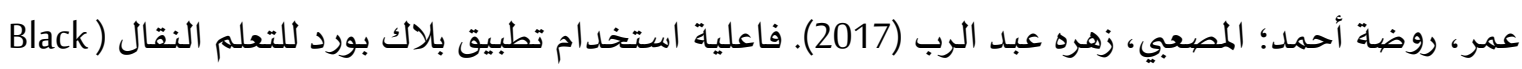
(Mobileboard

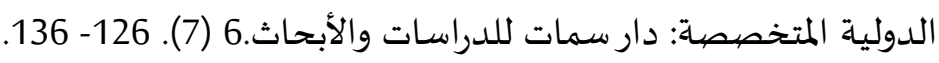
العمري، عمر حسين (2019). فاعلية استخدام منصة إدمودو في تنمية مهارات التعلم المنظم ذاتيا والتحصيل

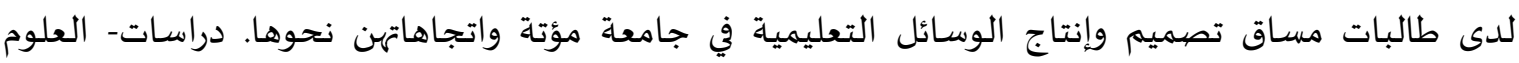
التربوية: الجامعة الأردنية -عمادة البحث العلمي. 46 (3). 113- 127. العودة، أحمد محمد فهد؛ وعبد المجيد، أشرف عويس محمد (2017). "فاعلية استخدام الفصول الإفتراضية الفية

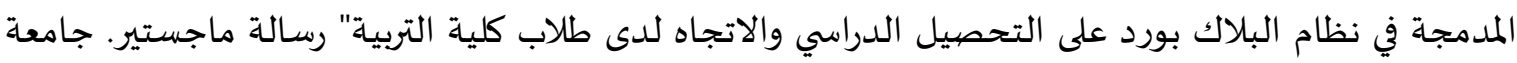

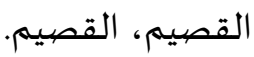
- ـ العييد، أفنان بنت عبد الرحمن (2019). توظيف منصة الإدمودو التعليمية Edmodo في التعلم المتنقل

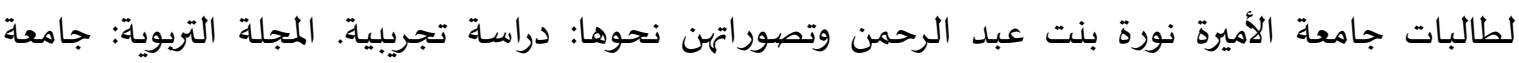
سوهاج- كلية التربية، (58). 45- 77. العييد، أفنان بنت عبد الرحمن؛ والشايع، حصة محمد (2017). شبكة مراجعة لبعض الأدبيات العلمية. مجلة العلوم التربوية والنفسية، 2 (1). 2518- 25780. - غزالة، آيات فوزي أحمد؛ نبيل، عبد الهادي أحمد السيد (2019). واقع اتجاه طلاب جامعة الجوف بالمملكة

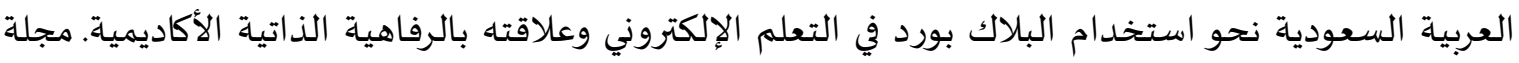
كلية التربية: جامعة كفر الشيخ- كلية التربية.19 (4).75- 168. القطعان، عطا الله محمد (2018). "فاعلية تدريس مقرر ريادة الأعمال إلكترونياً باستخدام البلاك بورد في

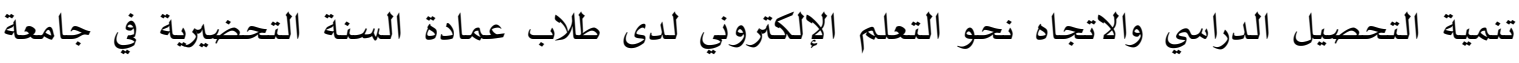
حائل." دراسات في الإرشاد النفسي والتربوي: جامعة أسيوط- كلية التربية- مركز الإرشاد النفسي والتربوي (3). 


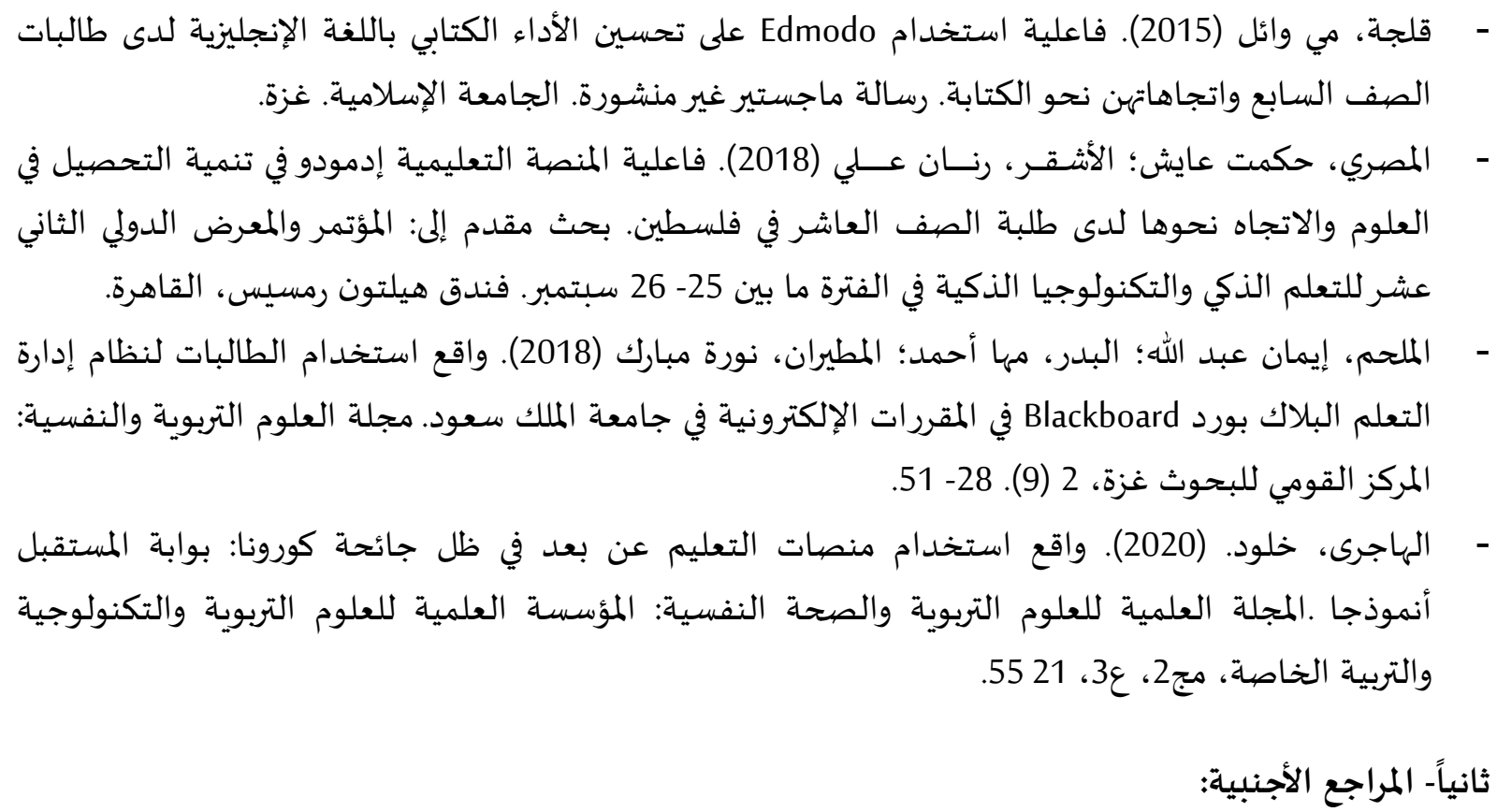

- Alqahtani, A. S. (2019). The use of Edmodo: its impact on learning and students' attitudes toward it. Journal of Information Technology Education, 18.

- Al- Said, K. M. (2015). Students' Perceptions of Edmodo and Mobile Learning and Their Real Barriers towards Them. Turkish Online Journal of Educational Technology-TOJET, 14 (2), 167-180.

- Balasubramani, K., \& Jaykumar, L. N. (2014). Student Preference Towards the Use of Edmodo as A learning Platform to Create Responsible Learning Environment. In Proceeding, Asia Euro Conference. Selangor: School of Hospitality, Tourism and Culinary Arts.

- Batsila, M., Tsihouridis, C., \& Vavougios, D. (2014). Entering the Web- 2 Edmodo World to Support Learning: Tracing Teachers' Opinion After Using it in their Classes. International Journal of Emerging Technologies in Learning, 9 (1).

- Edmodo. (2014). The Edmodo teacher guide: the social learning network for the classroom. vedRetrie 25 June 2020, http://susd.edmodo.com.

- Enriquez, M. A. S. (2014, March). Students' Perceptions on the Effectiveness of the Use of Edmodo as a Supplementary Tool for Learning. In DLSU Research Congress, De La Salle University (pp.106). Manila, Philippines.

- Giang, T. N., \& Minh, N. (2014, July). Edmodo- A new and effective blended learning solution. In International Conference of the Leadership \& Development in Higher Education for Sustanable Development, Ho Chi Minh City.

- Kongchan, C. (2008). How a non- digital- native teacher makes use of Edmodo. In 5th Intenational Conference ICT for Language Learning. Florence.

- Kurniawan, A. A. (2015). The use of edmodo to facilitate students' critical thinking of $8 \mathrm{G}$ class of SMPN 2 Yogyakarta. Universitas Sanata Dharma. 
- Mabrouk, H. A. S., \& Genedy, G. M. (2018). Effectiveness of flipped classrooms using the Blackboard System in developing art work skills and attitudes of Faculty of Education female students at Jouf University toward the use of practical skills. Journal of Research in Curriculum, Instruction \& Educational Technology, 4 (3), 141-161.

- Ryane, I. (2020). A case study of using Edmodo to enhance computer science learning for engineering students. International Journal of Emerging Technologies in Learning (iJET), 15 (3), $62-73$.

- Shams- Abadi, B. B., Ahmadi, S. D., \& Mehrdad, A. G. (2015). The effect of Edmodo on EFL learners' writing performance. International Journal of Educational Investigations, 2 (2), 88- 97.

- Thi Hanh, Tran (2018). Students' perceptions on the use of edmodo as a supplementary tool in learning. School of Foreign Languages- TNU. Retrieved on August 3, http://sti.vista.gov.vn/tw/Lists/TaiLieuKHCN/Attachments/271530/CTv178V174S142017123.pdf

- Yagci, T. (2015). Blended Learning via Mobile Social Media \& Implementation of" EDMODO" in Reading Classes. Advances in Language and Literary Studies, 6 (4), 41- 47.

- Yunkul, E., \& Cankaya, S. (2017). Students' attitudes towards Edmodo, a social learning network: A scale development study. Turkish Online Journal of Distance Education, 18 (2), 16- 29.

- Zainuddin, S. A., Azween, A., \& Alan, G. D. (2011). Social networking sites for learning: a review from Vygotskian perspective.

- Zainuddin, S. A., Azween, A., \& Alan, G. D. (2011). Social networking sites for learning: a review from Vygotskian perspective. http://eprints.utp.edu.my/5522/

- https://www.taibahu.edu.sa/Pages/AR/Sector/SectorPage.aspx?ID=41\&Pageld=320. 21 July 2021

- https://www.taibahu.edu.sa/Pages/AR/Service/ServiceDescription.aspx?ID=84. July 20, 2021 